\title{
Lunar Surface-to-Surface Power Transfer
}

Thomas W. Kerslake

Glenn Research Center, Cleveland, Ohio 


\section{NASA STI Program . . . in Profile}

Since its founding, NASA has been dedicated to the advancement of aeronautics and space science. The NASA Scientific and Technical Information (STI) program plays a key part in helping NASA maintain this important role.

The NASA STI Program operates under the auspices of the Agency Chief Information Officer. It collects, organizes, provides for archiving, and disseminates NASA's STI. The NASA STI program provides access to the NASA Aeronautics and Space Database and its public interface, the NASA Technical Reports Server, thus providing one of the largest collections of aeronautical and space science STI in the world. Results are published in both non-NASA channels and by NASA in the NASA STI Report Series, which includes the following report types:

- TECHNICAL PUBLICATION. Reports of completed research or a major significant phase of research that present the results of NASA programs and include extensive data or theoretical analysis. Includes compilations of significant scientific and technical data and information deemed to be of continuing reference value. NASA counterpart of peer-reviewed formal professional papers but has less stringent limitations on manuscript length and extent of graphic presentations.

- TECHNICAL MEMORANDUM. Scientific and technical findings that are preliminary or of specialized interest, e.g., quick release reports, working papers, and bibliographies that contain minimal annotation. Does not contain extensive analysis.

- CONTRACTOR REPORT. Scientific and technical findings by NASA-sponsored contractors and grantees.

- CONFERENCE PUBLICATION. Collected papers from scientific and technical conferences, symposia, seminars, or other meetings sponsored or cosponsored by NASA.

- SPECIAL PUBLICATION. Scientific, technical, or historical information from NASA programs, projects, and missions, often concerned with subjects having substantial public interest.

- TECHNICAL TRANSLATION. Englishlanguage translations of foreign scientific and technical material pertinent to NASA's mission.

Specialized services also include creating custom thesauri, building customized databases, organizing and publishing research results.

For more information about the NASA STI program, see the following:

- Access the NASA STI program home page at http://www.sti.nasa.gov

- E-mail your question via the Internet to help@ sti.nasa.gov

- Fax your question to the NASA STI Help Desk at 301-621-0134

- Telephone the NASA STI Help Desk at 301-621-0390

- Write to: NASA Center for AeroSpace Information (CASI) 7115 Standard Drive Hanover, MD 21076-1320 


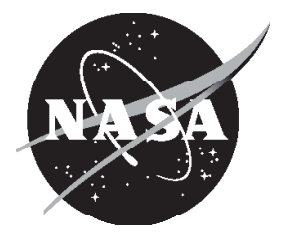

\section{Lunar Surface-to-Surface Power Transfer}

Thomas W. Kerslake

Glenn Research Center, Cleveland, Ohio

Prepared for the

Space Technology and Applications International Forum (STAIF-2008)

sponsored by the University of New Mexico's Institute for Space and Nuclear Power Studies (UNM-ISNPS)

Albuquerque, New Mexico, February 10-14, 2008

National Aeronautics and

Space Administration

Glenn Research Center

Cleveland, Ohio 44135 


\section{Acknowledgments}

The author would like to acknowledge and thank the following individuals, all from NASA Glenn Research Center, for their expert technical input to, and review of, this study: Dr. Geoff Landis (RF and laser beamed power), Mr. Jim Dolce

(RF and cable power transfer high-voltage power electronics parts and topology challenges), Mr. Lee Mason (DC/AC power cable design), Mr. Tom Parkey (costs) and Mr. H. James Fincannon (system design).

This report is a formal draft or working paper, intended to solicit comments and ideas from a technical peer group.

This report contains preliminary findings, subject to revision as analysis proceeds.

This report is a preprint of a paper intended for presentation at a conference.

Because changes may be made before formal publication, this preprint is made available with the understanding that it will not be cited or reproduced without the permission of the author.

Level of Review: This material has been technically reviewed by technical management.

Available from

NASA Center for Aerospace Information 7115 Standard Drive

Hanover, MD 21076-1320
National Technical Information Service 5285 Port Royal Road Springfield, VA 22161 


\title{
Lunar Surface-to-Surface Power Transfer
}

\author{
Thomas W. Kerslake \\ National Aeronautics and Space Administration \\ Glenn Research Center \\ Cleveland, Ohio 44135
}

\begin{abstract}
A human lunar outpost, under NASA study for construction in the 2020's, has potential requirements to transfer electric power up to $50-\mathrm{kW}$ across the lunar surface from 0.1 to $10-\mathrm{km}$ distances. This power would be used to operate surface payloads located remotely from the outpost and/or outpost primary power grid. This paper describes concept designs for state-of-the-art technology power transfer subsystems including AC or DC power via cables, beamed radio frequency power and beamed laser power. Power transfer subsystem mass and performance are calculated and compared for each option. A simplified qualitative assessment of option operations, hazards, costs and technology needs is also described. Based on these concept designs and performance analyses, a DC power cabling subsystem is recommended to minimize subsystem mass and to minimize mission and programmatic costs and risks. Avenues for additional power transfer subsystem studies are recommended.
\end{abstract}

\section{Introduction}

Consistent with "The Vision for Space Exploration," NASA is planning to send humans to the Moon and other deep space targets. As part of the lunar exploration planning, NASA convened a "Lunar Architecture Team" or LAT. One output of the LAT was a strategy to develop a permanent human outpost at the lunar South Pole on The Shackleton Crater rim (Cooke et al., 2006). This lunar outpost will be comprised of multiple elements distributed across the lunar surface, each requiring electric power. Thus, power must be transferred from power system elements to surface elements and surface payloads. A prime example payload element is an in situ resource utilization (ISRU) oxygen production plant. Such a plant requires considerable power and must be located remotely from the outpost to minimize induced contamination from dust generation during plant operations.

In support of lunar outpost power system development, the goal of this present study was to develop lunar surface-to-surface power transfer subsystem concept design options, compare option quantitative and qualitative metrics, and on the basis of this comparison, make a recommendation of the option with best balance of mass, performance, risk and cost. Most past studies on this topic have focused on a power cable power transfer approach (Gordon, 2001; Khan, et al., 2006; Sprouse, 1991). In the current study, the power transfer subsystem technology options not only include AC and DC power cables, but also radiofrequency (RF) beamed power and solid state laser module beamed power technology options. These concept designs include the required supporting equipment, such as power conditioning electronics and an Active Thermal Control System (ATCS), which can be dominant mass contributors to the total power transfer subsystem mass. The designs also incorporate the appropriate level of fault tolerance against critical and catastrophic faults required of human-rated space systems.

Concept designs were prepared for power transfer levels between 1 to $50 \mathrm{~kW}$ and transfer distances between 0.1 to $10 \mathrm{~km}$ that are consistent with LAT lunar outpost requirements. Using the subsystem design information as inputs, spreadsheet-based tools were developed and utilized to quantify design option mass and performance. Candidate power transfer subsystem options were compared on the basis of the following quantitative metrics: power transfer subsystem mass, power source plus power transfer subsystem mass, input power to output power (Pin/Pout) "gear ratio," power transfer subsystem efficiency, $\eta$ (equal to Payload Pout / Source Pin or equal to $\eta 1 * \eta 2 * \ldots * \eta i$ where $\eta \mathrm{i}$ is the individual component power efficiencies including parasitics) and the net payload element power (equal to the source power $* \eta$ ) for a $10-\mathrm{kW}$ source power (LAT payload requirement). Candidate power transfer subsystem options were also compared qualitatively based on concept of operations, hazards and controls assessment, comparative costs and technology development needs.

\section{Cable Power and Beamed Power Subsystem Elements}

$\mathrm{AC}$ and DC power cable subsystem elements that were included in this assessment are depicted in figure 1. RF or laser beamed power subsystem elements that were included in this assessment are depicted in figure 2 . 
Power subsystem concept drawings have not been produced, although figures 3 to 5 depict many of the key components that would be needed in each option.

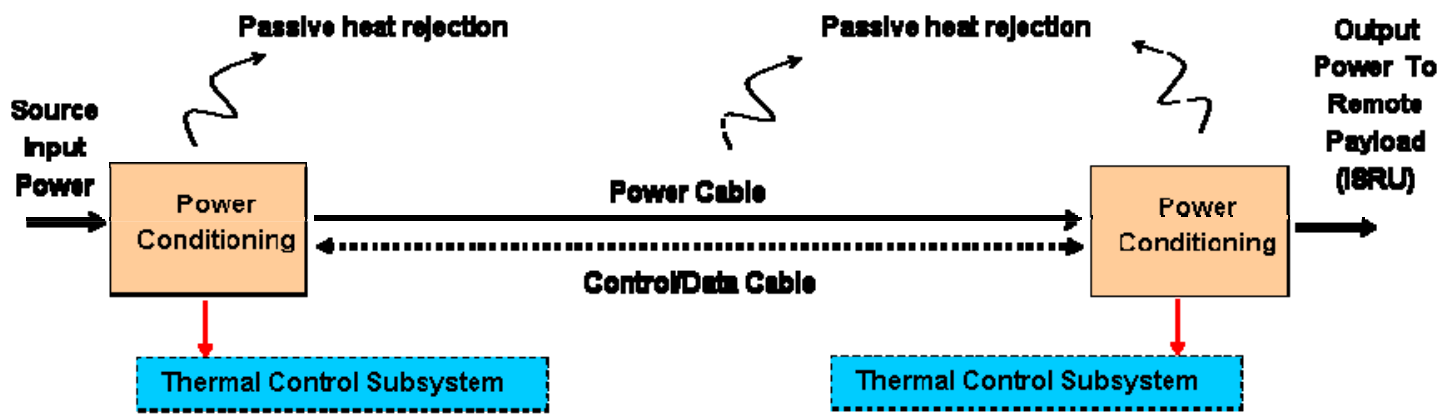

Cable Spool \& Deployer Mechanism

\section{Integration Structure \&. Misc}

Figure 1.-Cable power transfer subsystem elements.
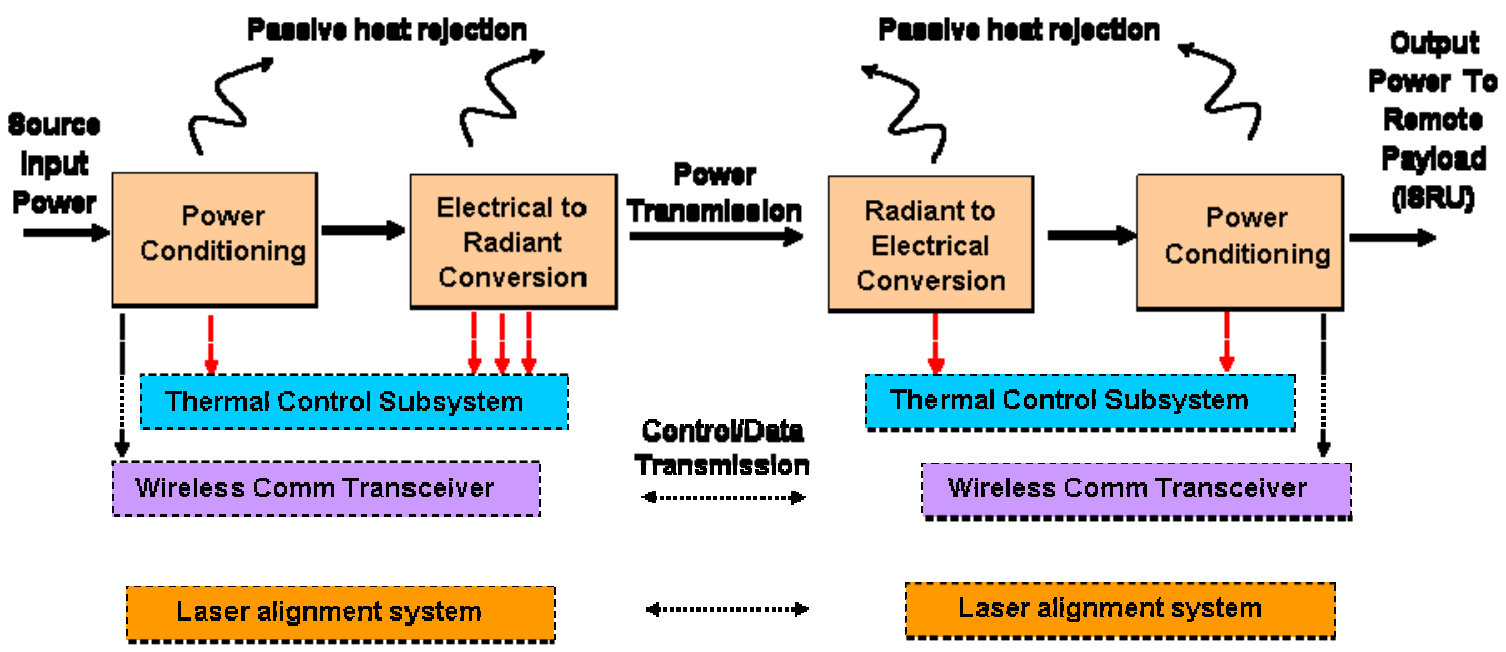

\section{Integration Structure \& Misc}

Figure 2.-Beamed power transfer subsystem elements.
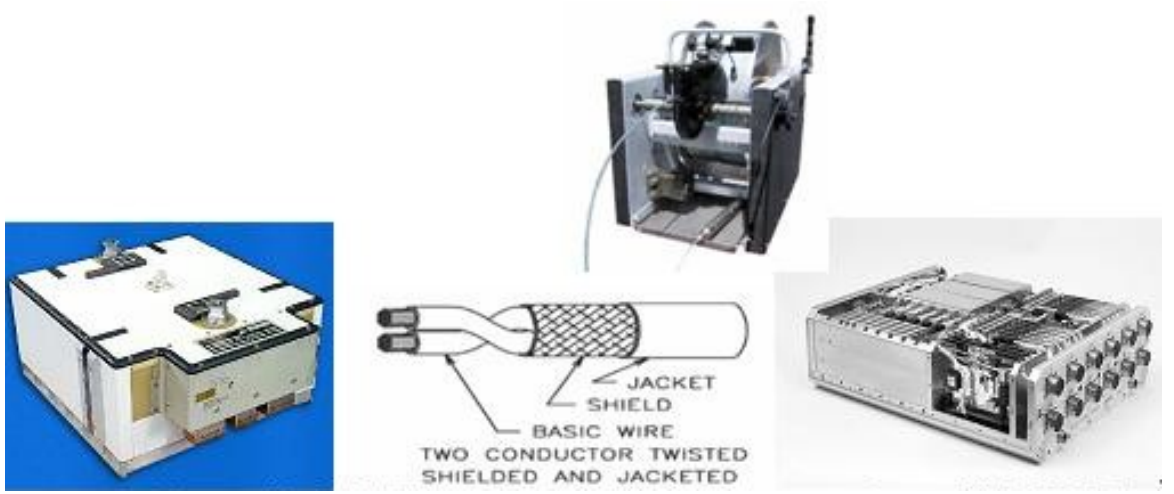

Figure 3.--Power cable subsystem components: electronics, cable and cable deployer. 

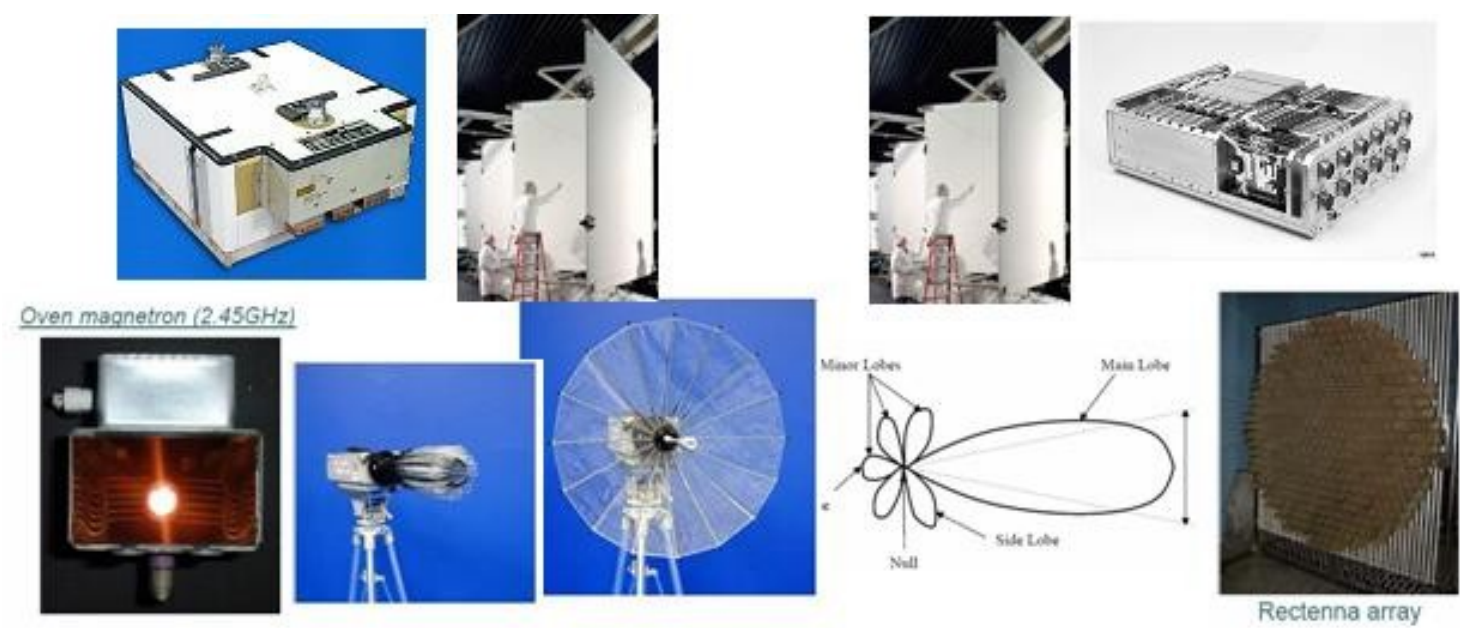

Figure 4.-RF subsystem components: electronics, ATCS, magnetrons, antenna and rectenna.

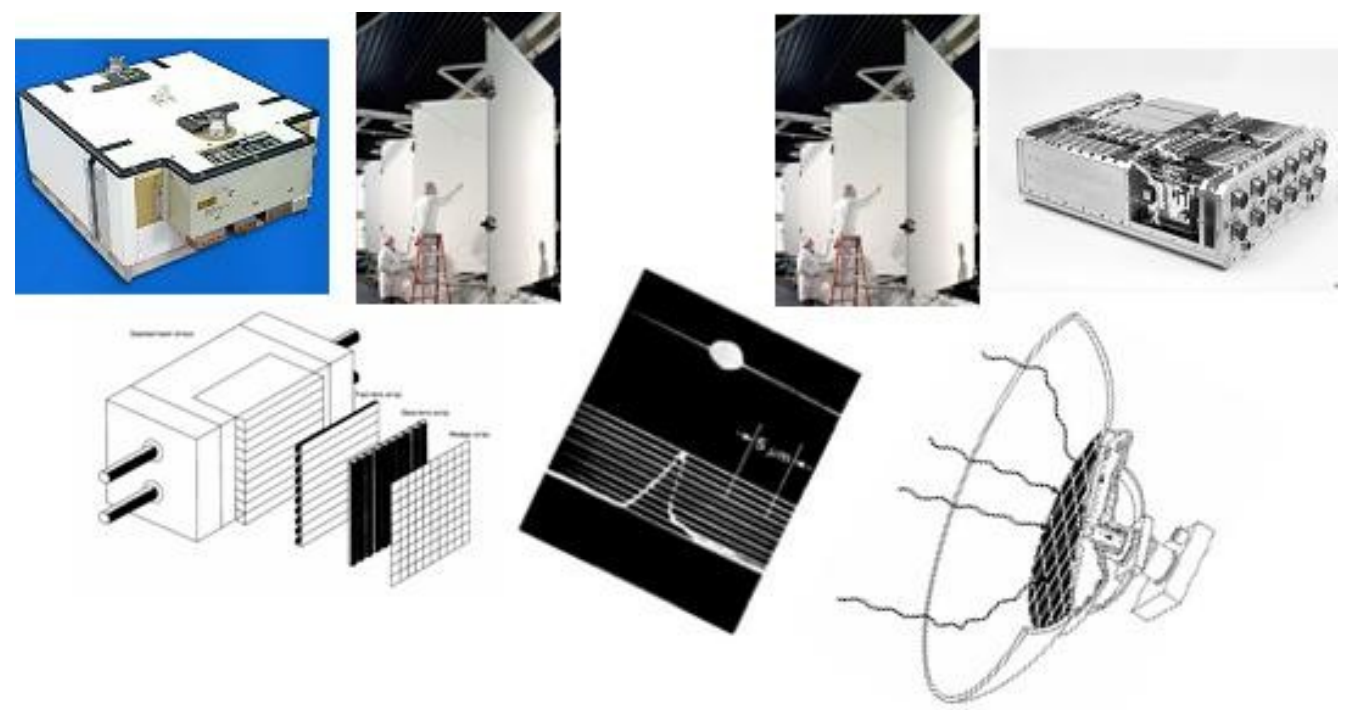

Figure 5.-Laser subsystem components: electronics, ATCS, laser modules with optics and receiver with optics.

\section{Subsystem Concept Design Inputs, Assumptions, Parameters and Governing Equations}

\section{Source and Payload Power/Voltage Levels}

The source voltage was treated as either regulated 160-VDC (consistent with the LAT solar Standard Power Unit source) or regulated $300-\mathrm{VAC}, 100 \mathrm{~Hz}$, single phase (consistent with a fission reactor / Stirling engine power plant). Source power input was varied parametrically as 1-, 5-, 10-, 20- and 50-kW. The assumed voltage output to the payload is regulated 28-VDC.

\section{DC and AC Power Cables}

The DC power cable operating voltage, V, was parametrically varied from 160-, 300-, 500-, 1000-, 2000-, 3000-, 4000- and 5000-VDC while the AC power cable operating voltage was parametrically varied from 500-, 1000-, 2000-, 3000-, 4000- and 5000-VAC rms (400 Hz, 3-phase, 0.9 power factor). Conductor wire gauge was chosen to achieve a cable power efficiency $(1-\Delta \mathrm{V} / \mathrm{V})$ in the range of 0.75 to 0.997 and meet maximum vacuum operation de-rated current requirements. The wire size was also constrained to be a minimum American Wire Gauge (AWG) size of 16 (for lunar surface deployment and operations structural robustness). Cable passive thermal control 
was assumed with a $300 \mathrm{~K}$ operating temperature consistent with the relatively cool lunar south polar surface application. Cable length was varied parametrically from 0.1-, 0.2-, 0.5-, 1-, 5- and 10-km. The cable was assumed to be spool-deployed to rest flat on the lunar surface and was configured as twisted pair, hot/return, round crosssection, stranded copper conductors with 3:2 conductor redundancy (fail-operate with full power, fail-safe with 50 percent power), ETFE (Tefzel) insulation, filler rods, and an abrasion-resistant, thermal control jacket. Cable electromagnetic interference (EMI) shielding and meteoroid armoring was not included. Cable connectors were included (at a 1 percent cable mass fraction) and small-gage, data/control communication wires, integrated with power cable, were included at a 5 percent cable mass fraction. A fixed 50-kg mass for the power cable spool and deployer mechanism was assumed based on an earlier NASA concept design. Power cable performance degradation was assumed to be negligible.

A separate, side study was performed to quantify the design impacts of using aluminum versus copper conductors and including meteoroid armoring / EMI shielding on power cables. The cable design inputs included: 270 -VDC operating voltage, $6.88 \mathrm{~kW}$ power level, 5 percent $\Delta \mathrm{V} / \mathrm{V}, 25$ percent cable routing factor, 11 percent mass factor (for data/control cabling and connectors), 3:2, 2:2 and 1:1 conductor configuration/redundancy levels, sourceto-payload separation distances of 50-, 100- and 200-m and stainless steel braiding for meteoroid armoring and EMI shielding. The cable minimum allowable bend radius was defined as 10 times the cable diameter.

Power cable power electronics include a DC source boost DC to DC Converter Unit (DDCU) (Weinberg Topography, $40-\mathrm{kHz}$ inversion frequency, 1 percent bus ripple) or an $\mathrm{AC}$ source boost $\mathrm{AC}$ to AC frequency converter unit (AACU) (DC link resonance topography, 5 percent bus ripple). At the payload end of the cable, a DC cable buck DDCU (Weinberg Topography, 40-kHz inversion frequency, 1 percent bus ripple) or AC cable buck AC to DC Rectifier (ACDU) was assumed. Power electronics were sized with internal 3:2 redundancy, a carbon composite enclosure, a plate-fin heat exchanger, control and monitoring hardware. These components are designed to be robust for long-duration, lunar surface thermal, radiation and ground operations/handling environments. No degradation in efficiency was assumed. Power electronics mass and performance were calculated using models developed by Metcalf, 2002 (International Space Station heritage algorithms evolved from prior lunar surface power electronics algorithms in Metcalf, 1992). Power electronics operational cooling and non-operational warming was provided by an ATCS that operates at an effective rejection temperature of $353 \mathrm{~K}$ (based on the temperature limit for 10 -year operations of electronic parts minus a $25 \mathrm{~K}$ assumed difference in part to mean rejection temperature). The ATCS 2-sided heat rejection radiator was assumed to have a 50/50 view to deep space and to a $200 \mathrm{~K}$ surface and a mass of $6 \mathrm{~kg} / \mathrm{m}^{2}$ planar radiator area. This mass value is consistent with large heat rejection systems flown and includes the mass of radiator panel, pumps, working fluid, heat exchangers, valves, plumbing, insulation, sensors, etc. No degradation in ATCS operating efficiency was assumed. A 5 percent system mass fraction was added to account for secondary structures and miscellaneous integration components.

\section{Design Limitations and Considerations}

For short cable lengths and/or high operating voltage, conductor current levels drop to very low values that would allow for very small wire gages. For this study, the minimum conductor size allowed was 16 AWG. If the minimum was reached, cable efficiency is increased as the gauge is held constant. For long cable lengths and/or low operating voltage, current levels increase to very high values. Generally, the cable efficiency input is decreased to reduce conductor mass and to maintain cable operating temperature within reasonable range as dissipation levels increase. Increased voltage drop introduces a modest penalty in sizing payload end power electronics. To save control cable mass (5 percent of total cable mass), one could consider multiplexing data/control/communication signals on the power conductors. However, this option is likely not viable given unacceptable operating safety issues introduced by EMI (possible inadvertent control action) and power fault isolation (open switches cut-off power as well as subsystem control and data signals).

For high voltage DC cables, there is a potential issue with availability of fast $(40-\mathrm{kHz})$, high quality chopper/rectifying diodes needed for buck DDCU operation above $1-\mathrm{kV}$ input. Terrestrial power converters commonly use 1200-V Integrated Gate Bipolar Transistors (IGBTs) with the typical operating limits expected to increase to the $3000-\mathrm{V}$ range in the next 20 years. An exception to this is $5000-\mathrm{V}$ solid-state IGBTs produced by Hitachi for ground applications. Integrated Gate Commutated Thyristor devices that operate at $1 \mathrm{kHz}$ do exist, but at this frequency, DDCUs would be prohibitively massive. The suitability of these terrestrial switching devices must be assessed for the current lunar surface power application. The DDCU mass increases markedly as the inversion frequency drops from the baseline value of $40-\mathrm{kHz}$ so that device high switching rate is paramount. 


\section{RF Subsystem}

The DC-to-RF conversion technology considered for this study is the state-of-the-art (SOA), mature $2.45 \mathrm{GHz}$ (122 mm wavelength) oven magnetron (Long, 1990) or the developing technology $5.8 \mathrm{GHz}(52 \mathrm{~mm}$ wavelength) magnetron (Mitani et al., 2006). The magnetron has an assumed specific mass of $2 \mathrm{~kg} / \mathrm{kW}$ that includes the waveguide and is actively cooled for this high power density application. Magnetron operating efficiencies, 0.7 at $2.45 \mathrm{GHz}$ and 0.4 at $5.8 \mathrm{GHz}$, were based on data in Mitani et al., 2006 (see fig. 6) over a range of anode operating currents and at a $-4000 \mathrm{VDC}$ cathode operating voltage. A passively-cooled, RF parabolic dish transmit antenna is assumed with the desire to have the largest possible area to minimize input power needed. It operates with an assumed efficiency of 0.75 and has an assumed $1-\mathrm{kg} / \mathrm{m}^{2}$ dish areal mass with an added 10 percent mass fraction for antenna secondary structures, mechanisms and alignment equipment. The transmit antenna gain was calculated as the maximum theoretical gain times the efficiency with the maximum theoretical gain given by $\left(\pi^{*} \mathrm{D} / \lambda\right)^{2}$. The free space transmission efficiency is given by $\left[1-\exp \left(-\Psi^{2}\right)\right]$ with the term $\Psi$ defined by $\left(\mathrm{A}_{\text {antenna }} * \mathrm{~A}_{\text {rectenna }}\right)^{1 / 2} /(\lambda * \mathrm{~L})$ and where $\mathrm{A}$ is area, $\lambda$ is the wavelength and $\mathrm{L}$ is the transmission distance.

A passively cooled, circular planar receive rectenna array is assumed with the desire to have the largest possible area to maximize power collection and minimize transmitter input power. The rectenna element operating efficiency as a function of incident power density, varies from 0.6 to 0.9, was taken from Long, 1990 (see fig. 7). The rectenna array has an assumed areal mass of $2 \mathrm{~kg} / \mathrm{m}^{2}$ with an added 10 percent mass fraction for secondary structure, mechanisms and alignment equipment.

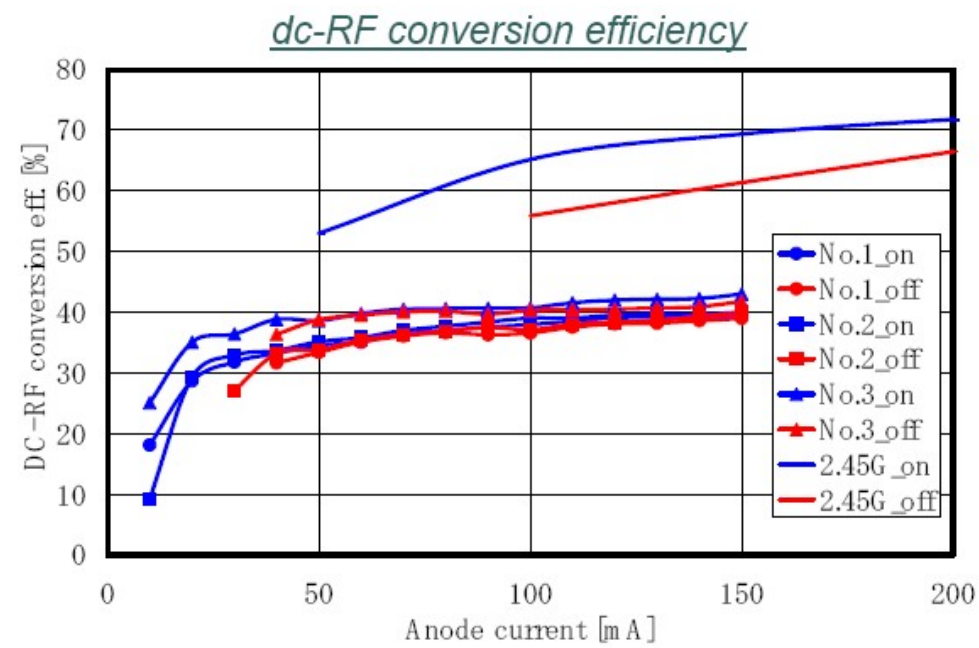

Figure 6.-Magnetron efficiency versus current at $2.45 \mathrm{GHz}$ (lines) and $5.8 \mathrm{GHz}$ (symbols) (Mitani et al., 2006).

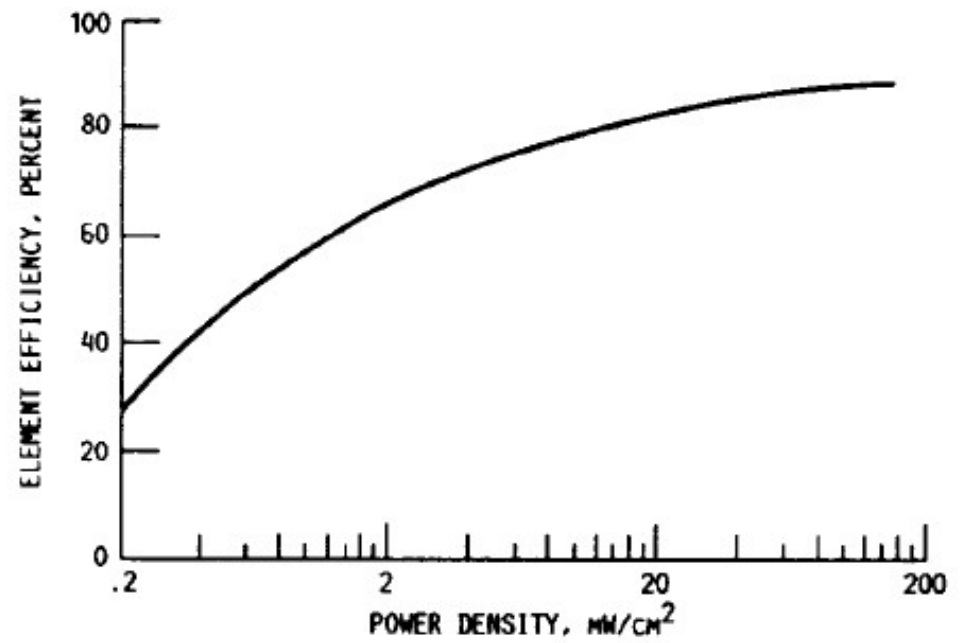

Figure 7.-Rectenna element efficiency versus power density $2.45 \mathrm{GHz}$ (Long, 1990). 
Both the transmit dish and receive rectenna must be deployable to allow for packaging on the lunar lander and this limits the aperture radii to approximately $\sim 4-\mathrm{m}$ or $50-\mathrm{m}^{2}$ projected area once deployed. Both must be alignable, but are non-tracking devices. Long-term performance degradation mechanisms were assumed to be negligible since accumulated dust particles on transmit/receiver surfaces are small compared to the RF wavelength, meteoroid and secondary ejecta impact damage is assumed to be inconsequential, radiation induced performance loss in rectenna semiconductors is assumed to very small for the radiation-hard Schottky diodes, and ground/regolith interference is assumed to be very small since the regolith is a dielectric material. The magnetron operating life in the oven application is only $\sim 5,000 \mathrm{hr}$, but with continuous use of the power transfer application, operating life is likely $>\sim 50,000 \mathrm{hr}$. The magnetron operating life can be further enhanced to meet 10-year mission requirements by derating the filament temperature and ensuring matched output.

Power electronics include a boost DDCU for the transmitter with a 0.95 efficiency at $100-\mathrm{kW}$ load and a $3.4 \mathrm{~kg} / \mathrm{kW}$ specific mass. The rectenna feeds regulated power to the payload element via a passively cooled, sequential shunt unit (SSU) (1.65 percent ripple) that is 0.97 efficient at 10-kW, 28-VDC output power and has a $13.3 \mathrm{~kg} / \mathrm{kW}$ specific mass. Power electronics are sized with internal 3:2 channel redundancy, carbon composite enclosure, plate-fin heat exchanger, internal card cages, control and monitoring hardware. The designs are robust for lunar surface thermal, radiation and ground operations/handling environments. No degradation in efficiency is assumed over the mission operating life. The ATCS, with attributes as described in the preceding section, cools the magnetrons and power electronics. RF data/control link system hardware (for RF power subsystem and payload) has an assumed mass of $8 \mathrm{~kg}$. RF EMI shielding (for hardware protection) includes grounded metallic shielding, with a $20-\mathrm{kg}$ mass, for components in the rectenna vicinity. The chosen level of failure tolerance is 0 -fault tolerant (design for minimum risk or DFMR) for the transmit horn/dish, receive rectenna array, and TCS radiator panel area and 1-fault tolerant (against loss of mission) for the power supplies, magnetron RF sources, receive rectenna array power conditioning and ATCS fluid cooling loops.

\section{Design Limitations and Considerations}

Increased RF operating frequency greatly improves antenna gain (reducing aperture sizes), but reduces magnetron conversion efficiency causing an increases magnetron ATCS mass. Increased operating frequency also reduces rectenna efficiency since dipole element and diode sizes shrink and the required areal packing density must increase (a technology driver since only 200 elements $/ \mathrm{m}^{2}$ are needed at $2.45 \mathrm{GHz}$ while 13,300 elements $/ \mathrm{m}^{2}$ are needed at $20 \mathrm{GHz}$ ). The reduced element spacing makes it more challenging to avoid inductive/capacitive coupling and to maintain dipole-diode impedance match. Increased rectenna edge scattering of incident radiation must also be accounted for at higher operating frequencies. These losses lead to increased source power required and an increase in the masses of the power source, input power electronics, magnetrons and ATCS (the last 3 items comprise $\sim 75$ percent of total RF power transfer subsystem mass at 2.45 or $5.8 \mathrm{GHz}$ ).

For proper rectification, the rectenna array must be operated at an incident power density above a threshold value. For example, it is desirable to have incident power density of $>200 \mathrm{~W} / \mathrm{m}^{2}$ to achieve a high 80 percent conversion efficiency at $2.45 \mathrm{GHz}$. This power density threshold constrains the combination of acceptable transmit power, antenna area and rectenna aperture area consistent with the given free space loss. Although larger aperture areas are needed to improve RF system performance, the difficulty of stowing, packaging and deploying RF apertures grows as the area increases. Even more challenging is the stowage, deployment and on-surface system integration of the large-area, low-temperature $(353 \mathrm{~K})$ ATCS radiator that is required. For example, a 10-kW RF power transfer subsystem needs a $79-\mathrm{m}^{2}, 2$-sided radiator for just for magnetron and input power electronics cooling.

\section{Laser Subsystem}

The laser is comprised of a solid state $(\mathrm{AlGaAs} / \mathrm{Ge}$ quantum well) laser diode module planar array with radiant output at $0.8 \mu \mathrm{m}$ wavelength (per Williams, et al., 1993). The laser conversion efficiency is optimistically assumed to be 0.5 at $1368 \mathrm{~W} / \mathrm{m}^{2} 800 \mathrm{~nm}$ light and $293 \mathrm{~K}$ operating temperature. In the current study, the laser efficiency is scaled logarithmically with operating intensity. Alternatively, the laser diode could be operated at an intensity near peak conversion efficiency while adjusting effective array output intensity by diode packing density (limited by electrical and thermal integration requirements). The laser efficiency is scaled with operating temperature based on empirical data from Scifres, et al., 1982. A fixed, alignable, circular laser diode module planar array with diameter of $1-\mathrm{m}\left(0.8-\mathrm{m}^{2}\right.$ area) is assumed. A smaller laser array area, within thermal control limitations, is desired to ease launch packaging and reduce mass. It is tacitly assumed that beam alignment, collimation and stability requirements 
can be met. It is further assumed that only collimating beam microlens optics are required and that primary parabolic optics are not needed for this application. A 91.7 percent optics transmission efficiency (Williams, et al., 1993) is assumed as is a perfectly circular beam cross-sectional shape. A $12 \mathrm{~kg} / \mathrm{kW}$ specific mass for laser modules plus collimating optics is assumed (Williams, et al., 1993) plus an added 10 percent mass fraction for secondary structure and mechanisms. A water heat pipe augmented ATCS is critically needed for coarse laser module temperature control to the baseline operating temperature of $293 \mathrm{~K}$ (needed for good efficiency). An increased laser module control/operating temperature of $325 \mathrm{~K}$ will also be assessed (lower laser conversion efficiency, but lowers required ATCS mass). Fine temperature control $\left(<0.25^{\circ} \mathrm{C}\right)$ of individual laser modules is needed to maintain phase stability and beam coherence. In this study, a laser module fine temperature control system (i.e., using discrete thermoelectric coolers) is not addressed. The input power supply to the laser diode modules provides regulated 50-VDC power.

The laser photovoltaic (PV) receiver array is populated with AlGaAs PV cells and is configured as a fixed, alignable, circular $1-\mathrm{m}$ diameter $\left(0.8-\mathrm{m}^{2}\right.$ area) planar aperture. A smaller receiver array area, within thermal control limitations, is desired to ease launch packaging and reduce mass. The PV cell packing factor assumed is 0.9 and an outer peripheral (or edge) mirror reflector ( $0.5-\mathrm{m}$ length in radial direction) with $3 \mathrm{~kg} / \mathrm{m}^{2}$ areal mass is assumed. The peripheral mirror is comprised of doubly-curved, silverized composite mirror facets. This mirror functions to contain laser light spillage and recycle spurious light on to the PV cell array (with 100 percent reflection efficiency and perfect reflected flux uniformity assumed). The mirror radial length is a driver for optics collimation and alignment accuracy requirements that will be discussed later in this paper. The PV receiver has an assumed areal mass of 2 $\mathrm{kg} / \mathrm{m}^{2}$ mass (with an added 10 percent mass fraction for secondary structure and mechanisms), an optimistic conversion efficiency of 0.5 at $1368 \mathrm{~W} / \mathrm{m}^{2}$ and $800 \mathrm{~nm}$ wavelength and a $320 \mathrm{~K}$ control operating temperature (Williams et al., 1993). The PV receiver efficiency is scaled logarithmically with operating intensity. A water heat pipe augmented ATCS is critically needed for receiver temperature control while operating at high power density. A passively cooled SSU regulator is used to supply regulated 28-VDC output power to the payload element.

Performance loss from degradation mechanisms over a 10 -year mission period is included. A 1.5 percent scattering and obscuration loss per year is assumed in subsystem output power due to lunar dust accumulation on laser/receiver optical surfaces. Transmission loss from suspended dust back-scattering along the optical path length is assumed to be negligible. Radiation induced performance loss in receiver PV cells is also assumed to be negligible. Meteoroid and secondary ejecta impact damage is assumed to introduce a 0.5 percent per year performance loss due to optical surface light scattering losses. Random loss of laser modules by the end of the mission is already built into 91.7 percent optics transmission loss factor described above while random receiver PV cell losses were assumed to be negligible.

The laser subsystem power electronics include a buck DDCU with 95 percent efficiency at $50-\mathrm{kW}$ and a $6.3 \mathrm{~kg} / \mathrm{kW}$ specific mass. At the payload element, a passively cooled SSU provides 28-VDC regulated output power with a 97 percent conversion efficiency at $10-\mathrm{kW}$ and a $13.3 \mathrm{~kg} / \mathrm{kW}$ specific mass. Power electronics are sized with internal 3:2 channel redundancy, a carbon composite enclosure, a plate-fin heat exchanger, internal card cages, control and monitoring hardware. The electronics boxes are designed robustly for lunar surface thermal, radiation and ground operations/handling environments. No degradation in performance efficiency is assumed. The ATCS cools the laser diode array, the PV receiver array and power electronics. The PV receiver array is cooled by the evaporator sections of water heat pipes whose condensers are coupled to the ATCS. RF data/control link system hardware for the laser power subsystem and the payload element has an assumed mass of $8 \mathrm{~kg}$. Misdirected and spurious laser light heating protective thermal blankets, with 20-kg mass, are assumed for shielding components in the PV receiver vicinity. The level of failure tolerance for laser optics, laser TCS radiator panel area and receiver PV array side reflector is 0 -fault tolerant (DFMR) while the laser power supply, laser/receiver cooling loops and receiver array SSU are 1-fault tolerant (against loss of mission).

\section{Design Limitations and Considerations}

Solid state laser module array cooling requirements control the minimum allowable aperture size based on $300 \mathrm{~K}$ water heat pipe evaporator radial flux operating limit (for dry out) assumed to be $\sim 100,000 \mathrm{~W} / \mathrm{m}^{2}$. Other water heat pipe operating limits have not yet been considered (capillary, sonic, etc.). For this study, a safety factor of 3 was chosen on heat pipe evaporator operating flux and consequently, a 1-m diameter laser module array was selected for a $10-\mathrm{kW}$ power transfer system point design. This limits PV receiver dissipated heat fluxes to $\sim 33,000 \mathrm{~W} / \mathrm{m}^{2}$. The laser module ATCS is largest single component mass in laser power transfer subsystem ( 27 percent). This value is decreased to 16 percent by going to the higher $325 \mathrm{~K}$ laser module control temperature, but results in less efficient laser operation leading to 20 percent higher source power requirement. Fine temperature control of each laser module is required to keep temperatures within $0.25{ }^{\circ} \mathrm{C}$ of each other. This is an engineering and technology challenge, beyond the current SOA, to phase-control 1000's to millions of laser diodes to achieve 
beam coherence. One would probably need to assume non-coherent beam collimation properties in the design of the system. Reduced coherence leads to greater than diffraction-limited beam divergence and the need to increase receiver aperture size. Thus, one must assess impact of larger inter-module temperature differences and the impact of spatial incoherence on beam divergence and receiver aperture sizing. For reference, the diffraction-limited laser beam divergence angle is given by $\beta * \lambda / \mathrm{D}$ and equal to $8 \mathrm{E}-07$ radians (46 micro-degrees) assuming a $\beta$ coefficient of 1 , a wavelength, $\lambda$, of $0.8 \mathrm{e}-06 \mathrm{~m}$ and diameter, $\mathrm{D}$, of $1-\mathrm{m}$. The diffraction-limited divergence angle is orders of magnitude smaller than the allowable divergence angle based on the assumed receiver design with peripheral reflector. This suggests that beam coherence is likely not required for a practical laser beamed power subsystem for lunar surface applications with relatively short beam distances (10-km or less). The last design limitation is the physical integration challenge associated with stowing and deploying large-area, low-temperature ATCS radiators. For a $10-\mathrm{kW}$ power transfer subsystem, an $80-\mathrm{m}^{2}, 2$-sided, $300 \mathrm{~K}$ laser radiator is required plus a $48-\mathrm{m}^{2}, 2$-sided, $320 \mathrm{~K}$ PV cell receiver radiator.

\section{Subsystem Concept of Operations}

A simple, notional concept of operations or "ConOps" for deployment, start-up and nominal operations was defined for each power transfer subsystem option.

\section{Power Cables}

The source power electronics and power cable assembly are pre-integrated with the lunar surface power source and the payload side power electronics are pre-integrated with payload, i.e., an ISRU plant. This offers an enormous benefit of electrical verification testing of the end-to-end system pre-launch and post-landing on the lunar surface prior to the deployment. First, the payload is deployed to the operational surface site with the small subsystem keepalive power, as needed, being provided by a dedicated battery with payload. With EVA surface crew and rover or telerobotic rover, the integrated power cable assembly and payload are removed and installed on the rover or rover trailer. The power cable remains connected to payload. For large mass power cable assemblies, pre-integration with a trailer may be needed. The rover would then pull the trailer instead of carrying the power cable assembly. The rover is then sortied to the selected power source (if not on the same lander) while deploying power cable to lunar surface. The power cable deploys via a pay-out mechanism that also straightens the cable to minimize free coiling. It is important to maintain no more than a $1.25 \mathrm{X}$ cable routing factor during deployment and select a routing path to minimize cross-cable traffic (trip hazard for EVA crew, cable damage hazard and fouling hazard for surface equipment). From the rover, the cable assembly is deployed to lunar surface next to the power source (if not already co-located on the same lander). Manually or telerobotically, the power and data connector(s) from the cable assembly are mated to those on the power source input power electronics (again, if not pre-integrated). The cable and connector continuity is next confirmed, the power electronics activated and the release, deployment and activation of the small ATCS radiators (only needed for $50-\mathrm{kW}$ power transfer case) occurs last. The system functionality and control communications are verified and issues are worked as needed. Lastly, the up-stream and down-stream power line inhibits are removed (i.e., switches closed) to allow power flow. The cable power subsystem can then be operated for 10 years without planned maintenance with 3:2 redundancy providing for fault tolerance from source to load (no DFMR or single fault items).

\section{RF}

The transmit side of the subsystem is pre-integrated with surface power module/node or is collocated with surface power module/node via surface crew EVA. The receiver side of subsystem is pre-integrated with the power payload (i.e., ISRU equipment) or is collocated with payload via surface crew EVA and receives keep-alive power from a dedicated payload battery. Manually or autonomously, the restraints are released and to stage the antenna and rectenna to their unfurling deployment positions. The antenna and rectenna are then deployed, positioned in the vertical configuration several meters above local ground level and aligned to have visual line of sight (LOS) with each other. The EVA crew then manually adjusts the antenna/rectenna alignments to achieve coarse pointing (using the alignment equipment). Next, the RF data/control communication system and power electronics are activated followed by deployment of the large-area ATCS radiators and activation of the ATCS units. Proper operation of the all subsystems is next verified. The power transfer subsystem is then activated at a low power rating and the payload power level received is measured. As needed, fine adjustments of antenna/rectenna azimuth/elevation settings are 
performed to maximize power transfer. The safety power shut-off/inhibit system is activated and proper operation is verified. This system is cued by sensors detecting unauthorized objects within the transmitter critical flux field of view. The EVA crew is next evacuated to a safe region and remotely the system is ramped up to full power for nominal power transfer operations. The beamed power subsystem must be operated regularly at low power level for payload and subsystem keep-alive thermal control power and health/status monitoring during eclipse periods and periods of down time for the payload. The beamed power subsystem is operated for 10 years with periodic realignments (to counteract regolith settling and thermal displacements) and maintenance activities to replace failed DFMR components (non-redundant items).

\section{Laser}

The laser side of the subsystem is pre-integrated with the surface power module/node or is collocated with surface power module/node via crew EVA. The PV receiver side of the system is pre-integrated with power payload (i.e., ISRU equipment) or is collocated with payload via crew EVA and receives keep-alive power from a dedicated payload battery. Manually or autonomously, restraints are released and the laser array and PV receiver array rectenna are staged to their vertical configuration several meters above local ground level. The visual LOS alignment between laser and receiver is next verified. The EVA crew then manually adjusts the laser/receiver to achieve coarse pointing (using the alignment equipment). The RF or optical data/control communication system and power electronics are then activated followed by deployment of the large-area ATCS radiators and activation of the ATCS units. Proper operation of the systems is then verified. The power transfer system is activated at low power rating and the payload power level received is measured. As needed, fine adjustment of laser/receiver azimuth/elevation settings is performed to maximize power transfer. The safety power shut-off/inhibit system is activated and proper operation is verified. This system is cued by sensors detecting unauthorized objects within the laser target area keep out zone. The EVA crew is next evacuated to a safe region and remotely the system is ramped up to full power for nominal power transfer operations. The beamed power subsystem must be operated regularly at low power level for payload and subsystem keep-alive thermal control power and health/status monitoring during eclipse periods and periods of down time for the payload. The beamed power subsystem is operated for 10 years with periodic realignments (to counter act regolith settling and thermal displacements), optical surface cleaning (to remove excessive dust) and maintenance activities to replace failed DFMR components (non-redundant items).

\section{Results}

\section{Mass and Performance Results}

\section{Power Cable Subsystem}

Key inputs and output results are shown in figures 8 and 9 to illustrate the subsystem mass dependence on payload power level with a fixed 1000-m cable length and 1000-VDC cable operating voltage. The mass is essentially proportional to power level except for power levels below $5 \mathrm{~kW}$ at which point the minimum cable conductor gauge is reached and further cable mass savings are not realized. The total subsystem mass is dominated by the cable mass item.

Figures 10 and 11 show key inputs and output results to illustrate the source power dependence on cable length with a fixed 10-kW power level and 1000-VDC cable operating voltage. The source power increases are more than proportional with longer cable length since greater cable perform loss is chosen to reduce cable conductor mass and minimize overall subsystem mass. For shorter cable lengths $(<500-\mathrm{m}$ which is about the cross-over point), low subsystem mass favors heavier gauge cabling with lower performance loss to keep power electronics mass, the dominant mass item, lower.

Subsystem inputs, performance and mass versus cable operating voltage are shown in Figure 12 below assuming a fixed $10-\mathrm{kW}$ power level and a $1000-\mathrm{m}$ cable length. The subsystem mass minimum occurs at a cable operating voltage of 2000 -VDC (see fig. 13). At higher voltages, smaller conductor sizes can not be used since the minimum wire size has been reached while at the same time, wire insulation thickness and mass increase with higher voltage. At lower voltages, higher current levels require the use of larger conductor sizes that greatly increase cable mass that dominates the subsystem mass. 
Inputs:

payload power, kW

distance, $\mathrm{m}$ Input Voltage level, VDC

Cable output Voltage level, VDC

Cable AC frequency, $h z$ (if used)

cable dV/V efficiency

Active TCS areal mass, kg/m2 radiator area

Cable operating temperature, $\mathrm{K}$

Electronics Control Temperature, $\mathrm{K}$

Control cabling mass, $\mathrm{kg} / \mathrm{m}$

Power cable connector mass fraction

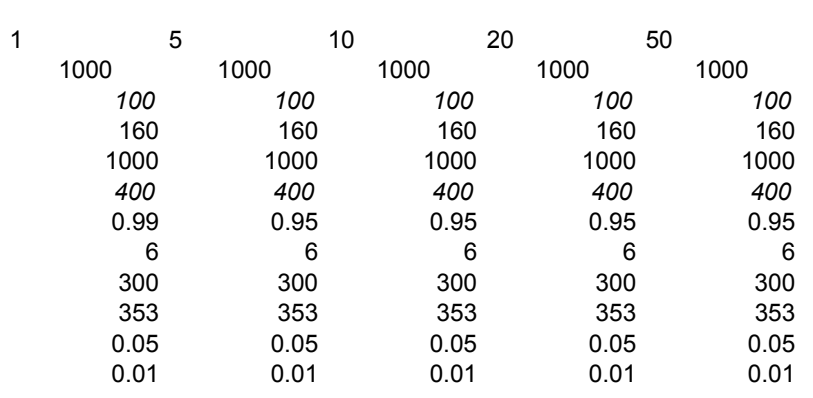

Outputs:

Input (STEP-UP DDCU) power conditioning efficiency

Output (STEP-DOWN DDCU) power conditioning efficiency

Step-down DDCU input power, kW

Step-up DDCU output power (cable input power), kW

Step-up DDCU input power, kW

Step-up DDCU thermal power, $\mathrm{kW}$

Step-down DDCU thermal power, kW

Step-up DDCU TCS radiator plane area, $\mathrm{m} 2$

Step-down DDCU TCS radiator plane area, $\mathrm{m} 2$

Cable Outer diameter, $\mathrm{cm}$

\begin{tabular}{|rrrrr}
0.919 & 0.944 & 0.948 & 0.950 & 0.951 \\
0.916 & 0.943 & 0.947 & 0.949 & 0.951 \\
1.09 & 5.30 & 10.56 & 21.07 & 52.58 \\
1.10 & 5.58 & 11.12 & 22.18 & 55.34 \\
$\mathbf{1 . 2 0}$ & $\mathbf{5 . 9 1}$ & $\mathbf{1 1 . 7 3}$ & $\mathbf{2 3 . 3 5}$ & $\mathbf{5 8 . 1 9}$ \\
0.10 & 0.33 & 0.61 & 1.17 & 2.85 \\
0.09 & 0.30 & 0.56 & 1.07 & 2.58 \\
0.09 & 0.32 & 0.59 & 1.13 & 2.76 \\
0.09 & 0.29 & 0.54 & 1.04 & 2.50 \\
0.87 & 0.86 & 0.99 & 1.17 & 1.52
\end{tabular}

Mass Outputs, kg:

Step up DDCU mass, kg

Power cable mass, kg

power cable connector mass, kg

control cable mass, $\mathrm{kg}$

Step Down DDCU mass, kg

Step up TCS mass, kg

Step down TCS mass, kg

Cabling spool \& deployer mechanism, kg

secondary structure $(5 \%)$

Total mass, kg

1

5

10

20

50

$\begin{array}{rrrrr}39.5 & 39.5 & 81.2 & 118.7 & 220.6 \\ 323.5 & 312.3 & 453.7 & 711.6 & 1425.2 \\ 3.2 & 3.1 & 4.5 & 7.1 & 14.3 \\ 50.0 & 50.0 & 50.0 & 50.0 & 50.0 \\ 42.0 & 71.3 & 108.0 & 174.0 & 368.6 \\ 0.6 & 1.9 & 3.5 & 6.8 & 16.6 \\ 0.5 & 1.8 & 3.3 & 6.2 & 15.0 \\ 50.0 & 50.0 & 50.0 & 50.0 & 50.0 \\ 6.6 & 8.2 & 12.3 & 17.8 & 33.5 \\ \mathbf{5 1 6 . 0} & \mathbf{5 3 8 . 1} & \mathbf{7 6 6 . 5} & \mathbf{1 1 4 2 . 2} & \mathbf{2 1 9 3 . 7} \\ & & & & \\ \mathbf{5 1 6 . 0} & \mathbf{1 0 7 . 6} & \mathbf{7 6 . 7} & \mathbf{5 7 . 1} & \mathbf{4 3 . 9}\end{array}$

Cable Power Transfer System Sp Mass, kg/kW

1.20

1.18

1.17

1.17

1.16

Figure 8.-Mass and performance versus payload power level. 
1-km, 1000-V Cable Power Transfer System: Mass

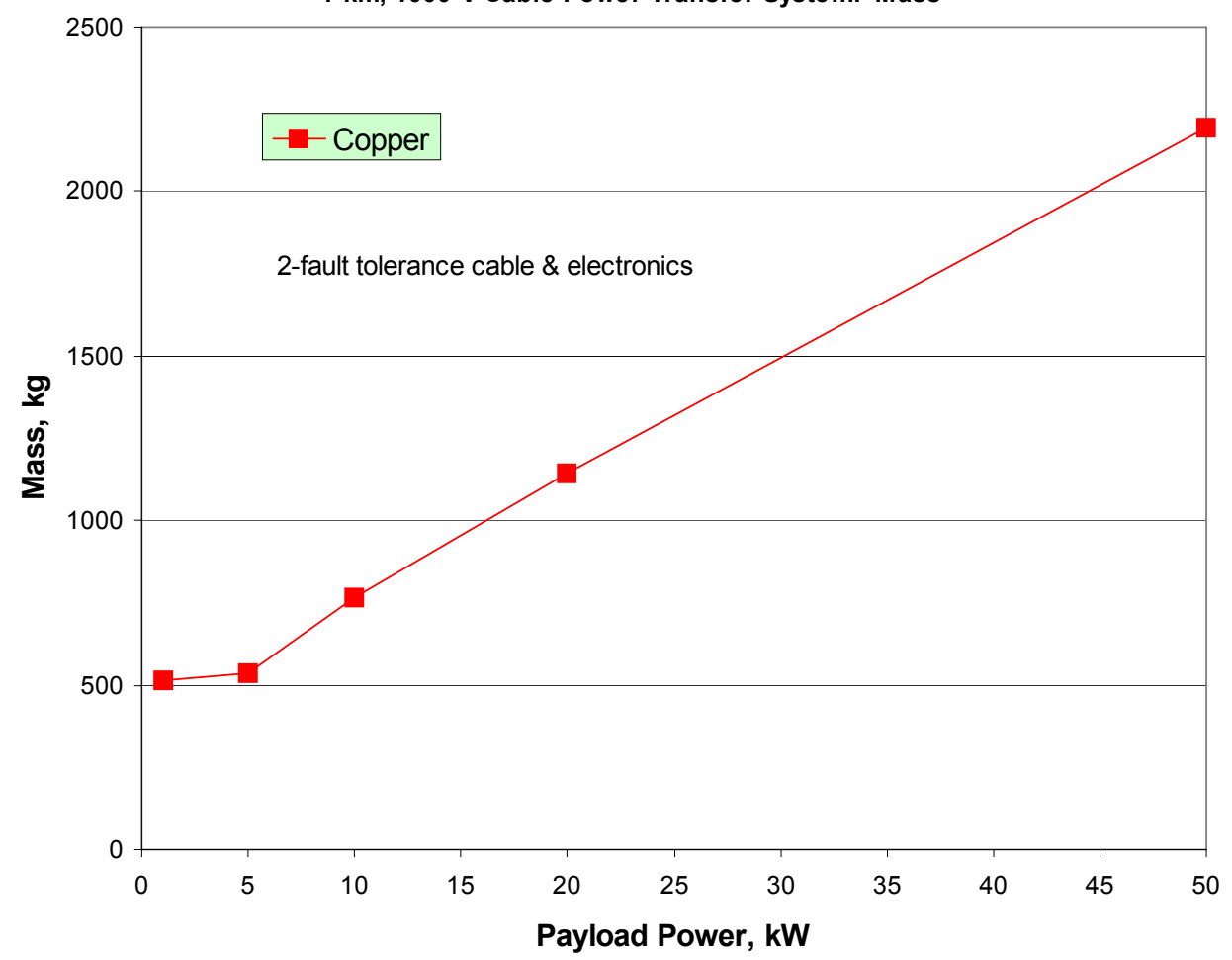

Figure 9.-Mass versus payload power level.

Inputs:

payload power, kW

distance, $m$

Input single phase AC frequency, $h z$ (if used)

Input Voltage level, VDC

Cable output Voltage level, VDC

Cable AC frequency, $h z$ (if used)

cable $\mathrm{dV} / \mathrm{V}$ efficiency

Active TCS areal mass, $\mathrm{kg} / \mathrm{m} 2$ radiator area

Cable operating temperature, $\mathrm{K}$

Electronics Control Temperature, $\mathrm{K}$

Control cabling mass, $\mathrm{kg} / \mathrm{m}$

Power cable connector mass fraction

Outputs:

Input (STEP-UP DDCU) power conditioning efficiency

Output (STEP-DOWN DDCU) power conditioning efficiency

Step-down DDCU input power, kW

Step-up DDCU output power (cable input power), kW Step-up DDCU input power, $\mathbf{k W}$

Step-up DDCU thermal power, kW

Step-down DDCU thermal power, kW

Step-up DDCU TCS radiator plane area, $\mathrm{m} 2$

Step-down DDCU TCS radiator plane area, $\mathrm{m} 2$

Cable Outer diameter, $\mathrm{cm}$

Mass Outputs, kg:

Step up DDCU mass, $\mathrm{kg}$

Power cable mass, $\mathrm{kg}$

power cable connector mass, $\mathrm{kg}$

control cable mass, $\mathrm{kg}$

Step Down DDCU mass, $\mathrm{kg}$

Step up TCS mass, kg

Step down TCS mass, $\mathrm{kg}$

Cabling spool \& deployer mechanism, kg

secondary structure $(5 \%)$

Total mass, $\mathbf{k g}$

Cable Power Transfer System Sp Mass, kg/kW

Cable Power Transfer System Sp Pwr, Pin/Pout

payload power, $\mathrm{kW}$
10

$50 \quad 10$
100
160
1000
400
0.995
6
300
353
0.05
0.01

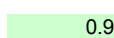

$0.947-0.948$

$\begin{array}{ll}0.947 & 0.948 \\ 0.947 & 0.947\end{array}$

$10.56 \quad 10.56$

10.61

11.21

$\mathbf{1 1 . 2 5}$

$\begin{array}{ll}0.56 & 10.56\end{array}$

$\begin{array}{rr} & 10 \\ 100 & 200 \\ 160 & \\ 1000 & 100 \\ 400 & 1000 \\ 0.99 & 400 \\ 6 & 0.99 \\ 300 & 6 \\ 353 & 300 \\ 0.05 & 353 \\ 0.01 & 0.05 \\ & 0.01\end{array}$

10

\begin{tabular}{rr}
\multicolumn{2}{c}{10} \\
100 & 1000 \\
160 & 100 \\
1000 & 160 \\
400 & 400 \\
0.95 & 0.95 \\
6 & \\
300 & 300 \\
353 & 353 \\
0.05 & 0.05 \\
0.01 & 0.01
\end{tabular}

10

5000

10

10000

$\begin{array}{rrr}100 & 100 & 100 \\ 160 & 160 & 160 \\ 1000 & 1000 & 1000 \\ 400 & 400 & 400 \\ 0.95 & 0.9 & 0.8 \\ 6 & 6 & 6 \\ 300 & 300 & 300 \\ 353 & 353 & 353 \\ 0.05 & 0.05 & 0.05 \\ 0.01 & 0.01 & 0.01\end{array}$

$\begin{array}{llr}0.59 & 0.59 & \mathbf{1 1 . 2 5} \\ 0.56 & 0.56 & 0.59\end{array}$

$\begin{array}{lll}0.59 & 0.59 & 0.59 \\ 0.56 & 0.56 & 0.56\end{array}$

$0.58 \quad 0.57$

$0.54 \quad 0.54$

0.87

$0.54 \quad 0.57$

$0.87 \quad 1.00$

$\begin{array}{cccc}0.948 & 0.948 & 0.948 & 0.948 \\ 0.947 & 0.947 & 0.947 & 0.947 \\ 10.56 & 10.56 & 10.56 & 10.56 \\ 11.12 & 11.12 & 11.73 & 13.20 \\ \mathbf{1 1 . 7 3} & \mathbf{1 1 . 7 3} & \mathbf{1 2 . 3 8} & \mathbf{1 3 . 9 2} \\ 0.61 & 0.61 & 0.64 & 0.72 \\ 0.56 & 0.56 & 0.56 & 0.56 \\ 0.59 & 0.59 & 0.62 & 0.70 \\ 0.54 & 0.54 & 0.54 & 0.54 \\ 0.86 & 0.99 & 1.22 & 1.18\end{array}$

10

10

10

10

10

10

10

$\begin{array}{|rrrrrrr|}79.4 & 79.6 & 79.6 & 81.2 & 81.2 & 83.4 & 88.6 \\ 16.0 & 31.8 & 93.0 & 156.0 & 453.7 & 4016.0 & 7382.9 \\ 0.2 & 0.3 & 0.9 & 1.6 & 4.5 & 40.2 & 73.8 \\ 2.5 & 5.0 & 10.0 & 25.0 & 50.0 & 250.0 & 500.0 \\ 108.0 & 108.0 & 108.0 & 108.0 & 108.0 & 108.0 & 108.0 \\ 3.5 & 3.4 & 3.4 & 3.5 & 3.5 & 3.7 & 4.2 \\ 3.3 & 3.3 & 3.3 & 3.3 & 3.3 & 3.3 & 3.3 \\ 50.0 & 50.0 & 50.0 & 50.0 & 50.0 & 50.0 & 50.0 \\ 12.2 & 12.2 & 12.2 & 12.3 & 12.3 & 12.4 & 12.7 \\ 275.0 & 293.6 & \mathbf{3 6 0 . 4} & \mathbf{4 4 0 . 9} & \mathbf{7 6 6 . 5} & \mathbf{4 5 6 7 . 0} & \mathbf{8 2 2 3 . 5} \\ & & & & & & \\ \mathbf{2 7 . 5} & \mathbf{2 9 . 4} & \mathbf{3 6 . 0} & \mathbf{4 4 . 1} & \mathbf{7 6 . 7} & \mathbf{4 5 6 . 7} & \mathbf{8 2 2 . 3} \\ & & & & & & \\ 1.12 & \mathbf{1 . 1 3} & \mathbf{1 . 1 3} & \mathbf{1 . 1 7} & \mathbf{1 . 1 7} & \mathbf{1 . 2 4} & \mathbf{1 . 3 9}\end{array}$

Figure 10.-Mass and performance versus payload distance. 
10-kW, 1000-V Cable Power Transfer System: Power

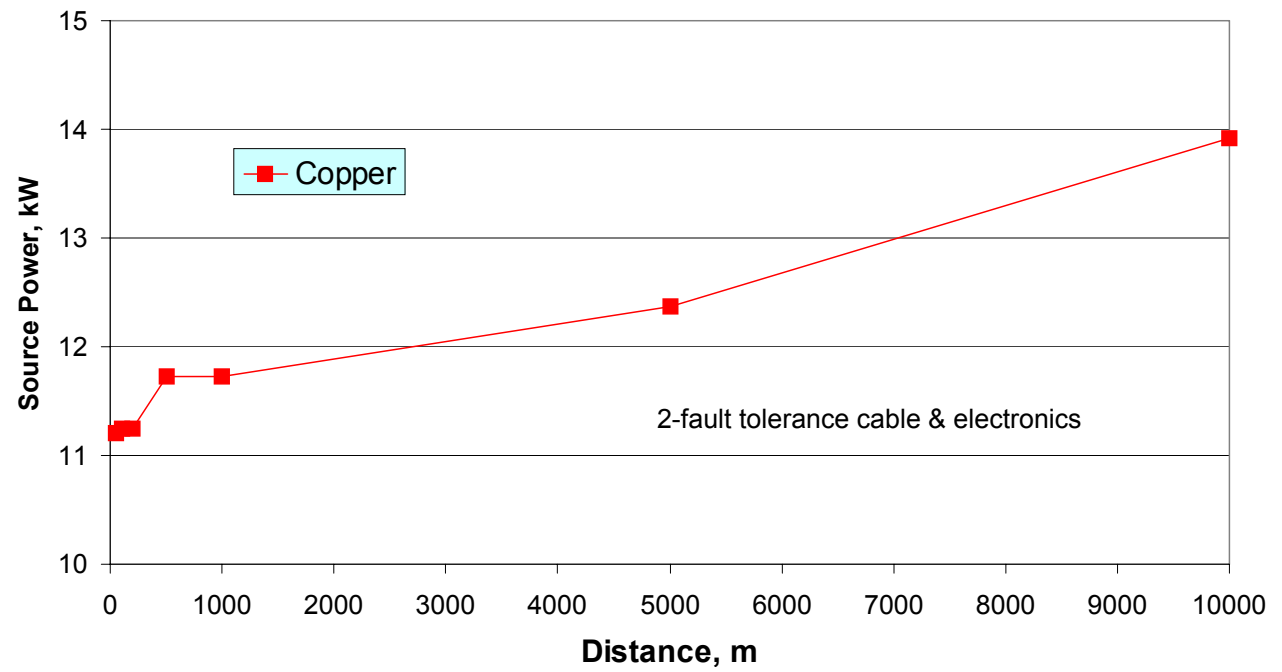

Figure 11.-Source power versus payload distance.

Inputs:

payload power, $\mathrm{kW}$

Input Voltage leve $A C$ frequ

Cable output Voltage level, VDC

Cable AC frequency, $h z$ (if used)

able $\mathrm{dV} / \mathrm{N}$ efficiency

Active TCS areal mass, $\mathrm{kg} / \mathrm{m} 2$ radiator area

Cable operating temperature, $\mathrm{K}$

Electronics Control Temperature, $\mathrm{K}$

Control cabling mass, $\mathrm{kg} / \mathrm{m}$

Power cable connector mass fraction

Outputs:

Input (STEP-UP DDCU) power conditioning efficiency Output (STEP-DOWN DDCU) power conditioning efficiency

Step-down DDCU input power, kW

Step-up DDCU output power (cable input power), kW Step-up DDCU input power, kW

Step-up DDCU thermal power, kW

Step-down DDCU thermal power, kW

Step-up DDCU TCS radiator plane area, $\mathrm{m} 2$

Step-down DDCU TCS radiator plane area, $\mathrm{m} 2$

Cable Outer diameter, $\mathrm{cm}$

Mass Outputs, kg:

Step up DDCU mass, $\mathrm{kg}$

Power cable mass, $\mathrm{kg}$

power cable connector mass, $\mathrm{kg}$

control cable mass, $\mathrm{kg}$

Step Down DDCU mass, kg

Step up TCS mass, $\mathrm{kg}$

Step down TCS mass, $\mathrm{kg}$

Cabling spool \& deployer mechanism, kg

secondary structure $(5 \%)$

Total mass, $\mathbf{k g}$

Cable Power Transfer System Sp Mass, kg/kW

Cable Power Transfer System Sp Pwr, Pin/Pout

\begin{tabular}{rrr}
1000 & \multicolumn{2}{r}{10} \\
100 & 1000 & \multicolumn{1}{c}{1000} \\
160 & 160 & 1 \\
160 & 300 & 5 \\
400 & 400 & 400 \\
0.75 & 0.8 & 0.9 \\
6 & 6 & \\
300 & 300 & 3 \\
353 & 353 & 353 \\
0.05 & 0.05 & 0.05 \\
0.01 & 0.01 & 0.01 \\
& & \\
1.000 & 0.948 & 0.948 \\
0.947 & 0.947 & 0.947 \\
10.56 & 10.56 & 10.56 \\
14.08 & 13.20 & 11.73 \\
$\mathbf{1 4 . 0 8}$ & $\mathbf{1 3 . 9 2}$ & $\mathbf{1 2 . 3 8}$ \\
0.00 & 0.72 & 0.64 \\
0.56 & 0.56 & 0.56 \\
0.00 & 0.70 & 0.62 \\
0.54 & 0.54 & 0.54 \\
1.63 & 1.12 & 1.22 \\
& &
\end{tabular}

$\begin{array}{rrr} & & 10 \\ & 1000 & 1000 \\ 00 & 100 & \\ 160 & 160 & \\ 500 & 1000 & \\ 400 & 400 & \\ 0.9 & 0.95 & \\ 6 & 6 & \\ 300 & 300 & \\ 353 & 353 & \\ .05 & 0.05 & \\ .01 & 0.01 & \end{array}$

\begin{tabular}{rrrr} 
& \multicolumn{2}{c}{10} & \multicolumn{2}{c}{10} \\
100 & 1000 & 1000 & 1000 \\
160 & 100 & 100 & 100 \\
000 & 160 & 160 & 160 \\
400 & 3000 & 4000 & 5000 \\
0.95 & 400 & 400 & 400 \\
6 & 0.99 & 0.995 & 0.995 \\
300 & 6 & 6 & 6 \\
353 & 300 & 300 & 300 \\
0.05 & 353 & 353 & 353 \\
0.01 & 0.05 & 0.05 & 0.05 \\
& 0.01 & 0.01 & 0.01
\end{tabular}

payload power, $\mathrm{kW} \quad 10$

10

10

$\begin{array}{rrrrr}0.948 & 0.948 & 0.948 & 0.948 & 0.948 \\ 0.947 & 0.947 & 0.947 & 0.947 & 0.947 \\ 10.56 & 10.56 & 10.56 & 10.56 & 10.56 \\ 11.12 & 11.12 & 10.67 & 10.61 & 10.61 \\ 1.73 & \mathbf{1 1 . 7 3} & \mathbf{1 1 . 2 5} & \mathbf{1 1 . 1 9} & \mathbf{1 1 . 1 9} \\ 0.61 & 0.61 & 0.59 & 0.58 & 0.58 \\ 0.56 & 0.56 & 0.56 & 0.56 & 0.56 \\ 0.59 & 0.59 & 0.57 & 0.56 & 0.56 \\ 0.54 & 0.54 & 0.54 & 0.54 & 0.54 \\ 0.99 & 0.78 & 0.89 & 0.91 & 0.99\end{array}$

\begin{tabular}{|rr|}
\hline 0.0 & 92.4 \\
1699.4 & 1115 \\
17.0 & 11. \\
50.0 & 50.0 \\
118.1 & 112 \\
0.0 & 4.2 \\
3.3 & 3.0 \\
50.0 & 50 \\
8.6 & 13 \\
\hline $\mathbf{1 9 4 6 . 3}$ & $\mathbf{1 4 5 1}$ \\
\hline
\end{tabular}

$\begin{array}{rr}78.4 & 78.4 \\ 361.0 & 399.7 \\ 3.6 & 4.0 \\ 50.0 & 50.0 \\ 107.9 & 108.2 \\ 3.4 & 3.4 \\ 3.3 & 3.3 \\ 50.0 & 50.0 \\ 12.1 & 12.2 \\ \mathbf{6 6 9 . 7} & \mathbf{7 0 9 . 1} \\ \mathbf{6 7 . 0} & \mathbf{7 0 . 9} \\ & \\ 1.12 & 1.12\end{array}$

$\begin{array}{llllllll}1.41 & 1.39 & 1.24 & 1.17 & 1.17 & 1.13 & 1.12 & 1.12\end{array}$

Figure 12.-Mass and performance versus DC cable operating voltage. 


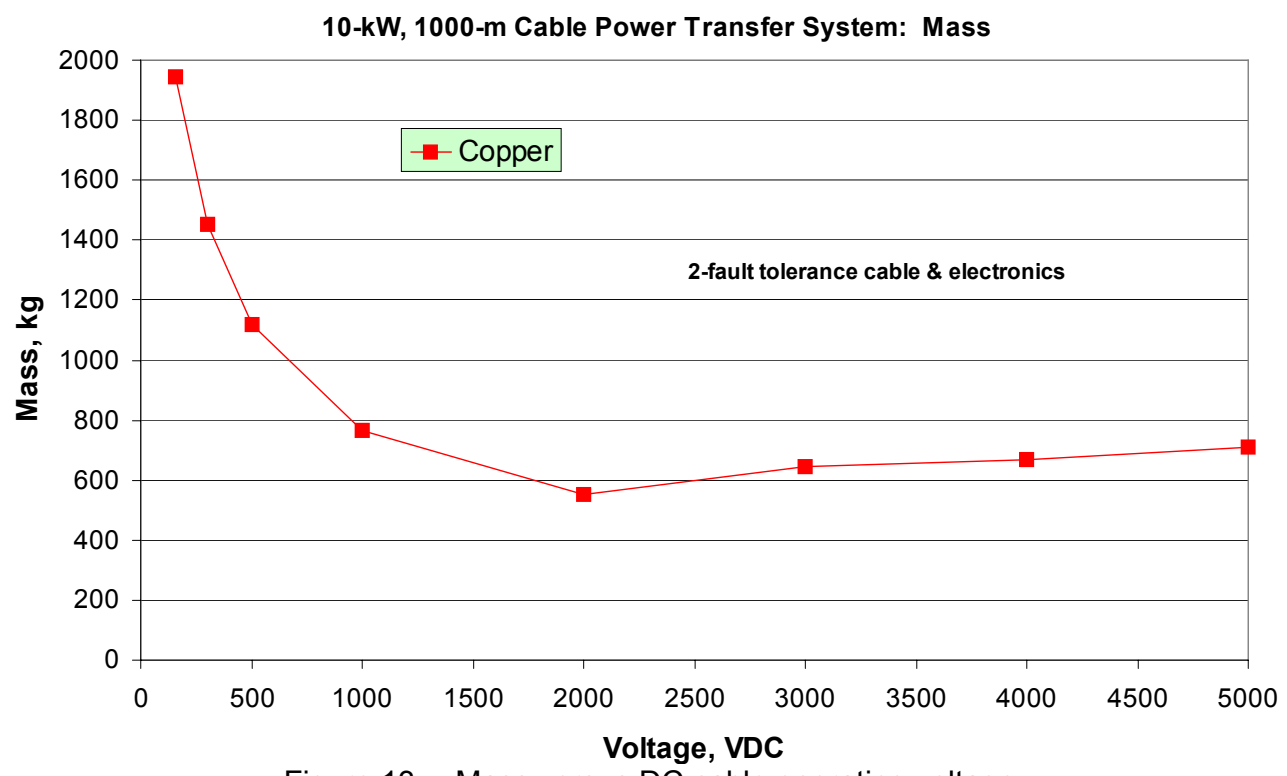

Figure 13.-Mass versus DC cable operating voltage.

A separate, side study was performed to assess the impacts of conductor material choice and cable shielding/ armoring approach. Results of this study are shown in figure 14 for relatively a short-length, 270-VDC power cable. For this class of power cable, the mass grows roughly proportional to cable length to the $1.5^{\text {th }}$ power. The cables with aluminum conductors are $\sim 20$ percent lighter than those using copper conductors, but are 15 percent larger in diameter. In addition, the aluminum conductor power cable minimum allowable bend radius and cable stowage spool diameter are also 15 percent larger than for copper conductor cables. The use of stainless steel armoring adds $\sim 40$ percent to the baseline cable mass suggesting that it may be more effective (lower mass) to instead add an extra conductor pair for redundancy against meteoroid impact damage failure. The requirement for lunar surface power cable EMI shielding has not been defined, yet if needed, the grounded stainless steel braiding could meet both EMI and armoring needs. Based on this limited study, the best overall power cable design option appears to be copper conductor power cable, unshielded, unarmored, but with 3:2 power conductor redundancy. Compared with aluminum conductor cabling, copper cabling has superior bend radius (lower deployment risk), lower stowed volume, greater fault current capacity, no galvanic corrosion controls needed and extensive spacecraft flight heritage.

\section{AC Power Cable Subsystem}

Figures 15 and 16 show key mass and performance inputs and outputs for an AC power cable subsystem with 1000 -m length and operating at 1000-VAC, $400 \mathrm{~Hz}, 3$-phase. Results indicate that subsystem mass is essential proportional to payload power level.

Figures 17 and 18 show the source power versus cable length for a 10-kW, 1000-VAC, $400 \mathrm{~Hz}, 3$-phase AC power cable. Source power growths slightly less than proportional to cable length since for longer cables, greater cable performance loss is accepted to reduce cable conductor mass.

The AC power cable subsystem mass minimum occurs at 2000-VAC as shown in figures 19 and 20 depicting the mass versus operating voltage for a $10-\mathrm{kW}, 1000-\mathrm{m}$ long power cable. For voltages at or above 1000-VAC, conductor minimum gauge size was reached at which point further conductor mass savings could not be realized for increasing cable operating voltages. 


\begin{tabular}{|c|c|c|c|c|c|c|}
\hline & \multicolumn{6}{|c|}{ Long Power Cable Mass, kg } \\
\hline & \multicolumn{3}{|c|}{ Cooper Conductors } & \multicolumn{3}{|c|}{ Aluminum Conductors } \\
\hline Length, $\mathrm{m}$ & $3: 2$ & 2:2 & 1:1 & $3: 2$ & $2: 2$ & 1:1 \\
\hline 50 & 25.1 & 18.4 & 14.9 & 23.6 & 17.4 & 13.5 \\
\hline 100 & 68.8 & 49.2 & 41.1 & 60.7 & 43.8 & 34.7 \\
\hline \multirow[t]{3}{*}{200} & 205.6 & 143.7 & 124.3 & 167.6 & 118.4 & 96.3 \\
\hline & \multicolumn{6}{|c|}{$\begin{array}{c}\text { Long Power Cable Mass w/SS Braided } \\
\text { Armoring/EMI Shielding, kg }\end{array}$} \\
\hline & \multicolumn{3}{|c|}{ Cooper Conductors } & \multicolumn{3}{|c|}{ Aluminum Conductors } \\
\hline Length,m & $3: 2$ & 2:2 & 1:1 & $3: 2$ & 2:2 & 1:1 \\
\hline 50 & 41.2 & 34.5 & 31.0 & 39.7 & 33.5 & 29.6 \\
\hline 100 & 100.9 & 81.3 & 73.2 & 92.8 & 75.9 & 66.8 \\
\hline \multirow[t]{3}{*}{200} & 269.8 & 207.9 & 188.5 & 231.8 & 182.6 & 160.5 \\
\hline & \multicolumn{6}{|c|}{ Cable OD, cm } \\
\hline & \multicolumn{3}{|c|}{ Cooper Conductors } & \multicolumn{3}{|c|}{ Aluminum Conductors } \\
\hline Length,m & $3: 2$ & 2:2 & 1:1 & $3: 2$ & $2: 2$ & 1:1 \\
\hline 50 & 0.87 & 0.87 & 1.00 & 0.95 & 0.95 & 1.12 \\
\hline 100 & 1.00 & 1.00 & 1.19 & 1.11 & 1.11 & 1.35 \\
\hline \multirow[t]{3}{*}{200} & 1.18 & 1.18 & 1.44 & 1.34 & 1.34 & 1.67 \\
\hline & \multicolumn{6}{|c|}{ Cable Min Bend Radius, cm } \\
\hline & \multicolumn{3}{|c|}{ Cooper Conductors } & \multicolumn{3}{|c|}{ Aluminum Conductors } \\
\hline Length,m & $3: 2$ & $2: 2$ & 1:1 & $3: 2$ & $2: 2$ & 1:1 \\
\hline 50 & 8.7 & 8.7 & 10.0 & 9.5 & 9.5 & 11.2 \\
\hline 100 & 10.0 & 10.0 & 11.9 & 11.1 & 11.1 & 13.5 \\
\hline 200 & 11.8 & 11.8 & 14.4 & 13.4 & 13.4 & 16.7 \\
\hline
\end{tabular}

Figure 14.-DC cable mass, diameter and bend radius versus design features.

Inputs:

payload power, $\mathrm{kW}$

distance, $m$

Input single phase AC frequency, hz (if used)

Input Voltage level, AC

Cable output Voltage level, VAC 3ph

Cable AC frequency, hz

cable dV/V efficiency

Active TCS areal mass, $\mathrm{kg} / \mathrm{m} 2$ radiator area

Cable operating temperature, $\mathrm{K}$

Electronics Control Temperature, $\mathrm{K}$

Control cabling mass, $\mathrm{kg} / \mathrm{m}$

Power cable connector mass fraction

$1000 \quad 5$
100
300
1000
400
0.99
6
300
353
0.05
0.01

$$
\begin{array}{r}
1000 \\
100 \\
300 \\
1000 \\
400 \\
0.96 \\
300 \\
353 \\
0.05 \\
0.01
\end{array}
$$

$10 \quad 20$

Outputs:

Input (STEP-UP AACU) power conditioning efficiency

Output (STEP-DOWN ADCU) power conditioning efficiency

Step-down ADCU input power, kW

Step-up AACU output power (cable input power), kW Step-up AACU input power, $k W$

Step-up ADCU thermal power, $\mathrm{kW}$

Step-down ADCU thermal power, kW

Step-up AACU TCS radiator plane area, $\mathrm{m} 2$

Step-down ADCU TCS radiator plane area, $\mathrm{m} 2$

Cable Outer diameter, $\mathrm{cm}$

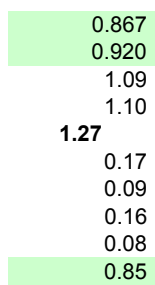

Mass Outputs, $\mathbf{k g}$ :

Step up AACU mass, kg

Power cable mass, $\mathrm{kg}$

power cable connector mass, $\mathrm{kg}$

control cable mass, $\mathrm{kg}$

Step Down ADCU mass, $\mathrm{kg}$

Step up TCS mass, $\mathrm{kg}$

Step down TCS mass, $\mathrm{kg}$

Cabling spool \& deployer mechanism, kg

secondary structure $(5 \%)$

Total mass, kg

0.956

5.23

6.07

$5.45-10.95$

0.63

12.16

0.23

0.61

0.22

0.87

1000

1000

1000

$\begin{array}{rrr}100 & 100 & 100 \\ 300 & 300 & 300\end{array}$

$\begin{array}{rrrr} & 300 & 300 & 300\end{array}$

$\begin{array}{lll}400 & 400 & 400\end{array}$

0.95

300

353

0.05

0.01

0.95
6

300

353

0.05

0.01

Cable Power Transfer System Sp Mass, kg/kW

$\begin{array}{lll}0.901 & 0.903 & 0.905 \\ 0.961 & 0.964 & 0.966\end{array}$

$\begin{array}{lll}10.41 & 20.75 & 51.76\end{array}$

$21.84 \quad 57.51$

24.18

63.55

$\begin{array}{rrr}1.20 & 24.35 & 6.04\end{array}$

$\begin{array}{lll}0.41 & 0.75 & 1.76\end{array}$

$\begin{array}{lll}1.17 & 2.27 & 5.85\end{array}$

$\begin{array}{lll}0.39 & 0.72 & 1.71\end{array}$

0.94

1.09

1.14

10

20

50

\begin{tabular}{|rrrrr}
81.9 & 177.4 & 275.2 & 446.1 & 936.4 \\
325.3 & 348.1 & 442.2 & 682.1 & 765.9 \\
3.3 & 3.5 & 4.4 & 6.8 & 7.7 \\
50.0 & 50.0 & 50.0 & 50.0 & 50.0 \\
56.0 & 98.0 & 145.9 & 239.6 & 525.5 \\
1.0 & 3.6 & 7.0 & 13.6 & 35.1 \\
0.5 & 1.3 & 2.4 & 4.3 & 10.2 \\
50.0 & 50.0 & 50.0 & 50.0 & 50.0 \\
9.5 & 16.5 & 24.0 & 37.7 & 77.9 \\
$\mathbf{5 7 7 . 4}$ & $\mathbf{7 4 8 . 5}$ & $\mathbf{1 0 0 1 . 1}$ & $\mathbf{1 5 3 0 . 3}$ & $\mathbf{2 4 5 8 . 6}$ \\
& & & & \\
$\mathbf{5 7 7 . 4}$ & $\mathbf{1 4 9 . 7}$ & $\mathbf{1 0 0 . 1}$ & $\mathbf{7 6 . 5}$ & $\mathbf{4 9 . 2}$ \\
& & & & \\
$\mathbf{1 . 2 7}$ & $\mathbf{1 . 2 1}$ & $\mathbf{1 . 2 2}$ & $\mathbf{1 . 2 1}$ & $\mathbf{1 . 2 7}$
\end{tabular}

Cable Power Transfer System Sp Pwr, Pin/Pout

1.27

1.21

$1.22 \quad 1.21$

1.27

Figure 15.-AC power cable subsystem mass and performance versus payload power level. 


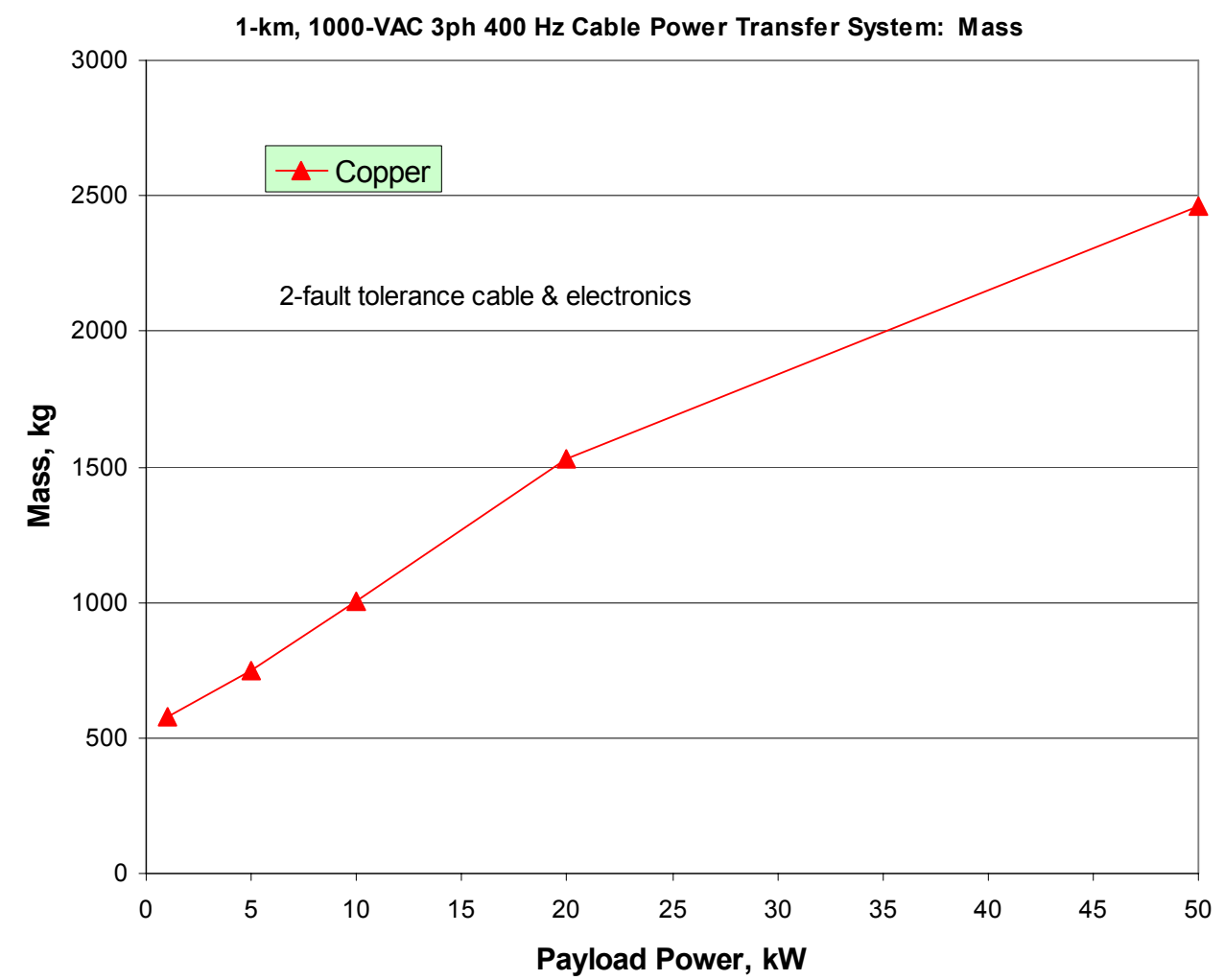

Figure 16. -AC power cable subsystem mass versus payload power level.

Inputs:

payload power, $\mathrm{kW}$

single phase AC frequency, $\mathrm{hz}$ (if used) Input Voltage level, AC

Cable output Voltage level, VAC 3ph

Cable AC frequency, hz

cable dV $N$ efficiency

Active TCS areal mass, $\mathrm{kg} / \mathrm{m} 2$ radiator area

Cable operating temperature, $\mathrm{K}$

Electronics Control Temperature, $\mathrm{K}$

Control cabling mass, $\mathrm{kg} / \mathrm{m}$

Power cable connector mass fraction

Outputs:

Input (STEP-UP AACU) power conditioning efficiency

Output (STEP-DOWN ADCU) power conditioning efficiency

Step-down ADCU input power, kW

Step-up AACU output power (cable input power), kW

Step-up AACU input power, kW

Step-up ADCU thermal power, kW

Step-down ADCU thermal power, kW

Step-up AACU TCS radiator plane area, $\mathrm{m} 2$

Step-down ADCU TCS radiator plane area, $\mathrm{m} 2$

Cable Outer diameter, $\mathrm{cm}$

Mass Outputs, kg:

Step up AACU mass, kg

Power cable mass, $\mathrm{kg}$

power cable connector mass, $\mathrm{kg}$

control cable mass, $\mathrm{kg}$

Step Down ADCU mass, kg

Step up TCS mass, kg

Step down TCS mass, $\mathrm{kg}$

Cabling spool \& deployer mechanism, kg

secondary structure $(5 \%)$

Total mass, kg

Cable Power Transfer System Sp Mass, kg/kW

payload power, kW
10

$\begin{array}{rrr}50 & 10 \\ 100 & \\ 300 & \\ 1000 & \\ 400 & \\ 0.995 & \\ 6 & \\ 300 & \\ 353 & \\ 0.05 & \\ 0.01 & \end{array}$

$\begin{array}{rr}100 & \\ 100 & 200 \\ 300 & \\ 1000 & \\ 400 \\ 0.995 \\ 6 \\ 300 \\ 353 \\ 0.05 \\ 0.01\end{array}$

200
100
300
1000
400
0.99
6
300
353
0.05
0.01

1050

$\begin{array}{rr} & 10 \\ 100 & 1000 \\ 300 & \\ 1000 & \\ 400 & \\ 400 \\ 0.96 & 400 \\ 6 & 0.9 \\ 300 & 30 \\ 353 & 35 \\ 0.05 & 0.05 \\ 0.01 & 0.0\end{array}$

105000

10

10000

$\begin{array}{rrr}100 & 100 & 100 \\ 300 & 300 & 300 \\ 000 & 1000 & 1000 \\ 400 & 400 & 400 \\ 0.95 & 0.85 & 0.8 \\ 6 & 6 & 6 \\ 300 & 300 & 300 \\ 353 & 353 & 353 \\ 0.05 & 0.05 & 0.05 \\ 0.01 & 0.01 & 0.01\end{array}$

$\begin{array}{rrrrrrr}0.901 & 0.901 & 0.901 & 0.901 & 0.901 & 0.901 & 0.902 \\ 0.961 & 0.961 & 0.961 & 0.961 & 0.961 & 0.961 & 0.961 \\ 10.41 & 10.41 & 10.41 & 10.41 & 10.41 & 10.41 & 10.41 \\ 10.46 & 10.46 & 10.51 & 10.84 & 10.95 & 12.24 & 13.01 \\ \mathbf{1 1 . 6 1} & \mathbf{1 1 . 6 1} & \mathbf{1 1 . 6 7} & \mathbf{1 2 . 0 3} & \mathbf{1 2 . 1 6} & \mathbf{1 3 . 5 9} & \mathbf{1 4 . 4 2} \\ 1.15 & 1.15 & 1.15 & 1.19 & 1.20 & 1.35 & 1.41 \\ 0.41 & 0.41 & 0.41 & 0.41 & 0.41 & 0.41 & 0.41 \\ 1.11 & 1.11 & 1.12 & 1.15 & 1.17 & 1.30 & 1.37 \\ 0.39 & 0.39 & 0.39 & 0.39 & 0.39 & 0.39 & 0.39 \\ 0.88 & 0.95 & 0.95 & 0.87 & 0.94 & 1.02 & 1.10\end{array}$

$10 \quad 10$

10

10

10

10

\begin{tabular}{|c|c|c|c|c|c|c|}
\hline 267.0 & 267.0 & 267.8 & 273.4 & 275.2 & 296.6 & 309.2 \\
\hline 17.8 & 45.8 & 91.2 & 173.8 & 442.2 & 2765.7 & 6906.9 \\
\hline 0.2 & 0.5 & 0.9 & 1.7 & 4.4 & 27.7 & 69.1 \\
\hline 2.5 & 5.0 & 10.0 & 25.0 & 50.0 & 250.0 & 500.0 \\
\hline 145.9 & 145.9 & 145.9 & 145.9 & 145.9 & 145.9 & 145.9 \\
\hline 6.7 & 6.7 & 6.7 & 6.9 & 7.0 & 7.8 & 8.2 \\
\hline 2.4 & 2.4 & 2.4 & 2.4 & 2.4 & 2.4 & 2.4 \\
\hline 50.0 & 50.0 & 50.0 & 50.0 & 50.0 & 50.0 & 50.0 \\
\hline 23.6 & 23.6 & 23.6 & 23.9 & 24.0 & 25.1 & 25.8 \\
\hline 516.0 & 546.8 & 598.5 & 703.1 & 1001.1 & 3571.2 & 8017.4 \\
\hline 51.6 & 54.7 & 59.9 & 70.3 & 100.1 & 357.1 & 801.7 \\
\hline 1.16 & 1.16 & 1.17 & 1.20 & 1.22 & 1.36 & 1.44 \\
\hline
\end{tabular}

Figure 17.-AC power cable subsystem mass and performance versus payload distance. 
10-kW, 1000-V Cable Power Transfer System: Power

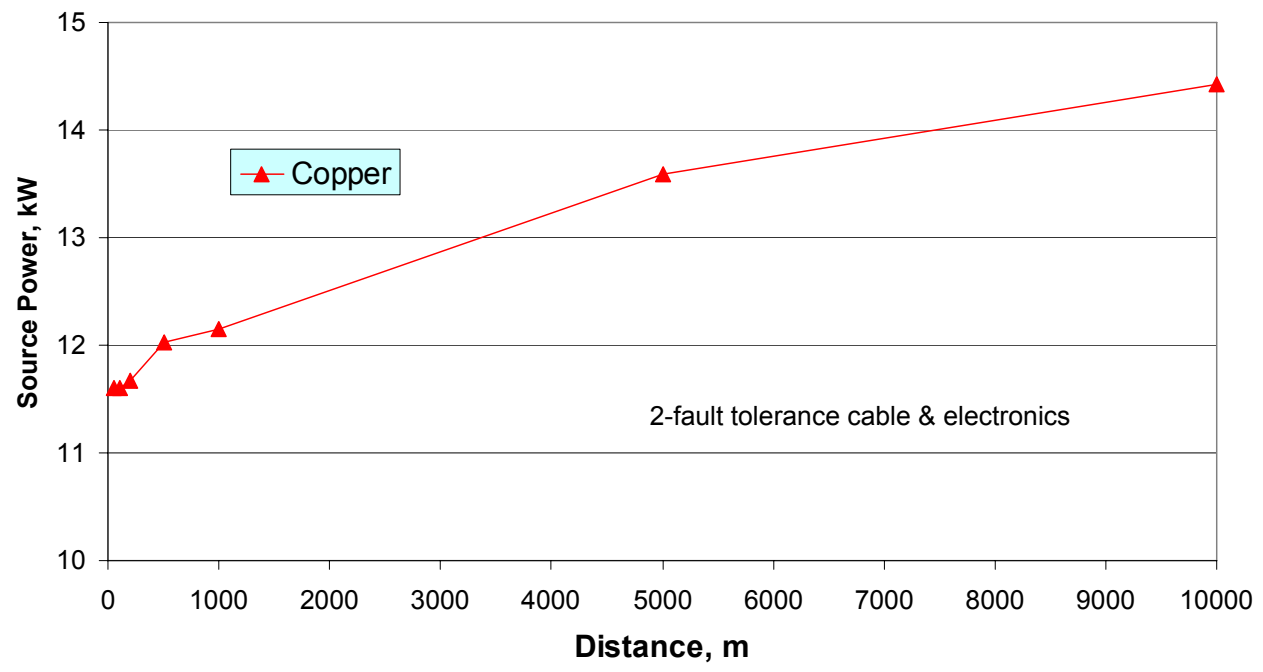

Figure 18.-AC power cable subsystem source power versus payload distance.

Inputs:

payload power, kW

distance, $\mathrm{m}$

Input single phase AC frequency, hz (if used)

Input Voltage level, AC

Cable output Voltage level, VAC 3ph

Cable AC frequency, hz

cable dV/V efficiency

Active TCS areal mass, $\mathrm{kg} / \mathrm{m} 2$ radiator area

Cable operating temperature, $\mathrm{K}$

Electronics Control Temperature, $\mathrm{K}$

Control cabling mass, $\mathrm{kg} / \mathrm{m}$

Power cable connector mass fraction

\begin{tabular}{rrrrrrrr}
10 & \multicolumn{6}{c}{10} & \multicolumn{2}{c}{10} & \multicolumn{1}{c}{10} \\
1000 & 1000 & 1000 & 1000 & 1000 & 1000 \\
100 & 100 & 100 & 100 & 100 & 100 \\
300 & 300 & 300 & 300 & 300 & 300 \\
$\mathbf{5 0 0}$ & 1000 & 2000 & 3000 & $\mathbf{4 0 0 0}$ & $\mathbf{5 0 0 0}$ \\
400 & 400 & 400 & 400 & 400 & 400 \\
0.95 & 0.96 & 0.979 & 0.991 & 0.995 & 0.997 \\
6 & 6 & 6 & 6 & 6 & 6 \\
300 & 300 & 300 & 300 & 300 & 300 \\
353 & 353 & 353 & 353 & 353 & 353 \\
0.05 & 0.05 & 0.05 & 0.05 & 0.05 & 0.05 \\
0.01 & 0.01 & 0.01 & 0.01 & 0.01 & 0.01
\end{tabular}

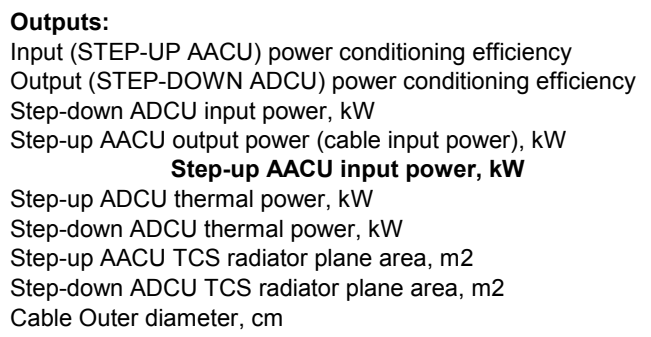

Outputs:

Input (STEP-UP AACU) power conditioning efficiency

Output (STEP-DOWN ADCU) power conditioning efficiency

Step-down ADCU input power, kW

Step-up AACU output power (cable input power), kW Step-up AACU input power, $\mathbf{k W}$

Step-up ADCU thermal power, kW

Step-down ADCU thermal power, kW

Step-up AACU TCS radiator plane area, $\mathrm{m} 2$

Step-down ADCU TCS radiator plane area, $\mathrm{m} 2$

Cable Outer diameter, $\mathrm{cm}$

payload power, kW

Mass Outputs, kg:

Step up AACU mass, kg

Power cable mass, kg

power cable connector mass, $\mathrm{kg}$

control cable mass, $\mathrm{kg}$

Step Down ADCU mass, kg

Step up TCS mass, $\mathrm{kg}$

Step down TCS mass, $\mathrm{kg}$

Cabling spool \& deployer mechanism, kg

secondary structure $(5 \%)$

Total mass, kg

Cable Power Transfer System Sp Mass, kg/kW

Cable Power Transfer System Sp Pwr, Pin/Pout

\begin{tabular}{|r|}
\hline $\mathbf{1 0}$ \\
\hline 275.7 \\
1138.0 \\
11.4 \\
50.0 \\
145.9 \\
7.0 \\
2.4 \\
50.0 \\
24.0 \\
\hline 1704.4 \\
\hline
\end{tabular}

0.901
0.961
10.41
10.95

12.16

16

1.20

0.41

1.17

0.39

0.01

0.01

0.01

0.01

0.01

$\begin{array}{rrrrrr}170.4 & 100.1 & 90.1 & 91.0 & 91.3 & 104.3 \\ 1.22 & 1.20 & 1.18 & 1.17 & 1.16 & 1.16\end{array}$

Figure 19._AC power cable subsystem mass and performance versus AC cable operating voltage. 


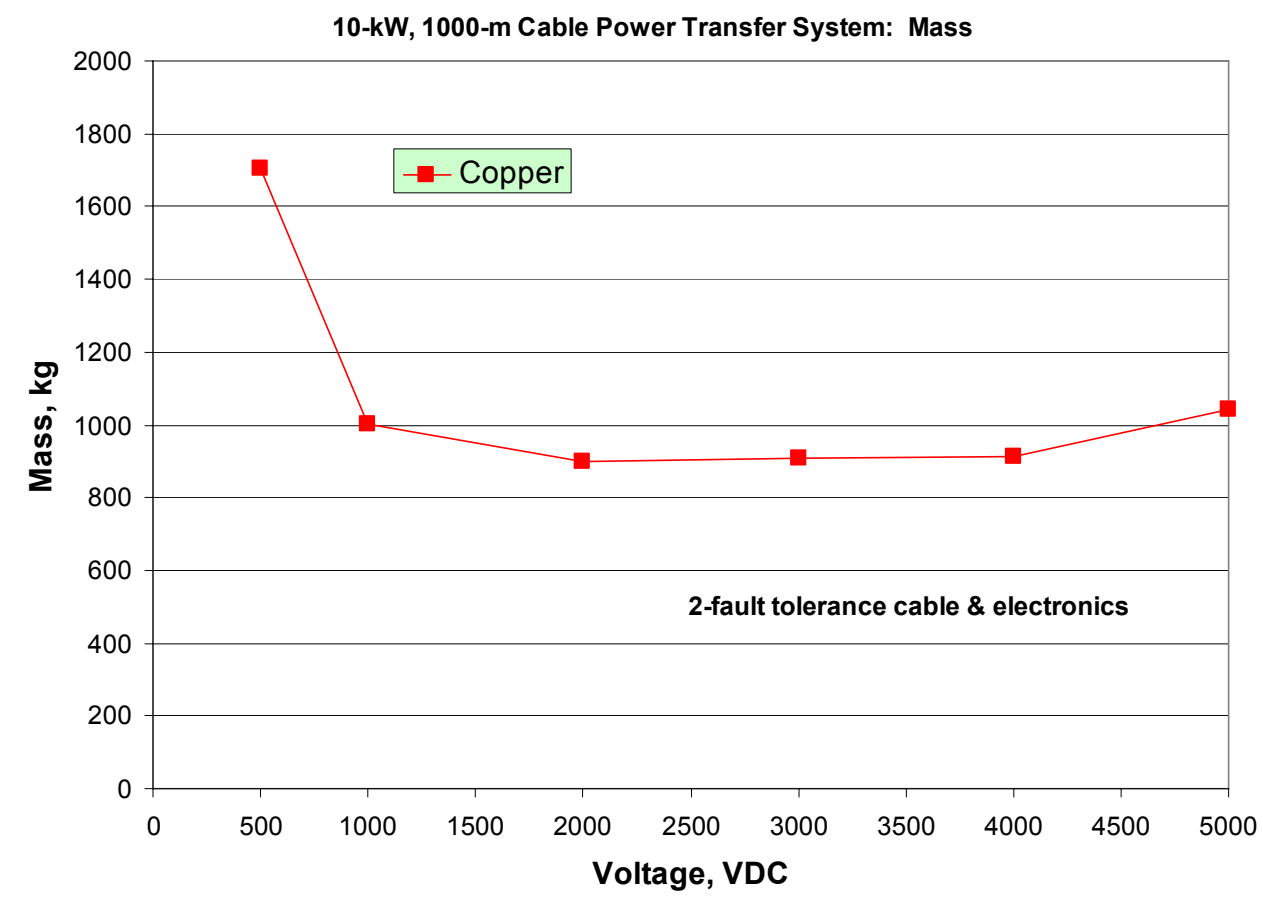

Figure 20.-Mass versus AC cable operating voltage.

\section{RF Subsystem}

Design inputs, design outputs and mass value are shown below in figure 21 for the RF beamed power transfer subsystem at various power levels and operating frequencies.

Figures 22 shows the required source power versus payload element power for RF beamed power transfer over a 1000-m distance. Source power grows slightly less than proportional to payload power since at higher operating power levels and fixed rectenna area, rectenna incident power density increases with high power levels leading to greater operating efficiency. RF subsystem mass is essentially proportional to payload power (see fig. 23). At the $10-\mathrm{kW}$ payload power level, the $5.8 \mathrm{GHz}$ system is only half the mass of the SOA, $2.45 \mathrm{GHz}$ system. The transmit antenna gain at the higher operating frequency is greatly improved leading to big improvements in free space transmission efficiency, decreases in the required input power and large mass savings in input power processing electronics, ATCS and magnetron items.

Figures 24 to 26 show design inputs, design outputs, mass and performance values of the RF subsystem as a function of transmission distance to the payload element. Both source power and subsystem mass grows by orders of magnitude with increasing transmission distance due to free space loss that increases exponentially. Free space loss can be reduced by increasing aperture areas, but aperture areas are already maximized subject to lander stowage constraints. Free space loss can also be reduced by decreasing RF wavelength or increasing frequency. By increasing frequency from 2.45 to $5.8 \mathrm{GHz}$, the subsystem source power can be cut in third while saving about half of the mass for a 1000-m transmission distance case. Further increases in RF frequency above $5.8 \mathrm{GHz}$ could offer further subsystem mass savings until the point when magnetron and rectenna efficiency losses (and the associated mass penalty) balance out mass savings from better transmit antenna performance. However, substantial technology investment will be required to fabricate efficient higher frequency rectennas that are currently beyond SOA. 
Inputs:

payload power, $\mathrm{kW}$

frequency, hz distance, $\mathrm{m}$

transmit antenna diameter, $m$

rectenna diameter, $\mathrm{m}$

magnetron efficiency

transmit power conditioning efficiency

rectenna power conditioning efficiency

transmit antenna efficiency

rectenna efficiency

rectenna \& TCS radiator IR emittance

rectenna \& TCS radiator solar absorptance

Active TCS areal mass, $\mathrm{kg} / \mathrm{m} 2$ radiator area

TCS control temperature, $\mathrm{K}$

Outputs:

wavelength - lambda, $\mathrm{m}$

transmit antenna area, $\mathrm{m} 2$

max theoretical transmit antenna gain factor

actual transmit antenna gain factor

actual transmit antenna gain factor, $\mathrm{dB}$

rectenna area, $\mathrm{m} 2$

tau

free space transmission efficiency

rectenna output power, kW

rectenna pwr conditioning thermal load, $\mathrm{kW}$

rectenna incident power, $\mathrm{kW}$

rectenna avg pfd, $\mathrm{W} / \mathrm{m} 2$ (want be $>\sim 200$ )

rectenna absorbed thermal load, $\mathrm{kW}$

rectenna operating temperature, $\mathrm{K}$

transmit antenna radiated power, $\mathrm{kW}$

transmit antenna input power, $\mathrm{kW}$
antenna magnetron input power, $\mathrm{kW}$

antenna pwr conditioning input power, kW

antenna pwr conditioning thermal power, $\mathrm{kW}$

antenna system TCS radiator plane area, $\mathrm{m} 2$
rectenna system TCS radiator plane area, $\mathrm{m} 2$

Mass Outputs, kg:

$\begin{array}{rc}\text { frequency, hz } & 2.45 \mathrm{E}+09 \\ \text { payload power, } \mathrm{kW} & \mathbf{1}\end{array}$

antenna power conditioning (DDCUs at $3.4 \mathrm{~kg} / \mathrm{kW}$ )

*antenna magnitrons $(2 \mathrm{~kg} / \mathrm{kW})$

antenna dish $(1 \mathrm{~kg} / \mathrm{m} 2)$

antenna secondary structure \& mechanisms $(10 \%)$

antenna system TCS mass

rectenna power conditioning (SSU at $13.3 \mathrm{~kg} / \mathrm{kW}$ )

rectenna array $(2 \mathrm{~kg} / \mathrm{m} 2)$

rectenna secondary structure \& mechanisms $(10 \%)$

rectenna system TCS mass

RF EMI shielding in rectenna vicinity

data/control RF comm system

Total mass, $\mathrm{kg}$

RF Power Transfer System Sp Mass, kg/kW

RF Power Transfer System Sp Pwr, Pin/Pout

1000
$2.45 \mathrm{E}$
8

* - multiple mass by $2 x$ to get single fault tolerance.

Figure 21.--Performance versus payload power and RF operating frequency.

1-km RF Power Transfer System: Power

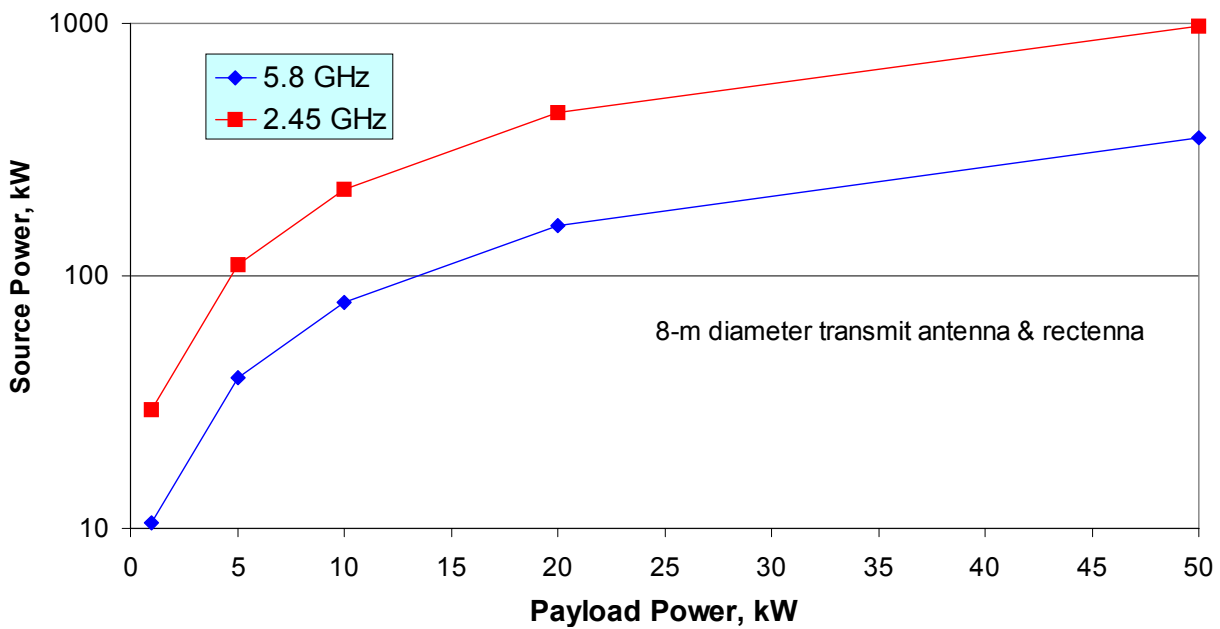

Figure 22.- Source power versus payload power level and RF operating frequency. 
1-km RF Power Transfer System: Mass

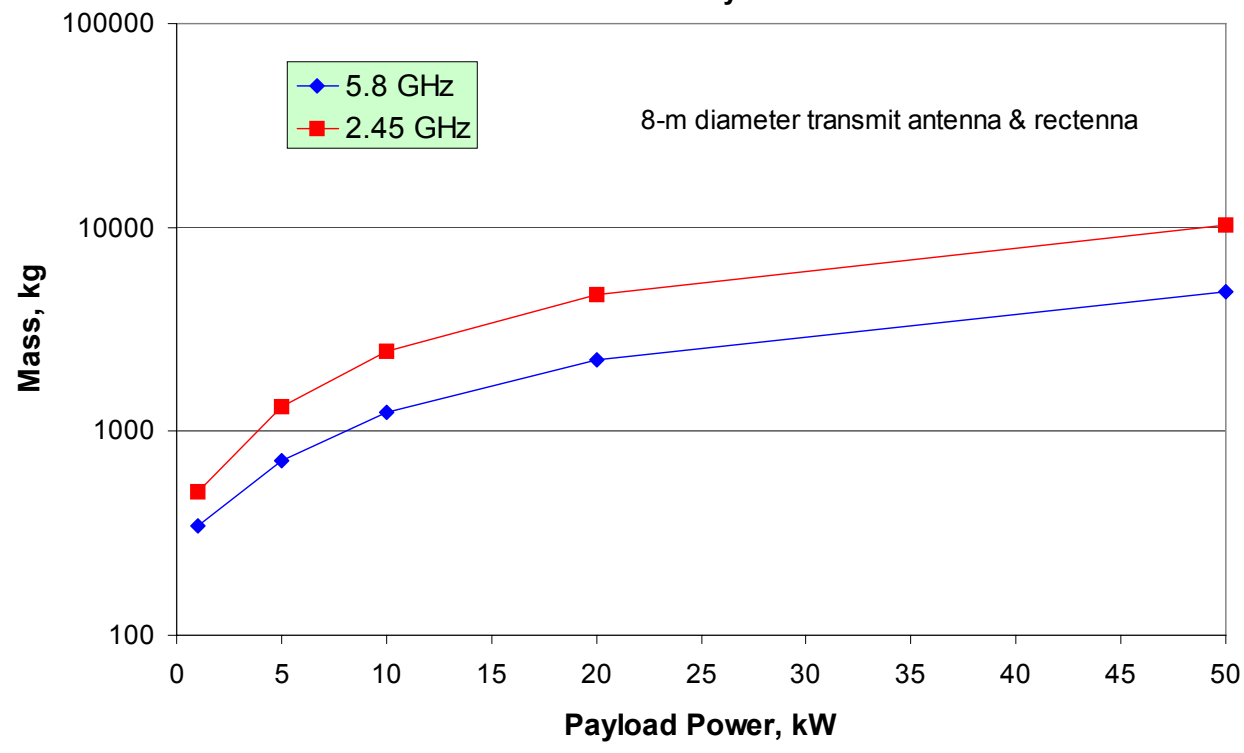

Figure 23.-Mass versus payload power level and RF operating frequency.

\begin{tabular}{|c|c|c|c|c|c|c|c|c|c|c|}
\hline payload power, kW & 10 & 10 & 10 & 10 & 10 & 0 & 10 & 10 & 10 & 10 \\
\hline distance, $\mathrm{m}$ & 100 & 500 & 1000 & 5000 & 10000 & 100 & 500 & 1000 & 5000 & 10000 \\
\hline frequency, $\mathrm{hz}$ & $2.45 \mathrm{E}+09$ & $2.45 \mathrm{E}+09$ & $2.45 \mathrm{E}+09$ & $2.45 \mathrm{E}+09$ & $2.45 \mathrm{E}+09$ & $5.80 \mathrm{E}+09$ & $5.80 \mathrm{E}+09$ & $5.80 \mathrm{E}+09$ & $5.80 \mathrm{E}+09$ & $5.80 E+09$ \\
\hline transmit antenna diameter, $\mathrm{m}$ & 4 & 8 & 8 & 8 & 8 & 3.7 & 8 & 8 & 8 & 8 \\
\hline rectenna diameter, $\mathrm{m}$ & 4 & 8 & 8 & 8 & 8 & 3.7 & 8 & 8 & 8 & 8 \\
\hline magnetron efficiency & 0.7 & 0.7 & 0.7 & 0.7 & 0.7 & 0.4 & 0.4 & 0.4 & 0.4 & 0.4 \\
\hline transmit power conditioning efficiency & 0.9 & 0.9 & 0.9 & 0.9 & 0.9 & 0.9 & 0.9 & 0.9 & 0.9 & 0.9 \\
\hline rectenna power conditioning efficiency & 0.95 & 0.95 & 0.95 & 0.95 & 0.95 & 0.95 & 0.95 & 0.95 & 0.95 & 0.95 \\
\hline transmit antenna efficiency & 0.75 & 0.75 & 0.75 & 0.75 & 0.75 & 0.7 & 0.7 & 0.7 & 0.7 & 0.7 \\
\hline rectenna efficiency & 0.85 & 0.8 & 0.8 & 0.8 & 0.8 & 0.85 & 0.8 & 0.8 & 0.8 & 0.8 \\
\hline rectenna \& TCS radiator IR emittance & 0.79 & 0.79 & 0.79 & 0.79 & 0.79 & 0.79 & 0.79 & 0.79 & 0.79 & 0.79 \\
\hline rectenna \& TCS radiator solar absorptance & 0.21 & 0.21 & 0.21 & 0.21 & 0.21 & 0.21 & 0.21 & 0.21 & 0.21 & 0.21 \\
\hline Active TCS areal mass, $\mathrm{kg} / \mathrm{m} 2$ radiator area & 6 & 6 & 6 & 6 & 6 & 6 & 6 & 6 & 6 & 6 \\
\hline TCS control temperature, $\mathrm{K}$ & 353 & 353 & 353 & 353 & 353 & 353 & 353 & 353 & 353 & 353 \\
\hline \multicolumn{11}{|l|}{ Outputs: } \\
\hline wavelength - lambda, $\mathrm{m}$ & 0.122 & 0.122 & 0.122 & 0.122 & 0.122 & 0.052 & 0.052 & 0.052 & 0.052 & 0.052 \\
\hline transmit antenna area, $\mathrm{m} 2$ & 12.6 & 50.3 & 50.3 & 50.3 & 50.3 & 10.8 & 50.3 & 50.3 & 50.3 & 50.3 \\
\hline max theoretical transmit antenna gain factor & 10532 & 42128 & 42128 & 42128 & 42128 & 50503 & 236098 & 236098 & 236098 & 236098 \\
\hline actual transmit antenna gain factor & 7899 & 31596 & 31596 & 31596 & 31596 & 35352 & 165269 & 165269 & 165269 & 165269 \\
\hline actual transmit antenna gain factor, $\mathrm{dB}$ & 3.9 & 4.5 & 4.5 & 4.5 & 4.5 & 4.5 & 5.2 & 5.2 & 5.2 & 5.2 \\
\hline rectenna area, $\mathrm{m} 2$ & 12.6 & 50.3 & 50.3 & 50.3 & 50.3 & 10.8 & 50.3 & 50.3 & 50.3 & 50.3 \\
\hline tau & 1.026 & 0.821 & 0.411 & 0.082 & 0.041 & 2.079 & 1.944 & 0.972 & 0.194 & 0.097 \\
\hline free space transmission efficiency & 0.651 & 0.490 & 0.155 & 0.007 & 0.002 & 0.987 & 0.977 & 0.611 & 0.037 & 0.009 \\
\hline rectenna output power, kW & 10.53 & 10.53 & 10.53 & 10.53 & 10.53 & 10.53 & 10.53 & 10.53 & 10.53 & 10.53 \\
\hline rectenna pwr conditioning thermal load, $\mathrm{kW}$ & 0.53 & 0.53 & 0.53 & 0.53 & 0.53 & 0.53 & 0.53 & 0.53 & 0.53 & 0.53 \\
\hline rectenna incident power, $\mathrm{kW}$ & 12.38 & 13.16 & 13.16 & 13.16 & 13.16 & 12.38 & 13.16 & 13.16 & 13.16 & 13.16 \\
\hline rectenna avg pfd, W/m2 (want be > 200) & 985 & 262 & 262 & 262 & 262 & 1152 & 262 & 262 & 262 & 262 \\
\hline rectenna absorbed thermal load, kW & 1.86 & 2.63 & 2.63 & 2.63 & 2.63 & 1.86 & 2.63 & 2.63 & 2.63 & 2.63 \\
\hline rectenna operating temperature, $\mathrm{K}$ & 274 & 260 & 260 & 260 & 260 & 278 & 260 & 260 & 260 & 260 \\
\hline transmit antenna radiated power, $\mathrm{kW}$ & 15.68 & 26.03 & 104.11 & 2602.77 & 10411.08 & 4.09 & 4.98 & 19.90 & 497.59 & 1990.38 \\
\hline transmit antenna input power, $\mathrm{kW}$ & 20.90 & 34.70 & 138.81 & 3470.36 & 13881.44 & 5.85 & 7.11 & 28.43 & 710.85 & 2843.39 \\
\hline antenna magnitron input power, $\mathrm{kW}$ & 29.86 & 49.58 & 198.31 & 4957.66 & 19830.63 & 14.62 & 17.77 & 71.08 & 1777.12 & 7108.49 \\
\hline antenna pwr conditioning input power, kW & 33.18 & 55.09 & 220.34 & 5508.51 & 22034.03 & 16.25 & 19.75 & 78.98 & 1974.58 & 7898.32 \\
\hline antenna pwr conditioning thermal power, $\mathrm{kW}$ & 12.28 & 20.38 & 81.53 & 2038.15 & 8152.59 & 10.40 & 12.64 & 50.55 & 1263.73 & 5054.92 \\
\hline antenna system TCS radiator plane area, m2 & 11.90 & 19.75 & 78.99 & 1974.78 & 7899.12 & 10.07 & 12.24 & 48.98 & 1224.44 & 4897.76 \\
\hline rectenna system TCS radiator plane area, $\mathrm{m} 2$ & 0.51 & 0.51 & 0.51 & 0.51 & 0.51 & 0.51 & 0.51 & 0.51 & 0.51 & 0.51 \\
\hline distance, $\mathrm{m}$ & 100 & 500 & 1000 & 5000 & 10000 & 100 & 500 & 1000 & 5000 & 10000 \\
\hline \multicolumn{11}{|l|}{ Mass Outputs, kg: } \\
\hline antenna power conditioning (DDCUs at $3.4 \mathrm{~kg} / \mathrm{kW}$ ) & 112.8 & 187.3 & 749.2 & 18728.9 & 74915.7 & 55.2 & 67.1 & 268.5 & 6713.6 & 26854.3 \\
\hline *antenna magnitrons $(2 \mathrm{~kg} / \mathrm{kW})$ & 119.5 & 198.3 & 793.2 & 19830.6 & 79322.5 & 58.5 & 71.1 & 284.3 & 7108.5 & 28433.9 \\
\hline antenna dish $(1 \mathrm{~kg} / \mathrm{m} 2)$ & 16.3 & 65.3 & 65.3 & 65.3 & 65.3 & 14.0 & 65.3 & 65.3 & 65.3 & 65.3 \\
\hline antenna secondary structure \& mechanisms $(10 \%)$ & 13.6 & 26.4 & 85.9 & 1989.6 & 7938.8 & 7.2 & 13.6 & 35.0 & 717.4 & 2849.9 \\
\hline antenna system TCS mass & 71.4 & 118.5 & 473.9 & 11848.7 & 47394.7 & 60.4 & 73.5 & 293.9 & 7346.6 & 29386.6 \\
\hline rectenna power conditioning (SSU at $13.3 \mathrm{~kg} / \mathrm{kW}$ ) & 140.0 & 140.0 & 140.0 & 140.0 & 140.0 & 140.0 & 140.0 & 140.0 & 140.0 & 140.0 \\
\hline rectenna array $(2 \mathrm{~kg} / \mathrm{m} 2)$ & 25.1 & 100.5 & 100.5 & 100.5 & 100.5 & 21.5 & 100.5 & 100.5 & 100.5 & 100.5 \\
\hline rectenna secondary structure \& mechanisms $(10 \%)$ & 2.5 & 10.1 & 10.1 & 10.1 & 10.1 & 2.2 & 10.1 & 10.1 & 10.1 & 10.1 \\
\hline rectenna system TCS mass & 3.1 & 3.1 & 3.1 & 3.1 & 3.1 & 3.1 & 3.1 & 3.1 & 3.1 & 3.1 \\
\hline RF EMI shielding in rectenna vicinity & 20.0 & 20.0 & 20.0 & 20.0 & 20.0 & 20.0 & 20.0 & 20.0 & 20.0 & 20.0 \\
\hline data/control RF comm system & 8.0 & 8.0 & 8.0 & 8.0 & 8.0 & 8.0 & 8.0 & 8.0 & 8.0 & 8.0 \\
\hline Total mass, $\mathbf{k g}$ & 532.3 & 877.4 & 2449.2 & 52744.8 & 209918.7 & 390.1 & 572.3 & 1228.7 & 22233.1 & 87871.7 \\
\hline RF Power Transfer System Sp Mass, kg/kW & 53.2 & 87.7 & 244.9 & 5274.5 & 20991.9 & 39.0 & 57.2 & 122.9 & 2223.3 & 8787.2 \\
\hline RF Power Transfer System Sp Pwr, Pin/Pout & 3.3 & 5.5 & 22.0 & 550.9 & 2203.4 & 1.6 & 2.0 & 7.9 & 197.5 & 789.8 \\
\hline
\end{tabular}

* - multiple by $2 x$ to get single fault tolerance.

Figure 24.-Mass and performance versus payload distance and RF operating frequency. 


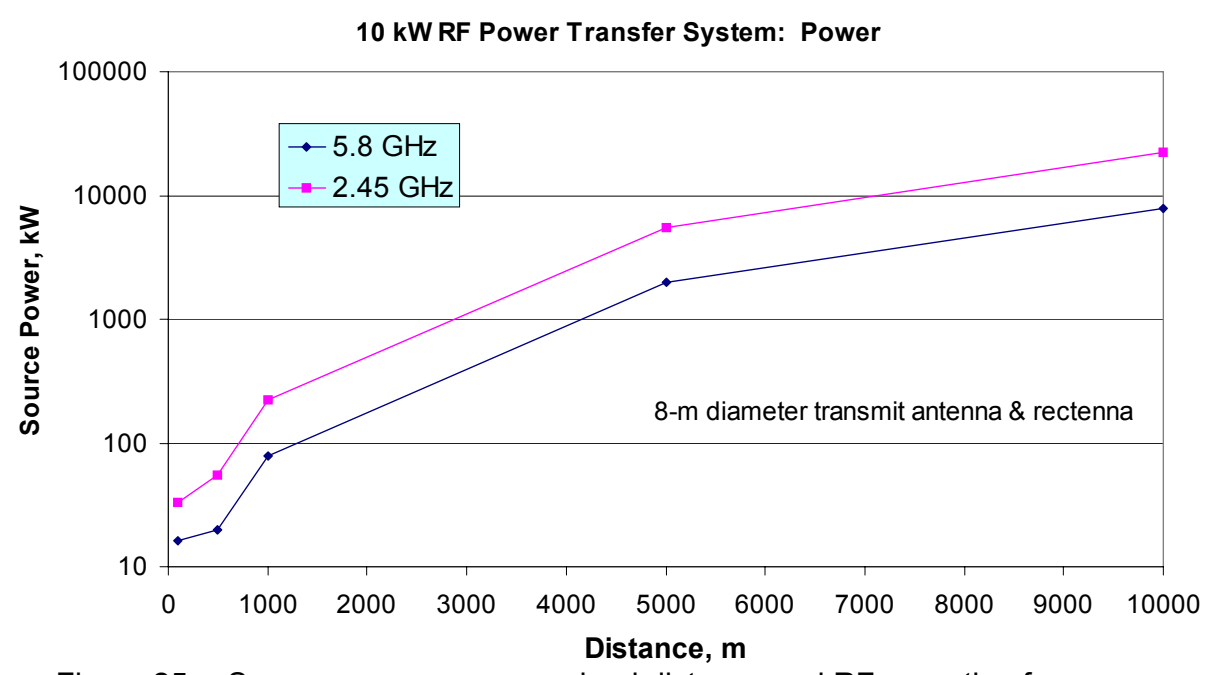

Figure 25.-Source power versus payload distance and RF operating frequency.

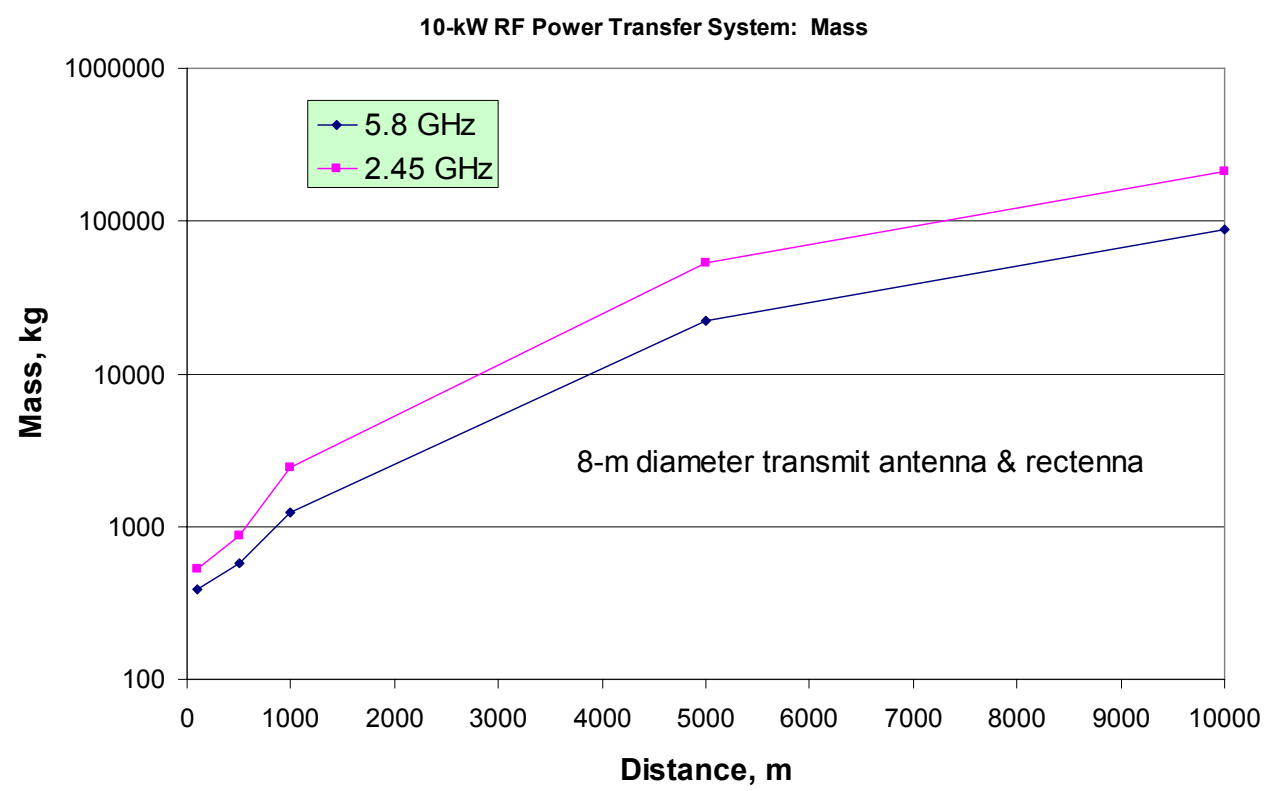

Figure 26.--Mass versus payload distance and RF operating frequency.

\section{Laser Subsystem}

To minimize subsystem mass and power, ease packaging on the lunar lander and simplify subsystem deployment, it is desirable to have a smaller laser aperture diameter as shown in figures 27 and 28 for the 1000-m distance, $10-\mathrm{kW}$ power transfer case. A 10 percent mass savings is possible if the laser diode array diameter can be reduced from 2- to $0.5-\mathrm{m}$. However, as the laser aperture area decreases, the thermal control heat fluxes increase. Thus, a balance must be struck between mass savings and needed thermal control system technology and performance.

The laser diode array output operating flux versus array diameter is shown in figure 29 with the associated cooling flux requirements versus array diameter shown in figure 30. Given the high required cooling fluxes and low laser control temperature (293 and $325 \mathrm{~K}$ ), a water heat pipe is an appropriate thermal control technology. With a heat pipe cooling flux margin of 3 for a given $100,000 \mathrm{~W} / \mathrm{m}^{2}$ operating limit (based on evaporator radial limit), a laser aperture diameter of $1-\mathrm{m}\left(0.8-\mathrm{m}^{2}\right.$ area $)$ was selected in an attempt to minimize subsystem mass while meeting cooling requirements. A $1-\mathrm{m}$ laser array diameter is also small enough for lunar lander packaging without the need for a deployable aperture (the laser array must still be staged from its stowed configuration to its operating configuration). 
1-km, 10-kW Laser Power Transfer System: Power

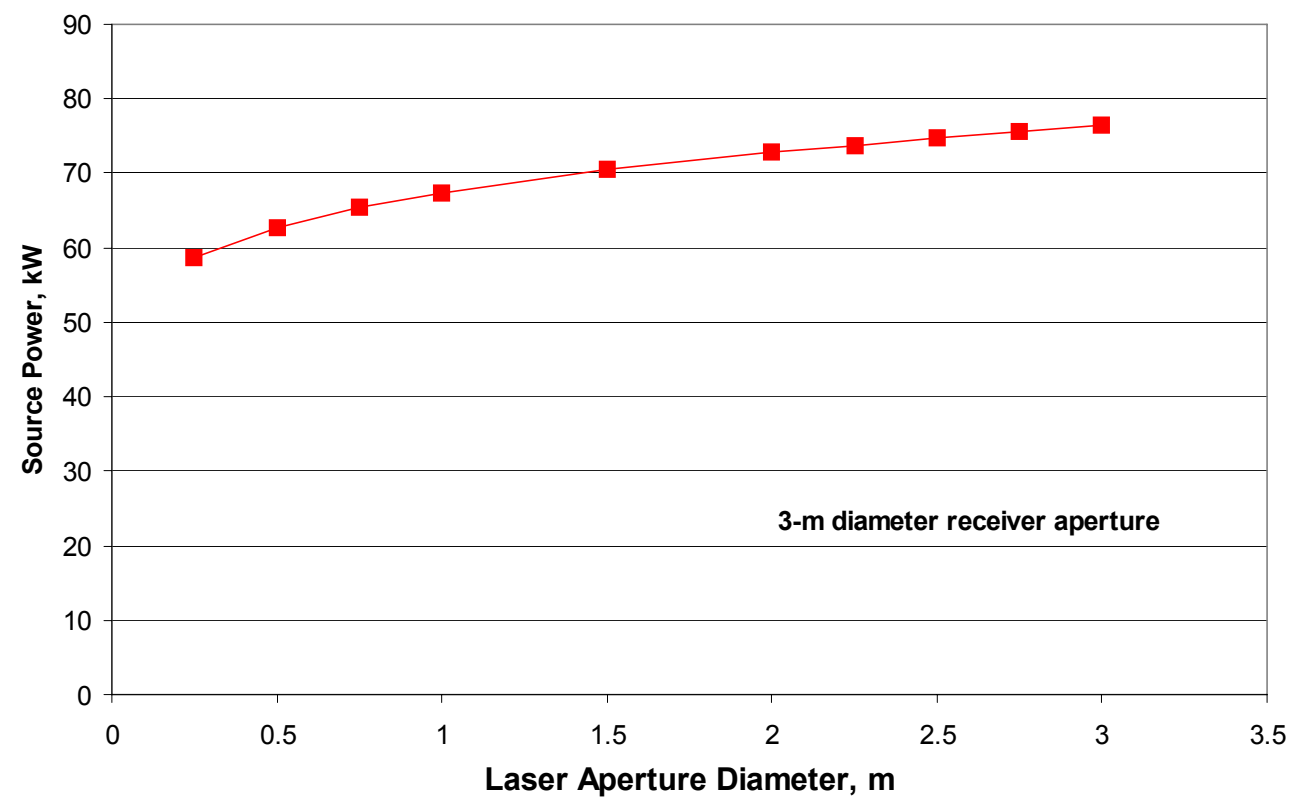

Figure 27.-Source power versus laser aperture diameter.

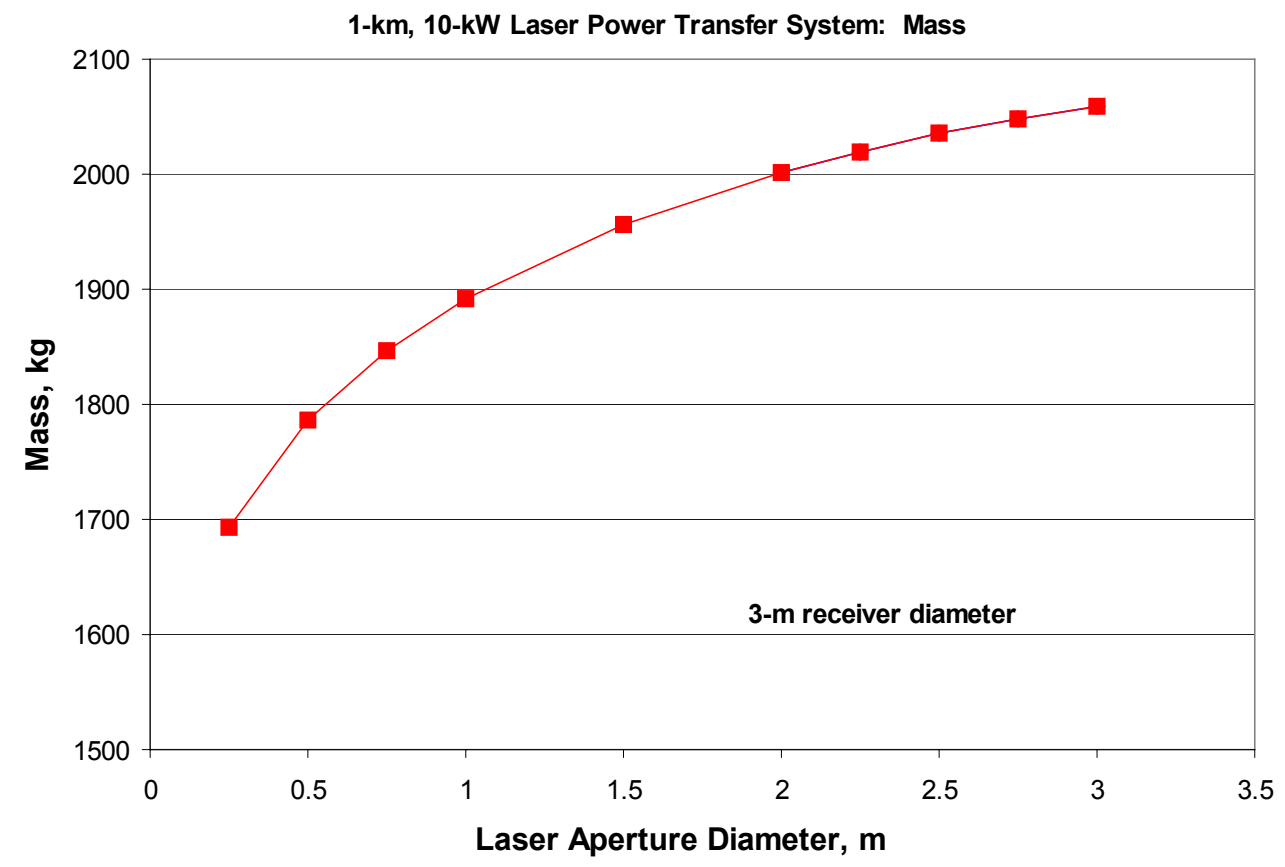

Figure 28.-Mass versus laser aperture diameter. 


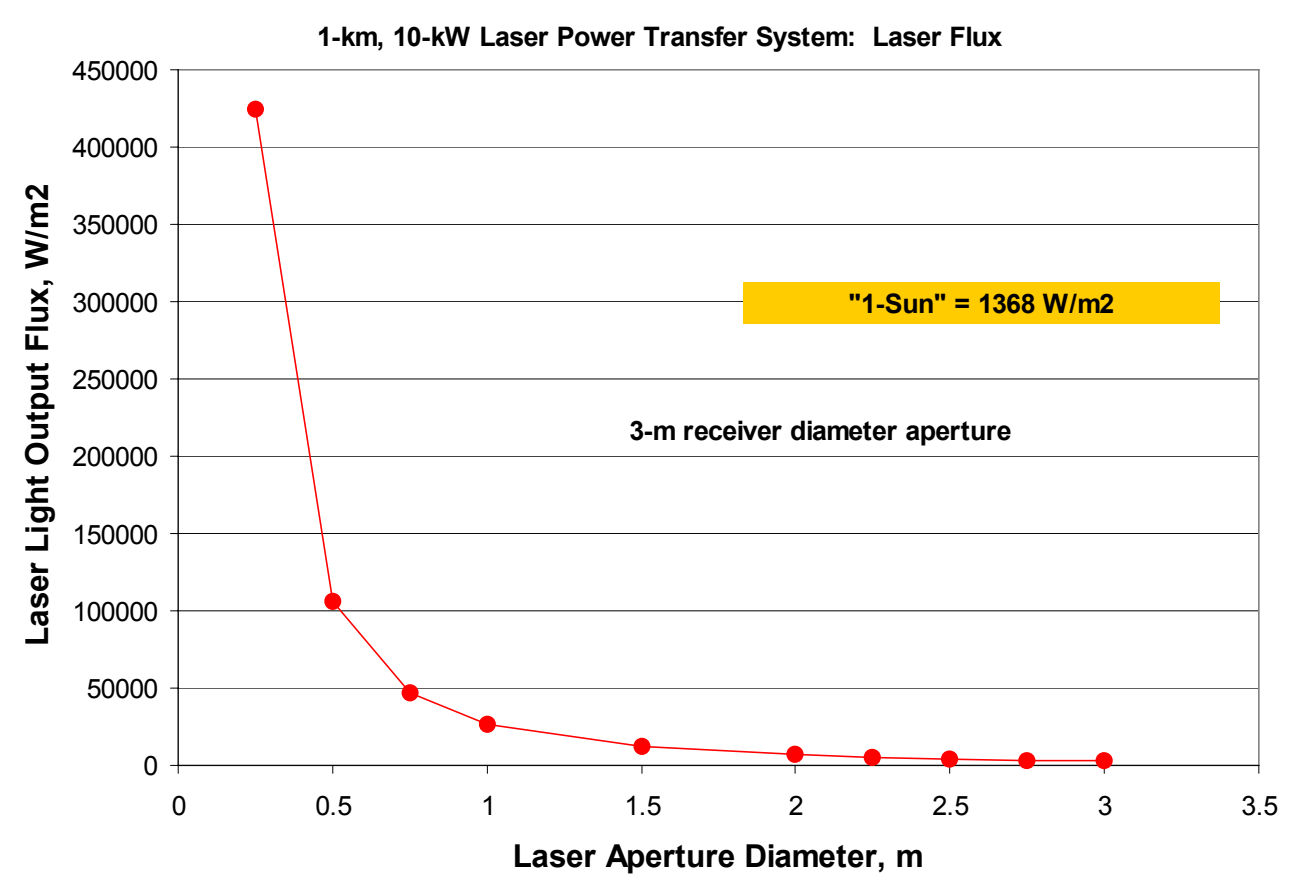

Figure 29.-Laser output flux versus laser aperture diameter.

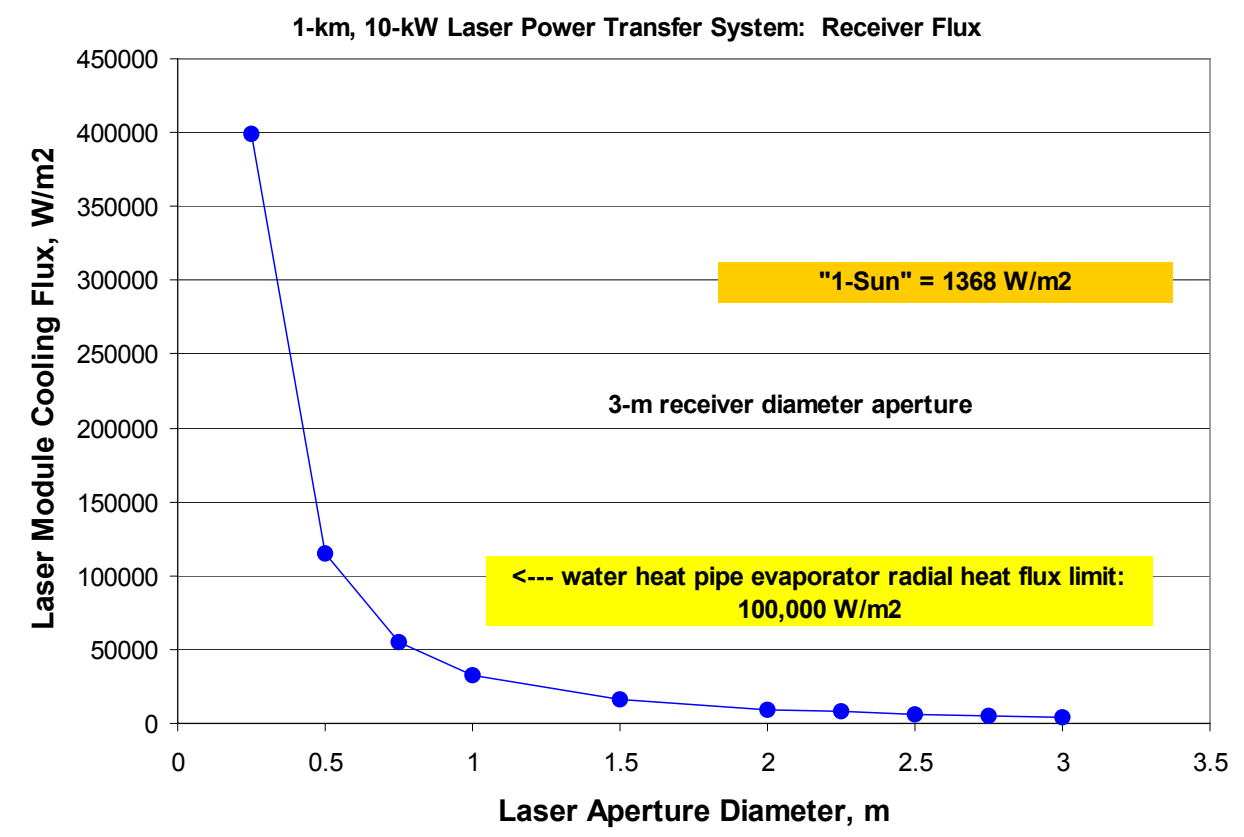

Figure 30.-Laser cooling flux versus laser aperture diameter. 
A passive thermal control calculation, with temperature results shown in figure 31 , confirms that an augmented thermal control system is needed for laser array temperature control $(293 \mathrm{~K})$ and PV receiver array temperature control $(320 \mathrm{~K})$.

Similar to the laser array, the PV array receiver diameter selection is based on minimizing subsystem mass and source power requirement within the constraints posed by thermal control and beam collimation/pointing performance. As shown in figures 32 and 33, to save on mass and power, it is desirable to select a smaller receiver aperture diameter. Also, to save a small mass, a smaller edge reflector ring size is desired consistent with laser beam collimation and pointing accuracy requirements.

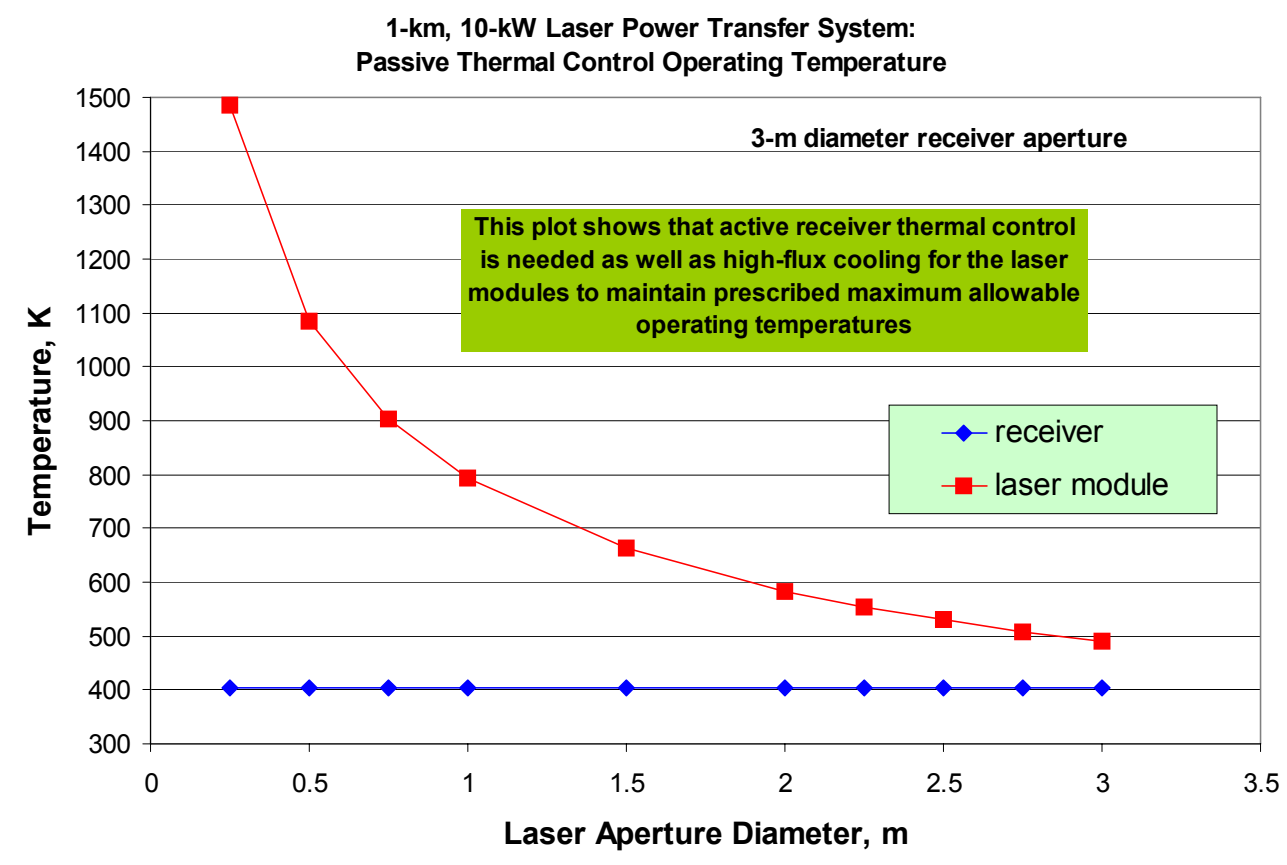

Figure 31.-Laser temperature versus laser aperture diameter.

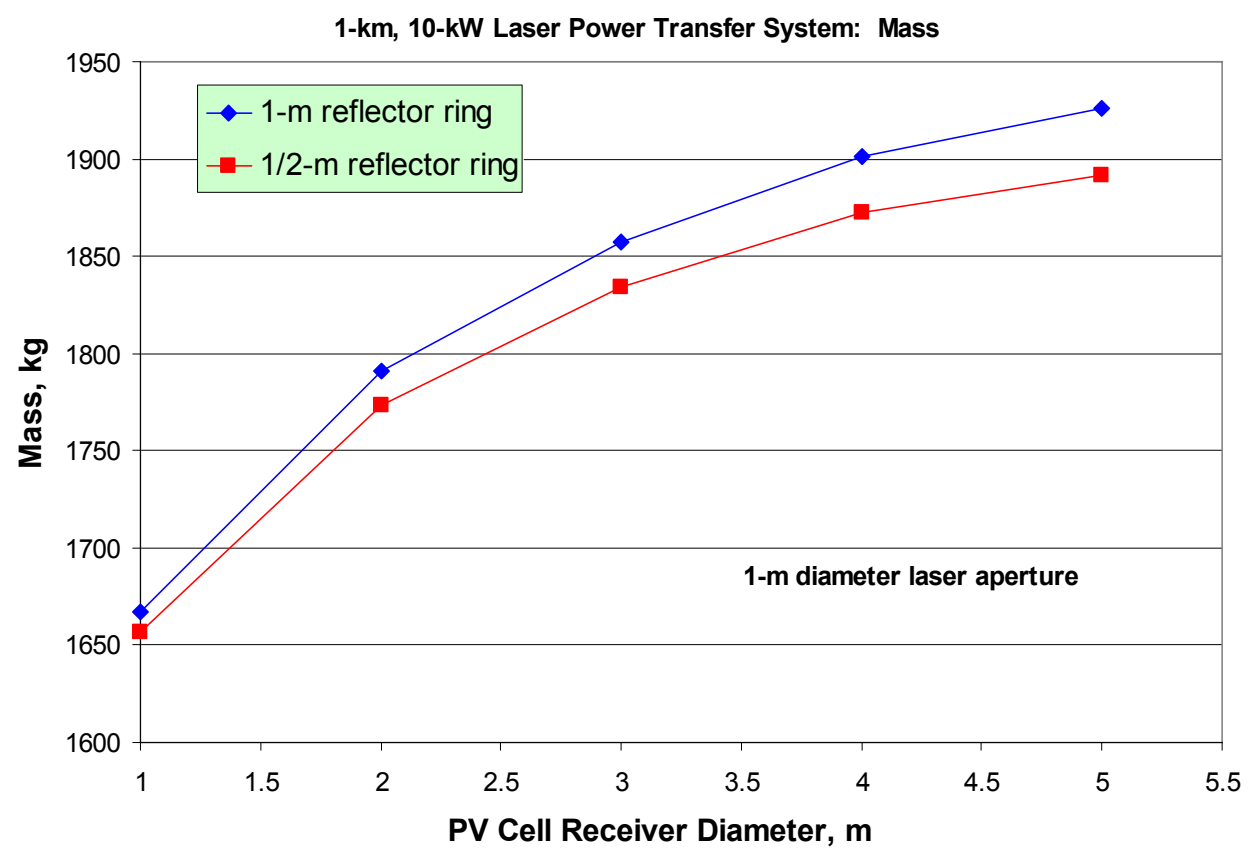

Figure 32.-Mass versus receiver diameter and reflector ring radial size. 


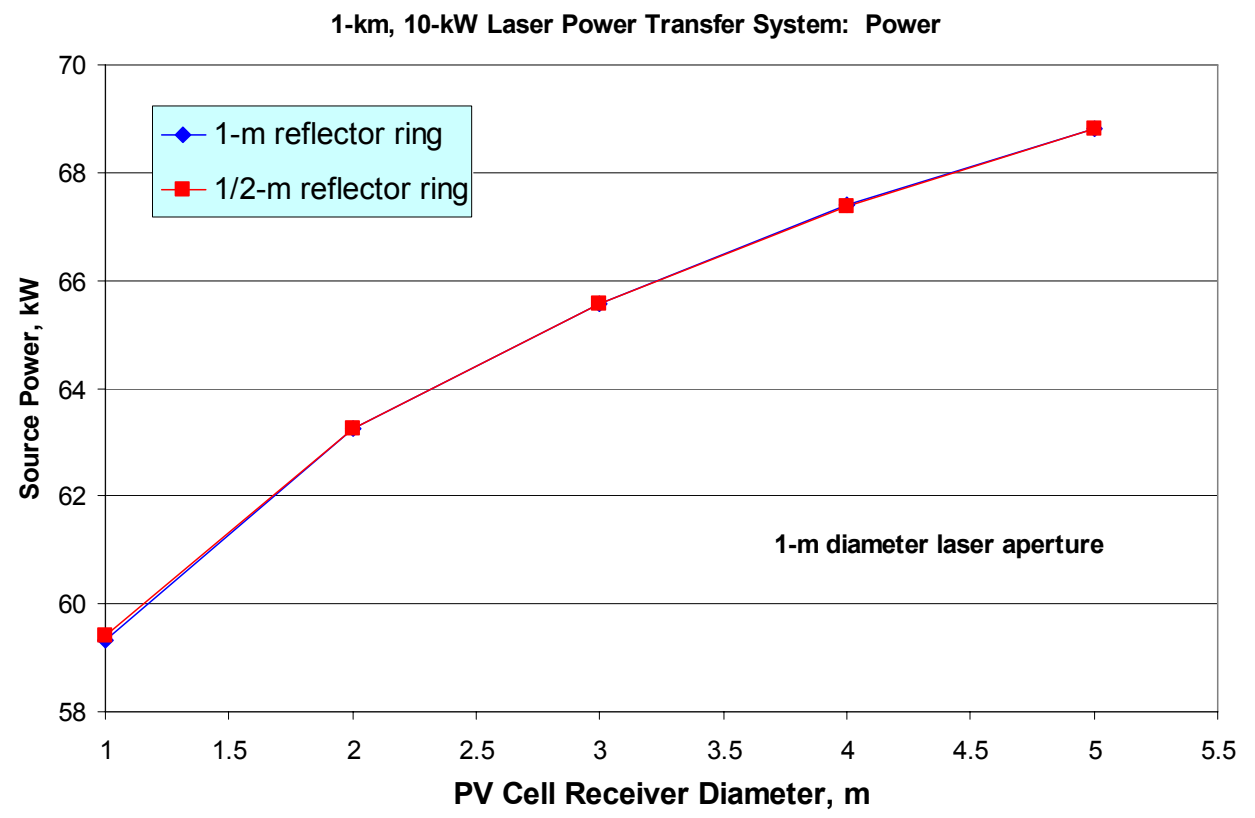

Figure 33.--Source power versus receiver diameter and reflector ring radial size.

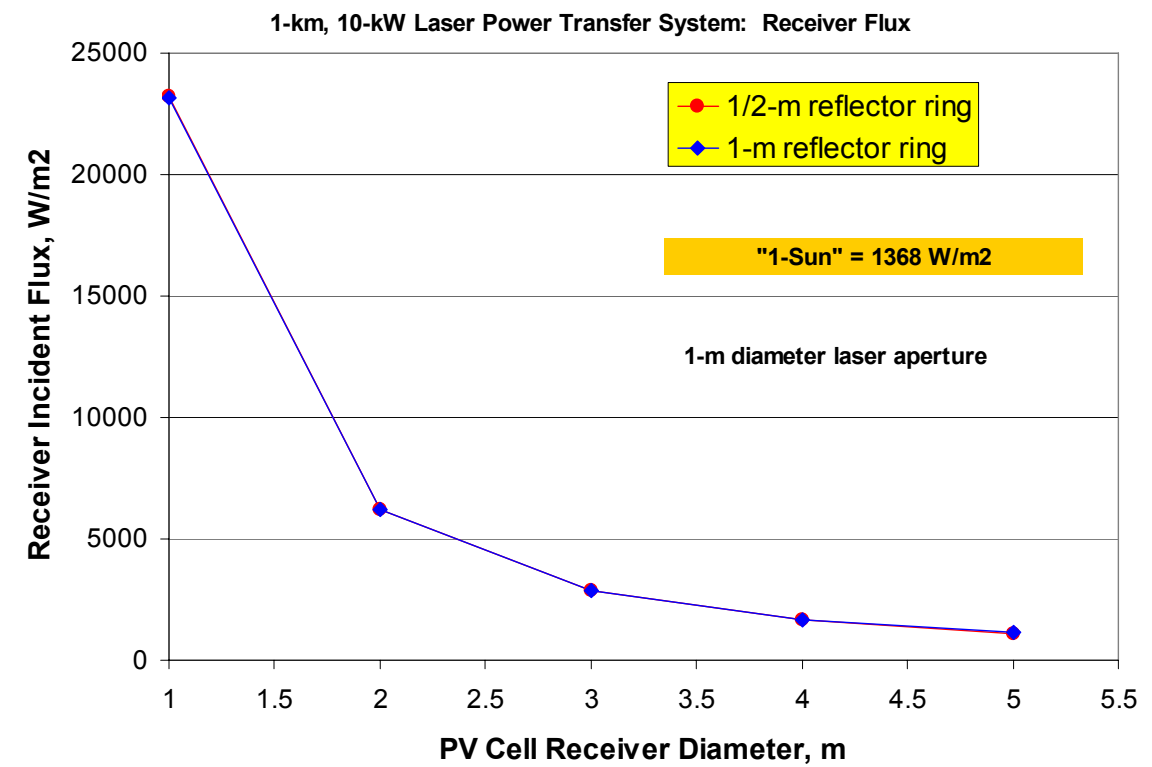

Figure 34.- Receiver incident flux versus receiver aperture diameter and reflector ring radial size. 
The PV receiver array diameter selection is based on mass properties and thermal cooling requirements. The incident laser flux on the receiver, including direct and edge-reflected light, versus receiver diameter is shown in figure 34. Augmented thermal cooling of PV receiver is needed over full range of diameter options to maintain a $320 \mathrm{~K}$ operating temperature (see fig. 35). Thus, in an attempt to keep subsystem mass to a minimum, the smallest receiver diameter, equal to laser diode array diameter of 1-m, was chosen. This keeps the receiver array plus edge reflector diameter small enough for lunar lander packaging without the need for a deployable aperture (although the $\mathrm{PV}$ receiver array must still be staged from its stowed configuration to its operating configuration).

Subsystem mass and performance versus payload power and laser diode operating temperature are shown in figures 36 to 38. Subsystem source power and mass are proportional to payload power. The laser diode at higher temperature ( $325 \mathrm{~K}$ over $293 \mathrm{~K}$ ) is less efficient, requires more input power, but requires a smaller thermal control system (heat pipes coupled to the ATCS) to maintain operating temperature. Since this ATCS is a larger mass contributor than the input power processing electronics, there is a net subsystem mass savings realized when going to higher laser diode operating temperature (see fig. 38).

For the chosen laser and receiver aperture sizes, the receiver incident flux versus payload power level is shown in figure 39 and the aperture passive operating temperatures versus payload power level are shown in figure 40. Over nearly the full range of payload operating power levels (at or above 1-kW), aperture passive thermal control is insufficient to satisfy the desired operating temperatures. Thus, an ATCS is needed for both the laser array and PV receiver array (highly reflective receiver edge mirrors likely can be operated with passive cooling only).

Due to the limitations in this preliminary study, the laser subsystem performance and mass are treated essentially independent of payload distance for the parameter range and assumptions adopted. Even with phase instability among laser diode modules (greater than 46 micro-degrees), the likely beam collimation angle will be very small compared to the maximum allowable beam divergence angle of 0.001 to 0.01 's degrees that is driven by the edge reflector dimension and light transmission distance (see fig. 41). The primary benefit of the edge reflector may be to capture outer perimeter laser light due to non-circular (elliptical) beam geometry (as depicted in the inset of fig. 41). Beam geometry quality is driven by the laser diode and microlens optics selected for this application.

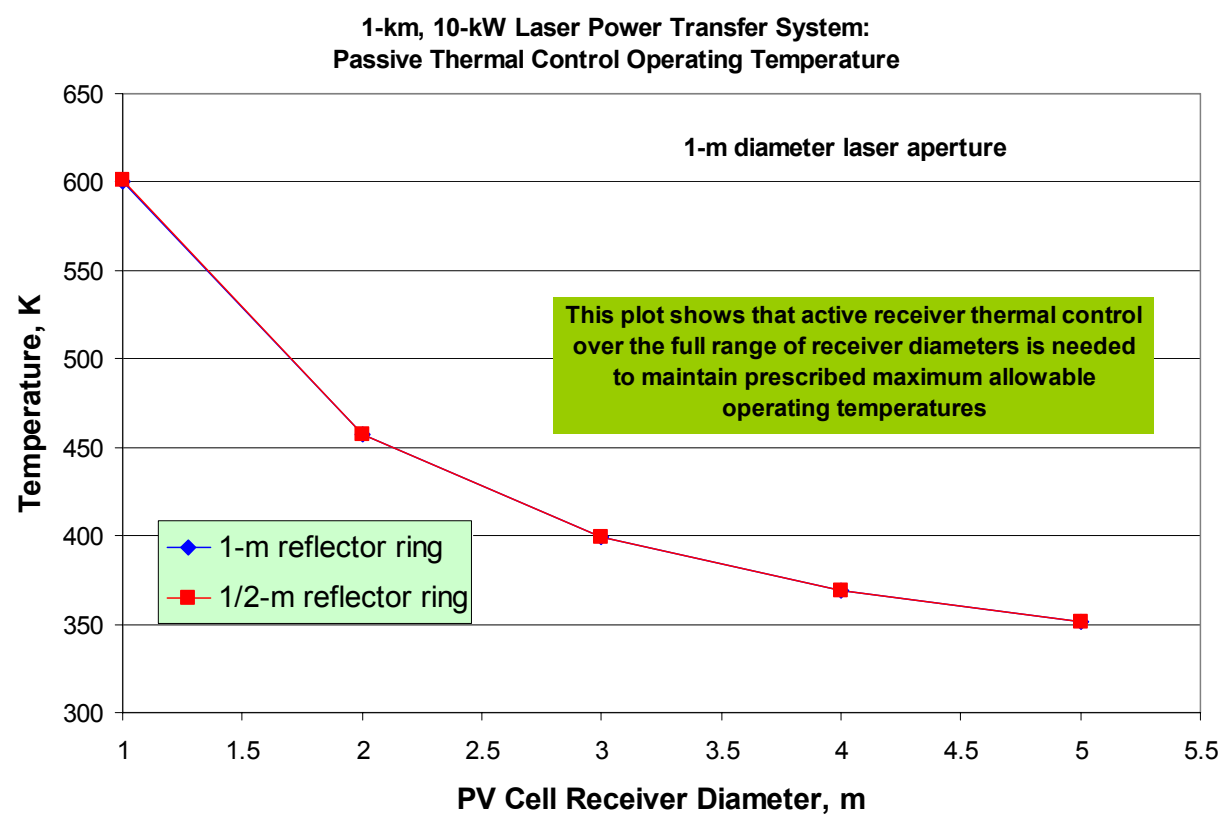

Figure 35.--Receiver temperature versus receiver aperture diameter and reflector ring radial size. 


\begin{tabular}{|c|c|c|c|c|c|c|c|c|c|c|}
\hline $\begin{array}{l}\text { Inputs: } \\
\text { payload power, kW }\end{array}$ & 1 & 5 & 10 & 20 & 50 & 1 & 5 & 10 & 20 & 50 \\
\hline distance, $\mathrm{m}$ & 1000 & 1000 & 1000 & 1000 & 1000 & 1000 & 1000 & 1000 & 1000 & 1000 \\
\hline laser diode wavelength, $\mathrm{m}$ & 8.00E-07 & $8.00 \mathrm{E}-07$ & 8.00E-07 & $8.00 \mathrm{E}-07$ & $8.00 \mathrm{E}-07$ & $8.00 \mathrm{E}-07$ & $8.00 \mathrm{E}-07$ & $8.00 \mathrm{E}-07$ & $8.00 \mathrm{E}-07$ & $8.00 \mathrm{E}-07$ \\
\hline laser optic aperture diameter, $\mathrm{m}$ & 1 & 1 & 1 & 1 & 1 & & 1 & 1 & 1 & \\
\hline PV receiver diameter, $m$ & 1 & 1 & 1 & 1 & 1 & 1 & 1 & 1 & 1 & 1 \\
\hline$P V$ receiver outer reflector diameter, $m$ & 2 & 2 & 2 & 2 & 2 & 2 & 2 & 2 & 2 & 2 \\
\hline scaled diode laser efficiency ( 0.5 at $1368 \mathrm{~W} / \mathrm{m} 2800 \mathrm{~nm}$ light) & 0.411 & 0.449 & 0.465 & 0.482 & 0.504 & 0.411 & 0.449 & 0.465 & 0.482 & 0.504 \\
\hline laser power conditioning efficiency & 0.9 & 0.9 & 0.9 & 0.9 & 0.9 & 0.9 & 0.9 & 0.9 & 0.9 & 0.9 \\
\hline PV receiver power conditioning efficiency & 0.95 & 0.95 & 0.95 & 0.95 & 0.95 & 0.95 & 0.95 & 0.95 & 0.95 & 0.95 \\
\hline laser optics transmission efficiency (see comment) & 0.92 & 0.92 & 0.92 & 0.92 & 0.92 & 0.92 & 0.92 & 0.92 & 0.92 & 0.92 \\
\hline $\mathrm{PV}$ receiver efficiency ( 0.5 at $1368 \mathrm{~W} / \mathrm{m} 2800 \mathrm{~nm}$ light) & 0.482 & 0.523 & 0.540 & 0.558 & 0.581 & 0.482 & 0.523 & 0.540 & 0.558 & 0.581 \\
\hline TCS radiator IR emittance & 0.79 & 0.79 & 0.79 & 0.79 & 0.79 & 0.79 & 0.79 & 0.79 & 0.79 & 0.79 \\
\hline TCS radiator solar absorptance & 0.21 & 0.21 & 0.21 & 0.21 & 0.21 & 0.21 & 0.21 & 0.21 & 0.21 & 0.21 \\
\hline PV receiver solar absorptance & 0.5 & 0.5 & 0.5 & 0.5 & 0.5 & 0.5 & 0.5 & 0.5 & 0.5 & 0.5 \\
\hline laser module solar absorptance (need band pass filter to get low alpha) & 0.21 & 0.21 & 0.21 & 0.21 & 0.21 & 0.21 & 0.21 & 0.21 & 0.21 & 0.21 \\
\hline Active TCS areal mass, $\mathrm{kg} / \mathrm{m} 2$ radiator area & 6 & 6 & 6 & 6 & 6 & 6 & 6 & 6 & 6 & 6 \\
\hline Electronics TCS control temperature, $\mathrm{K}$ & 353 & 353 & 353 & 353 & 353 & 353 & 353 & 353 & 353 & 353 \\
\hline Laser module TCS control temperature, $\mathrm{K}$ (desire $293 \mathrm{~K}$ ) & 293 & 293 & 293 & 293 & 293 & 325 & 325 & 325 & 325 & 325 \\
\hline PV receiver TCS control temperature, $\mathrm{K}$ & 320 & 320 & 320 & 320 & 320 & 320 & 320 & 320 & 320 & 320 \\
\hline Outputs: & & & & & & & & & & \\
\hline laser efficiency loss factor for higher control temperature & 1 & 1 & 1 & 1 & 1 & 0.8 & 0.8 & 0.8 & 0.8 & 0.8 \\
\hline EOL Power degradation factor & 0.8 & 0.8 & 0.8 & 0.8 & 0.8 & 0.8 & 0.8 & 0.8 & 0.8 & 0.8 \\
\hline Far-field Airy disk diameter, $\mathrm{m}$ & $1.95 \mathrm{E}-03$ & $1.95 \mathrm{E}-03$ & $1.95 \mathrm{E}-03$ & $1.95 \mathrm{E}-03$ & $1.95 \mathrm{E}-03$ & $1.95 \mathrm{E}-03$ & $1.95 \mathrm{E}-03$ & $1.95 \mathrm{E}-03$ & $1.95 \mathrm{E}-03$ & $1.95 \mathrm{E}-03$ \\
\hline Max allowable laser-receiver optical axis alignment error, deg & 0.0286 & 0.0286 & 0.0286 & 0.0286 & 0.0286 & 0.0286 & 0.0286 & 0.0286 & 0.0286 & 0.0286 \\
\hline Max allowable laser collimination angle (w/perfect alignment), deg & 0.0286 & 0.0286 & 0.0286 & 0.0286 & 0.0286 & 0.0286 & 0.0286 & 0.0286 & 0.0286 & 0.0286 \\
\hline laser optic aperture area, $\mathrm{m} 2$ & 0.8 & 0.8 & 0.8 & 0.8 & 0.8 & 0.8 & 0.8 & 0.8 & 0.8 & 0.8 \\
\hline $\mathrm{PV}$ receiver planar area, $\mathrm{m} 2$ & 0.8 & 0.8 & 0.8 & 0.8 & 0.8 & 0.8 & 0.8 & 0.8 & 0.8 & 0.8 \\
\hline PV receiver cell area, m2 & 0.7 & 0.7 & 0.7 & 0.7 & 0.7 & 0.7 & 0.7 & 0.7 & 0.7 & 0.7 \\
\hline PV receiver side reflector area, $\mathrm{m} 2$ & 2.4 & 2.4 & 2.4 & 2.4 & 2.4 & 2.4 & 2.4 & 2.4 & 2.4 & 2.4 \\
\hline $\mathrm{PV}$ receiver planar + side reflector area, $\mathrm{m} 2$ & 3.1 & 3.1 & 3.1 & 3.1 & 3.1 & 3.1 & 3.1 & 3.1 & 3.1 & 3.1 \\
\hline PV receiver output power, $\mathrm{kW}$ & 1.05 & 5.26 & 10.53 & 21.05 & 52.63 & 1.05 & 5.26 & 10.53 & 21.05 & 52.63 \\
\hline $\mathrm{PV}$ receiver pwr conditioning thermal load, $\mathrm{kW}$ & 0.05 & 0.26 & 0.53 & 1.05 & 2.63 & 0.05 & 0.26 & 0.53 & 1.05 & 2.63 \\
\hline $\mathrm{PV}$ receiver incident power, $\mathrm{kW}$ & 2.18 & 10.07 & 19.48 & 37.73 & 90.53 & 2.18 & 10.07 & 19.48 & 37.73 & 90.53 \\
\hline PV receiver avg flux, W/m2 & 695 & 3205 & 6201 & 12010 & 28818 & 695 & 3205 & 6201 & 12010 & 28818 \\
\hline PV receiver absorbed laser thermal load, $\mathrm{kW}$ & 1.13 & 4.81 & 8.95 & 16.68 & 37.90 & 1.13 & 4.81 & 8.95 & 16.68 & 37.90 \\
\hline perature, $\mathrm{K}(\mathrm{t}$ & 403 & 539 & 622 & 722 & 883 & 403 & 539 & 622 & 722 & 883 \\
\hline laser module passive operating temperature, $\mathrm{K}$ (keep $<293 \mathrm{~K}$ or need ATCS) & 485 & 675 & 782 & 907 & 1106 & 525 & 736 & 856 & 995 & 1216 \\
\hline laser radiated power, $\mathrm{kW}$ & 2.18 & 10.07 & 19.48 & 37.73 & 90.53 & 2.18 & 10.07 & 19.48 & 37.73 & 90.53 \\
\hline Avg laser module radiated flux, W/m2 at $800 \mathrm{~nm}$ & 2781 & 12820 & 24804 & 48039 & 115273 & 2781 & 12820 & 24804 & 48039 & 115273 \\
\hline laser module driver output power, $\mathrm{kW}$ & 2.37 & 10.94 & 21.18 & 41.01 & 98.41 & 2.37 & 10.94 & 21.18 & 41.01 & 98.41 \\
\hline laser input power, kW & 5.78 & 24.39 & 45.52 & 85.14 & 195.43 & 7.23 & 30.49 & 56.90 & 106.42 & 244.29 \\
\hline BOL laser pwr conditioning input power, $k W$ & 6.42 & 27.10 & 50.58 & 94.60 & 217.14 & 8.03 & 33.87 & 63.22 & 118.25 & 271.43 \\
\hline EOL laser pwr conditioning input power, kW & 8.03 & 33.87 & 63.22 & 118.25 & 271.43 & 10.04 & 42.34 & 79.02 & 147.81 & 339.29 \\
\hline laser pwr conditioning thermal power, kW & 0.80 & 3.39 & 6.32 & 11.82 & 27.14 & 1.00 & 4.23 & 7.90 & 14.78 & 33.93 \\
\hline laser module absorbed laser thermal power, kW & 3.41 & 13.45 & 24.34 & 44.13 & 97.02 & 4.26 & 16.81 & 30.43 & 55.16 & 121.28 \\
\hline laser power conditioning TCS radiator plane area, m2 & 0.78 & 3.28 & 6.13 & 11.46 & 26.30 & 0.97 & 4.10 & 7.66 & 14.32 & 32.87 \\
\hline laser module TCS radiator plane area, $\mathrm{m} 2$ & 10.53 & 43.84 & 80.01 & 145.67 & 321.22 & 5.87 & 25.45 & 46.72 & 85.33 & 188.55 \\
\hline PV receiver power conditioning TCS radiator plane area, $\mathrm{m} 2$ & 0.08 & 0.41 & 0.83 & 1.66 & 4.14 & 0.08 & 0.41 & 0.83 & 1.66 & 4.14 \\
\hline $\mathrm{PV}$ receiver cell array TCS radiator plane area, $\mathrm{m} 2$ & 5.37 & 25.37 & 47.96 & 90.00 & 205.54 & 5.37 & 25.37 & 47.96 & 90.00 & 205.54 \\
\hline payload power, kW & 1 & 5 & 10 & 20 & 50 & 1 & 5 & 10 & 20 & 50 \\
\hline Mass Outputs, kg & & 2134 & & & & 632 & & & & \\
\hline laser power conditioning (DDCUs at $6.3 \mathrm{~kg} / \mathrm{kW}$ ) & $\begin{array}{l}50.6 \\
26.2\end{array}$ & $\begin{array}{l}213.4 \\
120.8\end{array}$ & $\begin{array}{l}398.3 \\
233.8\end{array}$ & $\begin{array}{l}745.0 \\
452.8\end{array}$ & $\begin{array}{l}1710.0 \\
1086.4\end{array}$ & $\begin{array}{l}63.2 \\
26.2\end{array}$ & $\begin{array}{l}266.8 \\
120.8\end{array}$ & $\begin{array}{l}497.9 \\
233.8\end{array}$ & $\begin{array}{l}931.2 \\
452.8\end{array}$ & $\begin{array}{l}2137.5 \\
1086.4\end{array}$ \\
\hline $\begin{array}{l}\text { laser modules \& microlens optics ( } 12 \mathrm{~kg} / \mathrm{kW} \text { optical) } \\
\text { laser power conditioning TCS mass }\end{array}$ & $\begin{array}{r}26.2 \\
4.7\end{array}$ & $\begin{array}{r}12.8 \\
19.7\end{array}$ & $\begin{array}{r}20.0 \\
36.8\end{array}$ & $\begin{array}{r}452.8 \\
68.7\end{array}$ & 157.8 & $\begin{array}{r}20.2 \\
5.8\end{array}$ & 24.6 & $\begin{array}{r}233.8 \\
45.9\end{array}$ & $\begin{array}{r}452.8 \\
85.9\end{array}$ & $\begin{array}{r}1086.4 \\
197.2\end{array}$ \\
\hline laser module TCS mass & 63.2 & 263.0 & 480.0 & 874.0 & 1927.3 & 35.2 & 152.7 & 280.3 & 512.0 & 1131.3 \\
\hline laser secondary structure \& mechanisms ( $10 \%)$ & 14.5 & 61.7 & 114.9 & 214.0 & 488.2 & 13.0 & 56.5 & 105.8 & 198.2 & 455.2 \\
\hline litioning (SSU at $13.3 \mathrm{~kg} / \mathrm{kW}$ ) & 14.0 & 70.0 & 140.0 & 280.0 & 700.0 & 14.0 & 70.0 & 140.0 & 280.0 & 700.0 \\
\hline PV receiver ce & 1.6 & 1.6 & 1.6 & 1.6 & 1.6 & 1.6 & 1.6 & 1.6 & 1.6 & 1.6 \\
\hline g TCS mass & 0.5 & 2.5 & 5.0 & 9.9 & 24.9 & 0.5 & 2.5 & 5.0 & 9.9 & 24.9 \\
\hline PV receiver cell TCS mass & 32.2 & 152.2 & 287.8 & 540.0 & 1233.2 & 32.2 & 152.2 & 287.8 & 540.0 & 1233.2 \\
\hline PV receiver side reflector $(3 \mathrm{~kg} / \mathrm{m} 2)$ & 7.1 & 7.1 & 7.1 & 7.1 & 7.1 & 7.1 & 7.1 & 7.1 & 7.1 & 7.1 \\
\hline PV receiver secondary structure \& mechanisms $(10 \%)$ & 5.5 & 23.3 & 44.1 & 83.9 & 196.7 & 5.5 & 23.3 & 44.1 & 83.9 & 196.7 \\
\hline al shielding in PV receiver vicinity & 20.0 & 20.0 & 20.0 & 20.0 & 20.0 & 20.0 & 20.0 & 20.0 & 20.0 & 20.0 \\
\hline data/control RF comm system & 8.0 & 8.0 & 8.0 & 8.0 & 8.0 & 8.0 & 8.0 & 8.0 & 8.0 & 8.0 \\
\hline Total mass, $\mathbf{k g}$ & 248.0 & 963.4 & 1777.2 & 3304.9 & 7561.1 & 232.5 & 906.1 & 1677.2 & 3130.5 & 7199.1 \\
\hline Laser Power Transfer System Sp Mass, kg/kW & 248.0 & 192.7 & 177.7 & 165.2 & 151.2 & 232.5 & 181.2 & 167.7 & 156.5 & 144.0 \\
\hline Laser Power Transfer System Sp Pwr, Pin/Pout & 6.4 & 5.4 & 5.1 & 4.7 & 4.3 & 8.0 & 6.8 & 6.3 & 5.9 & 5.4 \\
\hline
\end{tabular}

* - add multiplying factor of 2 to acheive 1 -failure tolerance

Figure 36.-Laser subsystem performance and mass versus payload power and laser diode temperature. 
1-km Laser Power Transfer System: Power

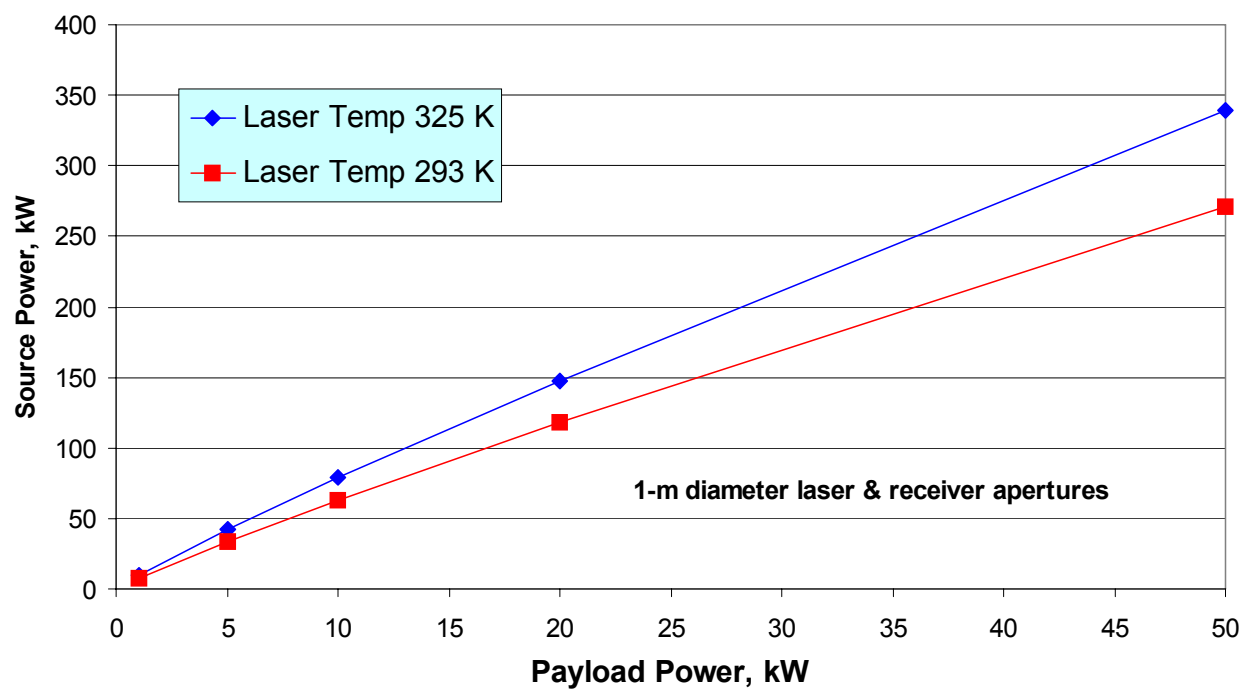

Figure 37.-Source power versus payload power.

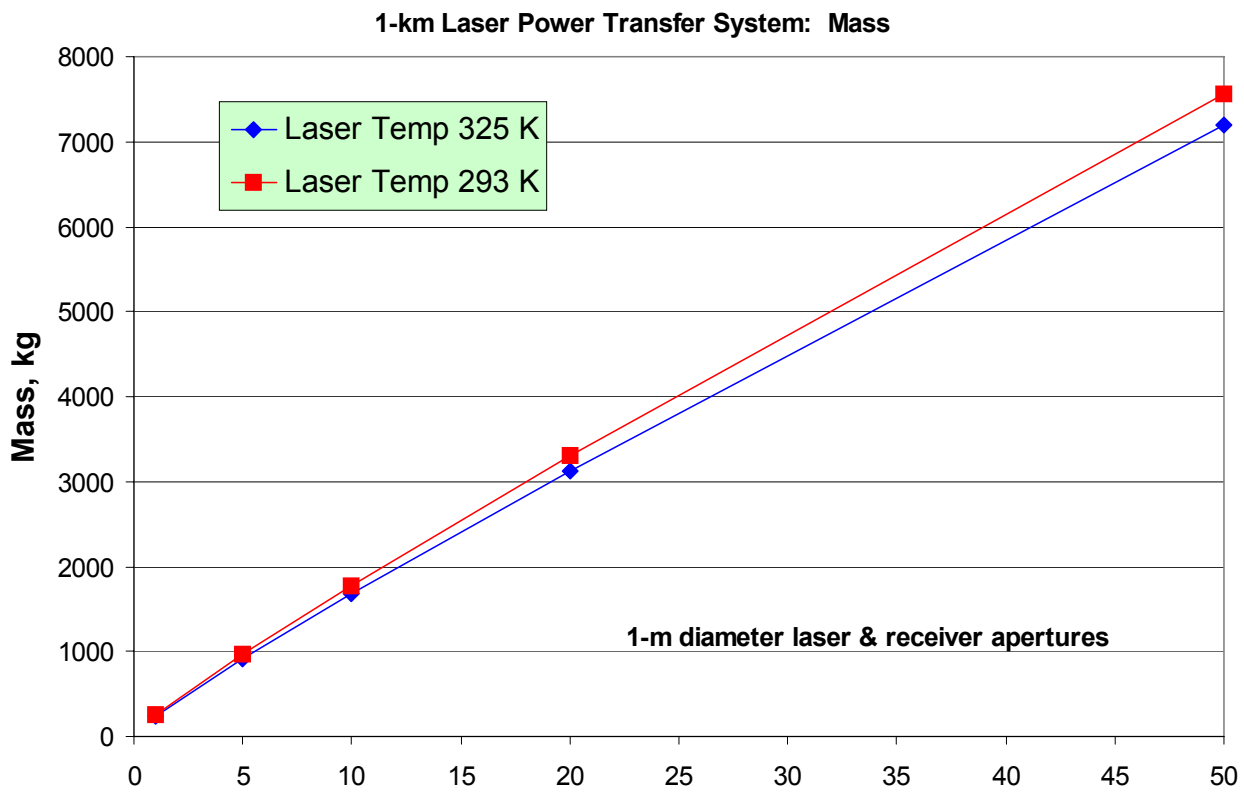

Payload Power, kW

Figure 38.-Mass versus payload power. 


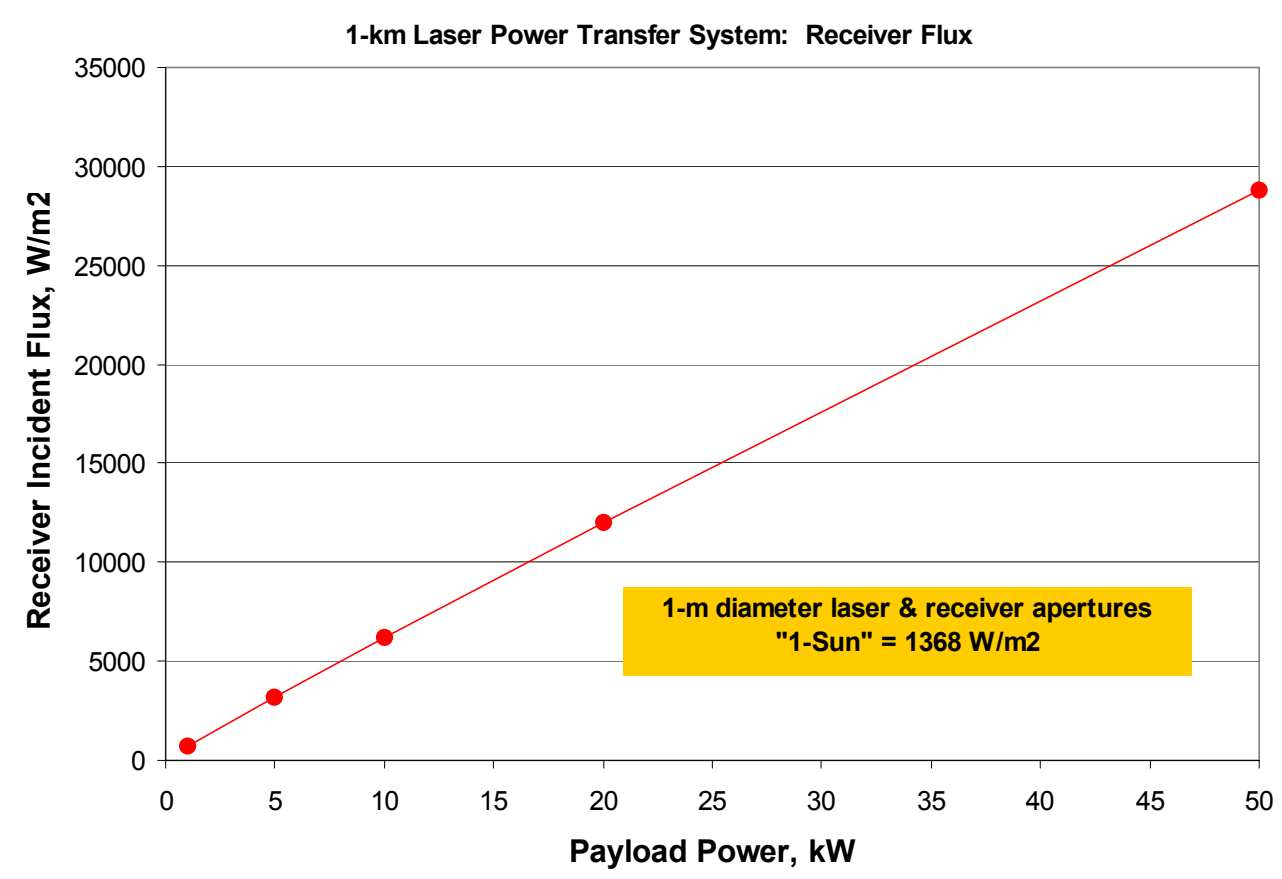

Figure 39.--Receiver incident flux versus payload power.

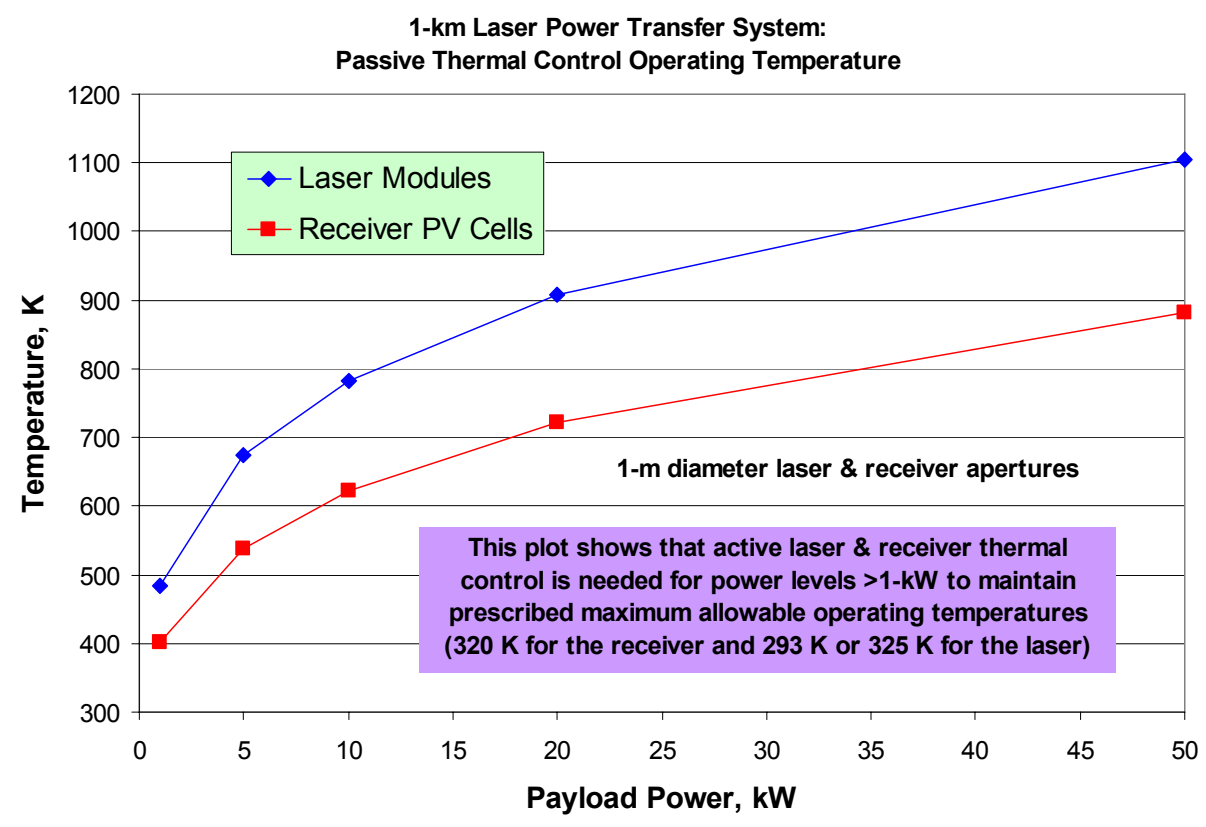

Figure 40.-Laser and receiver temperatures versus payload power. 


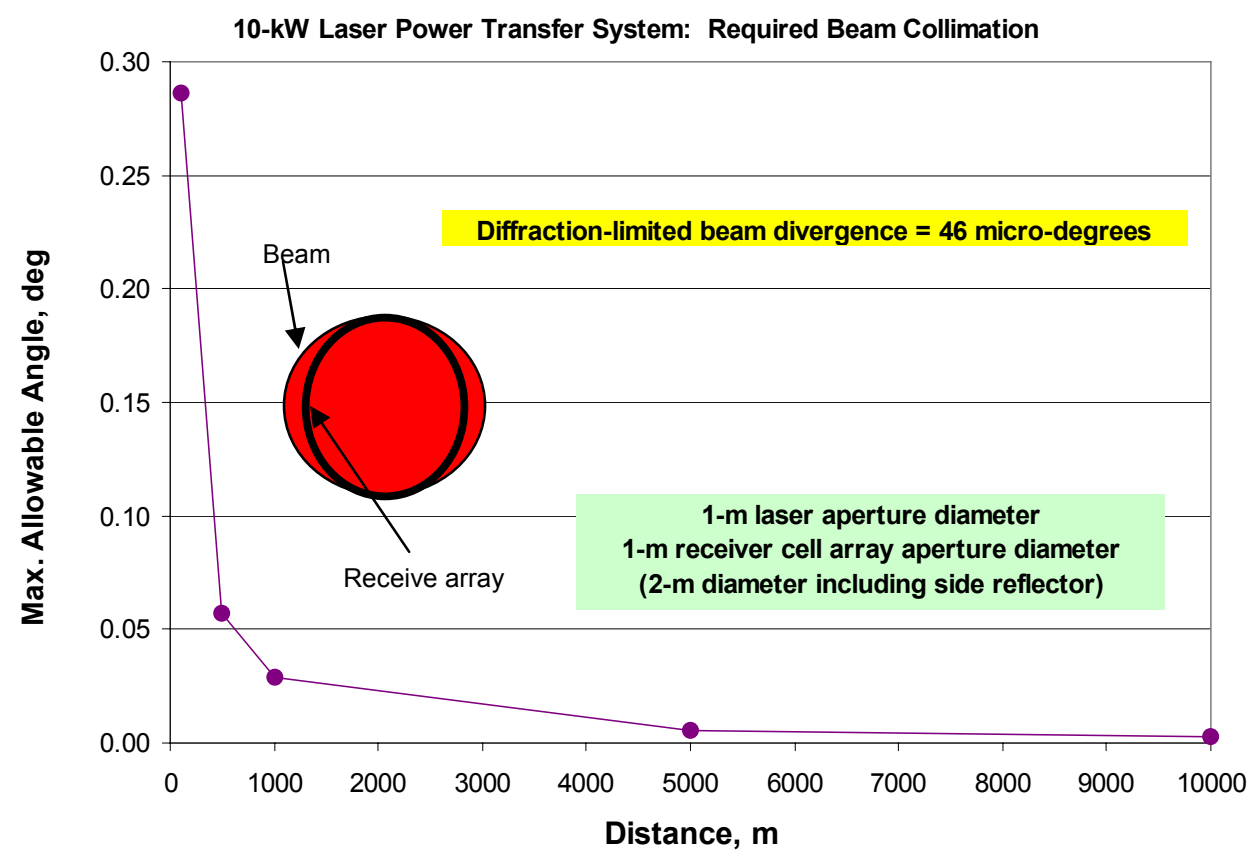

Figure 41.-Maximum allowable beam collimation or versus receiver distance.

\begin{tabular}{|c|c|c|c|}
\hline Net Efficiency of Power Transfer & & & \\
\hline Distance $=>$ & $0.1 \mathrm{~km}$ & & $10 \mathrm{~km}$ \\
\hline Design Option & Efficiency & Efficiency & Efficiency \\
\hline Copper Cable & & & \\
\hline 1000-VDC & $88.5 \%$ & $85.5 \%$ & $71.9 \%$ \\
\hline 300-VDC & $* * *$ & $71.9 \%$ & $* * *$ \\
\hline 1000-VAC $400 \mathrm{~Hz} 3 \mathrm{ph}$ & $86.2 \%$ & $82.0 \%$ & $69.4 \%$ \\
\hline $\mathrm{RF}$ & & & \\
\hline $2.45 \mathrm{GHz}$ & $30.3 \%$ & $4.5 \%$ & $0.05 \%$ \\
\hline $5.8 \mathrm{GHz}$ & $62.5 \%$ & $12.7 \%$ & $0.1 \%$ \\
\hline Laser & & & \\
\hline $293 \mathrm{~K}$ laser temperature & $19.6 \%$ & $19.6 \%$ & $19.6 \%$ \\
\hline $325 \mathrm{~K}$ laser temperature & $15.9 \%$ & $15.9 \%$ & $15.9 \%$ \\
\hline
\end{tabular}

Figure 42.-Power transfer net efficiency.

\section{Subsystem Comparative Metrics}

In this section, top-level subsystem mass and performance metrics defined above are compared for the DC power cable, AC power cable, beamed RF and beamed laser power transfer options. These data are presented in the next several figures in a few different ways assuming the payload power level is $10-\mathrm{kW}$ consistent with LAT requirements. First, figure 42 shows subsystem power transfer efficiency. Compared to cable power transfer options with $>70$ percent efficiency typical, the beamed power subsystem options have very low transmission efficiencies ( $<20$ percent) due to added power conversion steps, beam control and free space transmission loss (RF only). Comparing $\mathrm{AC}$ to $\mathrm{DC}$ power cabling, the AC cabling was slightly less efficient due to reactance (power factor) losses. If possible, careful impedance matching between the source and load could raise the power factor above 0.9 assumed and improve AC cable performance. The high frequency RF option was about twice as efficient as the lower frequency option. Comparing RF versus laser power transfer, at very short transmission distance (i.e., 100-m), the RF system is more efficient, while at large transmission distance (10-km and more), laser power transfer is more efficient.

Figure 43 shows the net power transfer to the remote payload if only $10-\mathrm{kW}$ of source power is available (consistent with LAT outpost payload power allocation). Cable power transfer options afford payload power levels of about $8-\mathrm{kW}$ while those of beamed power options are typically $2-\mathrm{kW}$ or less.

Another way to look at power rating is fixing the payload power consumption at $10-\mathrm{kW}$ and calculating the required source power for each power transfer subsystem. Figure 44 shows the source power input to payload power 
"gear ratio" as well as the subsystem specific mass given in $\mathrm{kg} / \mathrm{kW}$. Beamed power gear ratios fall in the range of 5 to 22 . For the $10-\mathrm{kW}$ payload power assumed, this gear ratio range translates to requiring essentially the full outpost power system output which is obviously unacceptable. By comparison, power cable option gear ratios are just above 1 and lead to a feasible required power draw. On a comparative mass basis, beamed power systems are about 2 to 3 times more massive per unit power transfer than power cable systems.

Nearly all power transfer subsystem masses are generally feasible in that they are a reasonable fraction of a typical lunar lander cargo down mass capacity of $\sim 15,000-\mathrm{kg}$. The exception is the RF subsystem operating over large distances (10-km and above) requiring a very large system mass that would need to be deployed sequentially with multiple dedicated landers. In this case, very large RF free space loss drives up the source input power level to unreasonably high levels that requires massive equipment for power processing and conversion. Power cable option masses are considerably less than beamed power options.

The last subsystem level metric comparison is for subsystem plus source power system mass. This represents the total mass on the lunar surface needed to power the remote payload element. Based on LAT results, the solar standard power unit option \#2 has a specific mass of $183 \mathrm{~kg} / \mathrm{kW}$ with lunar day-time only source power operation for remote payload element operation (excluding night time and non-operating period keep-alive power). This source mass is applied to all power transfer subsystem cases except those of the AC power cable. The AC power cable subsystem is well suited for use with the LAT nuclear fission surface power system with a specific mass of $252 \mathrm{~kg} / \mathrm{kW}$ (for the $25-\mathrm{kW}$ self-shielded reactor option). The nuclear power source allows for continuous day-night power transfer availability. Mass results are shown below in figure 46 and show that the power cable power transfer options are clearly the lowest mass approach (with a slight mass advantage for DC power cables over AC power cables). At the 10-kW payload power level, the laser beamed power option mass comprises most of the lander down mass capability while the RF beamed power option mass exceeds it. Hence, beamed power options would require essentially a dedicated landing of, or even multiple dedicated landings of, separate system components. This attribute increases subsystem lunar surface deployment complexity and mission risk.

\begin{tabular}{|c|c|c|c|}
\hline \multirow{2}{*}{$\begin{array}{l}\text { Net Power Transfer To Payload } \\
\text { Distance => }\end{array}$} & \multicolumn{3}{|c|}{10 kW Input Power } \\
\hline & $0.1 \mathrm{~km}$ & $\mathrm{~m}$ & \\
\hline Design Option & $\begin{array}{l}\text { Power to } \\
\text { End User, kW }\end{array}$ & $\begin{array}{c}\text { Power to } \\
\text { End User, kW }\end{array}$ & $\begin{array}{l}\text { Power to } \\
\text { End User, kW }\end{array}$ \\
\hline \multicolumn{4}{|l|}{ Copper Cable } \\
\hline 1000-VDC & 8.85 & 8.55 & 7.19 \\
\hline 300-VDC & $* * *$ & 7.19 & $* * *$ \\
\hline 1000-VAC $400 \mathrm{~Hz} 3 \mathrm{ph}$ & 8.62 & 8.20 & 6.94 \\
\hline \multicolumn{4}{|l|}{ 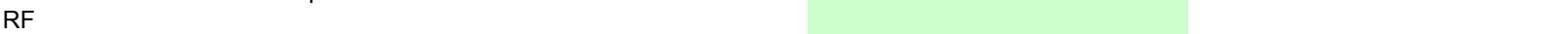 } \\
\hline $2.45 \mathrm{GHz}$ & 3.03 & 0.45 & 0.00 \\
\hline $5.8 \mathrm{GHz}$ & 6.25 & 1.27 & 0.01 \\
\hline \multicolumn{4}{|l|}{ Laser } \\
\hline $293 \mathrm{~K}$ laser temperature & 1.96 & 1.96 & 1.96 \\
\hline $325 \mathrm{~K}$ laser temperature & 1.59 & 1.59 & 1.59 \\
\hline
\end{tabular}

Figure 43.-Comparison of net power to payload with 10-kW source power.

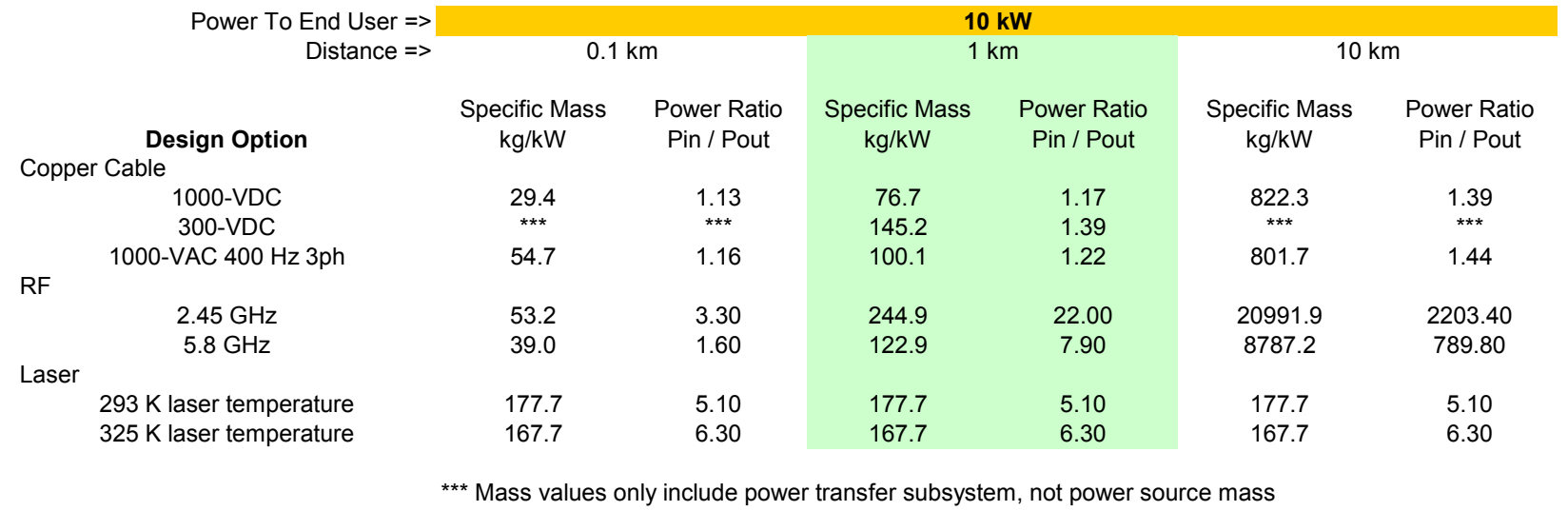

Figure 44.-Performance metrics comparison. 


\begin{tabular}{|c|c|c|c|}
\hline \multirow{2}{*}{$\begin{array}{r}\text { Mass of Power Transfer Subsystem } \\
\text { Distance => }\end{array}$} & \multicolumn{3}{|c|}{$10 \mathrm{~kW}$} \\
\hline & $0.1 \mathrm{~km}$ & $1 \mathrm{~km}$ & 10 km \\
\hline Design Option & $\begin{array}{c}\text { Mass } \\
(\mathrm{kg})\end{array}$ & $\begin{array}{c}\text { Mass } \\
(\mathbf{k g})\end{array}$ & $\begin{array}{c}\text { Mass } \\
(\mathbf{k g})\end{array}$ \\
\hline \multicolumn{4}{|l|}{ Copper Cable } \\
\hline 1000-VDC & 294 & 767 & 8223 \\
\hline $300-V D C$ & $* * *$ & 1452 & $* * *$ \\
\hline 1000-VAC $400 \mathrm{~Hz} 3 \mathrm{ph}$ & 547 & 1001 & 8017 \\
\hline \multicolumn{4}{|l|}{ RF } \\
\hline $2.45 \mathrm{GHz}$ & 532 & 2449 & 209,919 \\
\hline $5.8 \mathrm{GHz}$ & 390 & 1229 & 87,872 \\
\hline \multicolumn{4}{|l|}{ Laser } \\
\hline $293 \mathrm{~K}$ laser temperature & 1777 & 1777 & 1777 \\
\hline $325 \mathrm{~K}$ laser temperature & 1677 & 1677 & 1677 \\
\hline
\end{tabular}

Figure 45.-Power transfer subsystem mass comparisons.

\begin{tabular}{|c|c|c|c|}
\hline $\begin{array}{l}\text { Mass of Source Power System Plus } \\
\text { Power Transfer Subsystem }\end{array}$ & \multicolumn{3}{|c|}{$10 \mathrm{~kW}$} \\
\hline Distance $=>$ & $0.1 \mathrm{~km}$ & $1 \mathrm{~km}$ & $10 \mathrm{~km}$ \\
\hline Design Option & $\begin{array}{l}\text { Mass } \\
(\mathbf{k g})\end{array}$ & $\begin{array}{c}\text { Mass } \\
(\mathbf{k g})\end{array}$ & $\begin{array}{c}\text { Mass } \\
(\mathbf{k g})\end{array}$ \\
\hline \multicolumn{4}{|l|}{ Copper Cable } \\
\hline 1000-VDC & 2,361 & 2,907 & 10,765 \\
\hline $300-V D C$ & $* * *$ & 3,994 & $* * *$ \\
\hline 1000-VAC $400 \mathrm{~Hz} 3 \mathrm{ph}$ & 3,470 & 4,075 & 11,646 \\
\hline \multicolumn{4}{|l|}{ 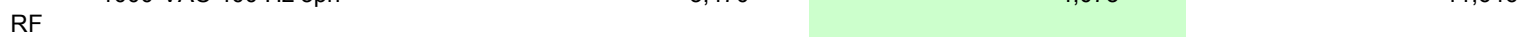 } \\
\hline $2.45 \mathrm{GHz}$ & 6,567 & 42,683 & $4,239,579$ \\
\hline $5.8 \mathrm{GHz}$ & 3,316 & 15,677 & $1,532,288$ \\
\hline \multicolumn{4}{|l|}{ Laser } \\
\hline $293 \mathrm{~K}$ laser temperature & 11,104 & 11,104 & 11,104 \\
\hline $325 \mathrm{~K}$ laser temperature & 13,199 & 13,199 & 13,199 \\
\hline
\end{tabular}

Figure 46.-Comparison of combined mass of source power system plus power transfer subsystem.

\section{Subsystem Hazards and Controls}

\section{Power Cable}

There will be high voltage in power electronics boxes, cable conductors and cable connector pins. To prevent inadvertent contact of EVA crew with high voltage, the electronics are housed in grounded, full physical enclosures. Power cable conductors are encapsulated in dielectric insulation and insulated wires are encapsulated in an insulated jacket. Connector outer shells are grounded and high voltage pins are recessed to avoid inadvertent contact and pin damage. Free laying power cables on the lunar surface represent an EVA crew trip hazard and a fouling hazard to surface rovers. Apollo experience showed nuisance cable coiling that prevented cables from laying flush on the lunar surface. For this study, a power cable spool and payout/dispenser mechanism was included that straightens the natural cable curvature due to spool stowage. This should allow the cable to lay substantially flat on the lunar surface to minimize trip/fouling hazards. The cable outer sheathing will be white in color and should remain conspicuously visible to mobile crew members against the black lunar regolith for years of operation (prior to complete dust coverage). Lunar outpost layout should allow for deploying remote payload element power cables in areas of limited crew and rover activity. For short segments of the cable run where this is not possible, it is recommended that flat cable guard surfaces be deployed on top of cable run to allow for unimpeded rover and EVA crew passage while protecting cables from unintended structural loadings. The size, number and mass of such power cable guards has not yet been assessed.

\section{RF}

There will be high voltage in magnetrons, magnetron cabling and magnetron power electronics boxes. To prevent inadvertent contact of EVA crew with high voltage, the electronics and magnetrons are housed in grounded, full physical enclosures. Power cable conductors are encapsulated in dielectric insulation with connector outer shells grounded and high voltage pins are recessed to avoid inadvertent contact and pin damage. Down-range of the operating transmit antenna, there is a substantial RF radiation hazard from the primary RF beam, primary beam 
spillage, side lobe radiation and reflected RF radiation. This radiation represents a hazard to EVA crew (intraocular heating) and EVA suit function, the payload and rectenna system equipment, surface rovers and lander/ascent vehicles. Surface equipment that must be in the payload element vicinity must use grounded EMI shielding to protect hardware from induced electrical currents and potentials. In addition, some equipment may require thermal insulation blankets to minimize RF heating effects. For EVA crew, rovers and lander/ascent vehicles, incorporating EMI shielding is likely not practical. As such, crew and vehicle keep-out zones must be defined in conjunction with implementing manual and sensor-automated emergency transmitter power shut-off switching should an unauthorized object enter the keep out zone. The definition of these hazard control systems and their integration with the outpost design and operations has not yet been assessed.

\section{Laser}

For the laser subsystem, the primary hazard is high flux levels ( $\sim 5$-suns for $10-\mathrm{kW}$ power transfer). Thus, equipment in the receiver and payload area must incorporate thermal protection insulation blankets. Any EVA crew member, rover or lander/ascent vehicle down-range of the operating laser also face a high flux hazard. Even though the laser beam will likely not be highly coherent, an EVA crew eye safety hazard exists from primary and reflected laser beam energy. EVA suit helmet laser-reflective visors would likely be an effective control method for this hazard. Similar to the RF beamed system, the laser beamed power system would require crew and vehicle keep-out zones to be defined in conjunction with implementing manual and sensor-automated emergency laser power shut-off switching should an unauthorized object enter the keep out zone. The definition of these hazard control systems and their integration with the outpost design and operations has not yet been assessed.

\section{Comparative Observations}

The cable power subsystem options have fewer, more robust hardware elements and fewer interfaces. No planned maintenance is required and no line of sight is required. Elements consist of mature hardware technologies with little or no technology development needed. The power cable options have simple performance/interface verification characteristics that are known throughout all mission phases (before, during and after subsystem emplacement). The power cable options have a simple concept of operations, benign, controllable hazard characteristics and can be deployed telerobotically or by EVA crew using existing mobility assets at the outpost. Cable deployment is more challenging for very long cables $(10$ 's $\mathrm{km}$ ) or cables that must be deployed over impassable terrain. Cable distances $<10-\mathrm{km}$ are sufficient to hook-up all outpost surface elements on the Shackleton Crater rim and for elements that may be emplaced within Shackleton Crater.

The beamed power transfer subsystem options have more hardware elements with greater performance sensitivities and more interfaces that leads to a more complex subsystem with planned maintenance likely required. Beamed power subsystems require unobstructed line of sight from transmitter to receiver that drives the need for detailed terrain topographic data out to a distance of $10-\mathrm{km}$ from the outpost. The resulting local topography then impacts the allowable placement of the power source transmitter and the remote payload that is receiving the beamed power. Beam power subsystems require a mix of mature and advanced hardware technologies that will require substantial technology investments. The verification of beamed power subsystem performance/interfaces can only be performed in situ on the lunar surface after system deployment, alignment and activation. Beamed power systems have more involved concept of operations due to the greater number of element deployments, the precise transmitter-receiver alignment needed, the 2-step low-power/high-power subsystem activation and the set-up and verification of keep out zones. Beamed power subsystems must control critical (loss of mission) and catastrophic (loss of crew) hazards and as such, will likely require intensive crew EVA operations for the safe deployment, alignment and activation of subsystem. A primary benefit of beamed power subsystems is that long power cables do not need to be deployed across the lunar surface. Also, the laser beamed power subsystem, with it's relative insensitivity to transmission distance, would appear to be attractive (relatively low mass) for very long distance (multiple 10's km) power transfer applications, if needed for a lunar surface architecture, assuming a proper line of sight can be established.

\section{Technology Development Requirements}

The primary technology need for the DC power cable system is fast $(40-\mathrm{kHz})$, high quality chopper/rectifying diodes buck DDCU operation with input voltage levels above 1-kV. The AC power cable subsystem does not have any major technology needs. Power cable deployment on the lunar surface is considered to require an engineering 
and operations development. For the RF subsystem, high efficiency magnetron and rectenna technologies at operating frequencies above $2.45 \mathrm{GHz}$ are badly needed. Large aperture, deployable rectenna structures are required as well. For the laser subsystem, the major technology needs include large laser diode array module phase control and packaging with high performance integral water heat pipe evaporators and module thermal electric coolers. Both $\mathrm{RF}$ and laser subsystems require low-mass, high-performance, tightly-integrated, large-area, deployable heat rejection radiators which, although not a new technology, will require substantial engineering development.

\section{Qualitative Relative Costs}

This section on subsystem costs, although qualitative and speculative, is intended to bring some level of attention to costs. NASA has been tasked with implementing a human exploration program within the constraints of a largely fixed budget so that cost is an important figure of merit for any lunar architecture. By inspection, the power cable subsystem options are at the highest technology readiness level (TRL) with the lowest complexity and fewest hardware requirements. Power cable options also have the lowest source power input required that keeps equipment sizes as small as possible. These factors should allow the power cable option to be lowest cost option by a considerable margin (perhaps an order-of -magnitude). The RF subsystem components are low to moderate TRL for most $2.45 \mathrm{GHz}$ system components and low TRL for most $>5.8 \mathrm{GHz}$ system components. The RF subsystem ATCS elements are at moderate to high TRL. The RF system has the highest power "gear ratio" that requires very large equipment sizes for the input power electronics and ATCS radiator. The RF subsystem should be a high cost power transfer subsystem option. For the laser subsystem, laser diode module array components are at low to moderate TRL while the PV cell receiver array components are at moderate to high TRL. The laser subsystem ATCS elements are at low to high TRL while integrated thermoelectric coolers with laser diode modules, module phase control and high performance heat pipe cooling system are at low TRL. The laser subsystem has a moderately high power "gear ratio" requiring large equipment sizes for the input power electronics and ATCS radiators. Due to the greatest need for technology and engineering development, the laser subsystem should be the highest cost power transfer subsystem option compared with RF and power cable options.

\section{Avenues for Further Study}

For the DC power cable option, high-voltage solid-state switching technology should be better defined and the appropriate performance characteristics fed back into the design of the buck DDCU. For the RF subsystem, advanced power beaming technology options must be further explored including higher device operating frequencies and a Klystron (instead of magnetron) RF source (particularly for higher frequency applications). A larger rectenna area would help to reduce RF subsystem masses. Thus, it makes sense to further investigate the benefits afforded by advanced rectenna structure technologies with highly compact stowage and excellent deployment or erectable properties to enable much larger area aperture designs. For the laser subsystem, the performance and mass of SOA and advanced technology laser diode arrays should be further explored. The output of this effort would be a definition of the current best measured mass and performance characteristics plus an estimate of realistically achievable performance and mass improvements in the coming 10-year timeframe consistent with technology investment funding. Quantitative costs for technology development, engineering development/qualification and the flight system programs should be prepared to allow for a better comparison between power transfer subsystem options. The next level of detail for beamed power system implementation and integration with the lunar outpost design and operations should be defined including component site selections, component thermal control needs, deployment/activation procedures/operations, maintenance needs, degradation mechanisms, hazards assessment and hazard control plans. The parameter trade space could be expanded and the beamed power subsystem option performance metrics could be re-evaluated against those for a DC power cable subsystem. This assessment may serve to identify any surface application niche whereby power beaming is enabling over power cables, such as very long distance power transmission. A last recommendation for further study is to size another beamed power technology option using solar concentrators and redirectable reflectors to beam reflected sunlight on to PV arrays located at the payload area. This will greatly reduce source power requirements and may save mass over other beamed power options. Unlike the other beamed power options, this reflected solar beamed power system only provides power during local lunar surface daylight periods. Thus, a separate payload power system will be required for night time keep-alive power. 


\section{Conclusion}

The study goal was achieved: that is, to develop lunar surface-to-surface power transfer subsystem preliminary concept designs and compare their efficiency and mass performance metrics. Given the technology options considered (AC/DC power cables, RF beamed power and solid state laser beamed power) over the range of operating conditions applicable to the LAT lunar outpost (1- to $50-\mathrm{kW}$ power level over 0.1 - to $10-\mathrm{km}$ transmission distance), the author concludes that DC power cable technology is the superior option. The AC power cable option is a very close second place finisher. The cable power transfer subsystem is superior over the beamed power options due to lower mass, lower component count, lower complexity, more mature technology, lower source power, higher payload power delivered with higher power transfer efficiency, more modest thermal control requirements, considerably less technology development needs, likely lower cost, more simple concept of operations, long-term operation without maintenance or degradation, minimal hazards to crew and surface equipment, no line of sight restrictions and adaptability. The power cable option is adaptable since it can be replaced or reused with relative ease or even potentially daisy-chained together, with minor impacts to the system design and concept of operations, to accommodate last minute (or real-time) changes in outpost element configuration. These power cable option advantages lead to lower over all mission and programmatic risks. The challenges of the power cable subsystem option include high-voltage, high-frequency switch technology, the engineering design/development of a lunar surface cable spool and deployer mechanism and deployment of power cable over impassable terrain. For the latter challenge, one could change the rover-trailer cable deployment method to a mortar deployment method. This mortar deployment method was developed for a lunar surface data cable deployment application: specifically, deployment of a seismometer array planned for the Apollo 16 mission. This method is also employed terrestrially for naval shipto-ship or ship-to-shore line deployment.

\section{References}

Cooke, D., Lavoie, T., and Volosin, J., "Lunar Exploration Strategy and Architecture Status Plenary Panel," 2nd Space Exploration Conference, American Institute of Aeronautics and Astronautics, Houston, TX, Dec. 6, 2006.

Gordon, L.B., "Electrical Transmission on the Lunar Surface, Part I-DC Transmission," NASA/CR—2001210759/PARTI, Mar. 2001.

Khan, Z., et al., "Power System Concepts for the Lunar Outpost: A Review of the Power Generation, Energy Storage, Power Management and Distribution (PMAD) System Requirements and Potential Technologies for Development of the Lunar Outpost," NASA/TM-2006-214248, Jun. 2006.

Long, K.J., "Analysis of a Mars-Stationary Orbiting Microwave Power Transmission System," NASA TM-101344, 1990.

Metcalf, K.J., "Lunar PMAD Technology Assessment,” NASA CR--89225, February 1992.

Metcalf, K.J., "Power Management and Distribution (PMAD) Model Development, Final Report," Rocketdyne Division, Boeing Corp., NASA Glenn Research Center, NAS3-01140, Order No. C-77988-T, May 13, 2002.

Mitani, Tomohiko, et al., "Study on High-efficiency and Low-noise Wireless Power Transmission for Solar Power Station/Satellite," The 2nd Joint International Conference on "Sustainable Energy and Environment (SEE 2006)," The Joint Graduate School of Energy and Environment, Bangkok, Thailand, Nov. 21-23, 2006.

Scifres, D.R., et al., "High Power (600 mW CW) Phase-Locked Semiconductor Laser Arrays," IEEE International Electron Devices Meeting, vol. 28, 1982, p. 354-356.

Sprouse, K.M., "Infrastructure for Deployment of Power Systems (Task Order No. 7)," NASA CR-187167, June 1991.

Williams, M.D., et al., "Power Transmission by Laser Beam From Lunar-Synchronous Satellite," NASA TM-4496, 1993. 


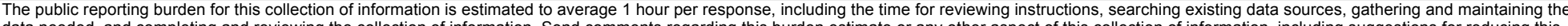

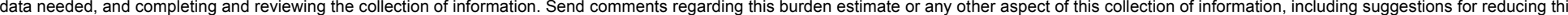

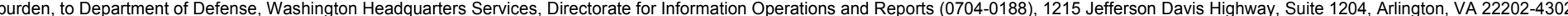

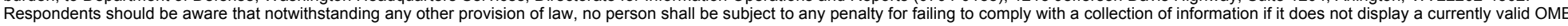
control number.

PLEASE DO NOT RETURN YOUR FORM TO THE ABOVE ADDRESS.

\section{REPORT DATE (DD-MM-YYYY) \\ 2. REPORT TYPE \\ 3. DATES COVERED (From - To)}

01-12-2007

Technical Memorandum

\section{TITLE AND SUBTITLE}

Lunar Surface-to-Surface Power Transfer

5a. CONTRACT NUMBER

5b. GRANT NUMBER

5c. PROGRAM ELEMENT NUMBER

\section{AUTHOR(S)}

Kerslake, Thomas, W.

\section{5d. PROJECT NUMBER}

5e. TASK NUMBER

5f. WORK UNIT NUMBER

WBS 644423.06.32.03.05.03

8. PERFORMING ORGANIZATION REPORT NUMBER

E-16242

National Aeronautics and Space Administration

John H. Glenn Research Center at Lewis Field

Cleveland, Ohio 44135-3191

9. SPONSORING/MONITORING AGENCY NAME(S) AND ADDRESS(ES)

National Aeronautics and Space Administration

Washington, DC 20546-0001

10. SPONSORING/MONITORS
ACRONYM(S)
NASA
11. SPONSORING/MONITORING
REPORT NUMBER
NASA/TM-2007-215041

\section{DISTRIBUTION/AVAILABILITY STATEMENT}

Unclassified-Unlimited

Subject Categories: 20, 32, 33, and 36

Available electronically at http://gltrs.grc.nasa.gov

This publication is available from the NASA Center for AeroSpace Information, 301-621-0390

\section{SUPPLEMENTARY NOTES}

\section{ABSTRACT}

A human lunar outpost, under NASA study for construction in the 2020's, has potential requirements to transfer electric power up to 50-kW across the lunar surface from 0.1 to $10-\mathrm{km}$ distances. This power would be used to operate surface payloads located remotely from the outpost and/or outpost primary power grid. This paper describes concept designs for state-of-the-art technology power transfer subsystems including AC or DC power via cables, beamed radiofrequency power and beamed laser power. Power transfer subsystem mass and performance are calculated and compared for each option. A simplified qualitative assessment of option operations, hazards, costs and technology needs is also described. Based on these concept designs and performance analyses, a DC power cabling subsystem is recommended to minimize subsystem mass and to minimize mission and programmatic costs and risks. Avenues for additional power transfer subsystem studies are recommended.

\section{SUBJECT TERMS}

Electric power; Power lines; Power beams; Laser power beaming; Radiofrequencies

\begin{tabular}{|c|c|c|c|c|}
\hline \multicolumn{3}{|c|}{ 16. SECURITY CLASSIFICATION OF: } & \multirow{2}{*}{$\begin{array}{l}\text { 17. LIMITATION OF } \\
\text { ABSTRACT } \\
\text { UU }\end{array}$} & \multirow{2}{*}{$\begin{array}{l}\text { 18. NUMBER } \\
\text { OF } \\
\text { PAGES } \\
40\end{array}$} \\
\hline $\begin{array}{l}\text { a. REPORT } \\
U\end{array}$ & $\begin{array}{l}\text { b. ABSTRACT } \\
U\end{array}$ & $\begin{array}{l}\text { c. THIS } \\
\text { PAGE } \\
\text { U }\end{array}$ & & \\
\hline
\end{tabular}

19a. NAME OF RESPONSIBLE PERSON STI Help Desk (email:help@sti.nasa.gov) 19b. TELEPHONE NUMBER (include area code) 301-621-0390 

